\title{
The Bioink: A Comprehensive Review on Bioprintable Materials
}

\author{
Monika Hospodiuk ${ }^{1,2}$, Madhuri Dey ${ }^{2,3}$, Donna Sosnoski ${ }^{1,2}$, Ibrahim T. Ozbolat ${ }^{1,2,4,5, \text { * }}$ \\ ${ }^{1}$ Engineering Science and Mechanics Department, Penn State University, State College, PA 16801, USA \\ ${ }^{2}$ The Huck Institutes of the Life Sciences, Penn State University, State College, PA 16801, USA \\ ${ }^{3}$ Department of Chemistry, Penn State University, University Park, PA, 16802 \\ ${ }^{4}$ Materials Research Institute, Penn State University, State College, PA 16801, USA \\ ${ }^{5}$ Biomedical Engineering Department, Penn State University, State College, PA 16801, USA
}

\begin{abstract}
This paper discusses "bioink", bioprintable materials used in three dimensional (3D) bioprinting processes, where cells and other biologics are deposited in a spatially controlled pattern to fabricate living tissues and organs. It presents the first comprehensive review of existing bioink types including hydrogels, cell aggregates, microcarriers and decellularized matrix components used in extrusion-, droplet- and laser-based bioprinting processes. A detailed comparison of these bioink materials is conducted in terms of supporting bioprinting modalities and bioprintability, cell viability and proliferation, biomimicry, resolution, affordability, scalability, practicality, mechanical and structural integrity, bioprinting and post-bioprinting maturation times, tissue fusion and formation postimplantation, degradation characteristics, commercial availability, immune-compatibility, and application areas. The paper then discusses current limitations of bioink materials and presents the future prospects to the reader.

Keywords: Bioink, Bioprinting, Hydrogels, Cell Aggregates, Microcarriers, Decellularized Matrix Components, Tissue and Organ Biofabrication
\end{abstract}

\section{Introduction}

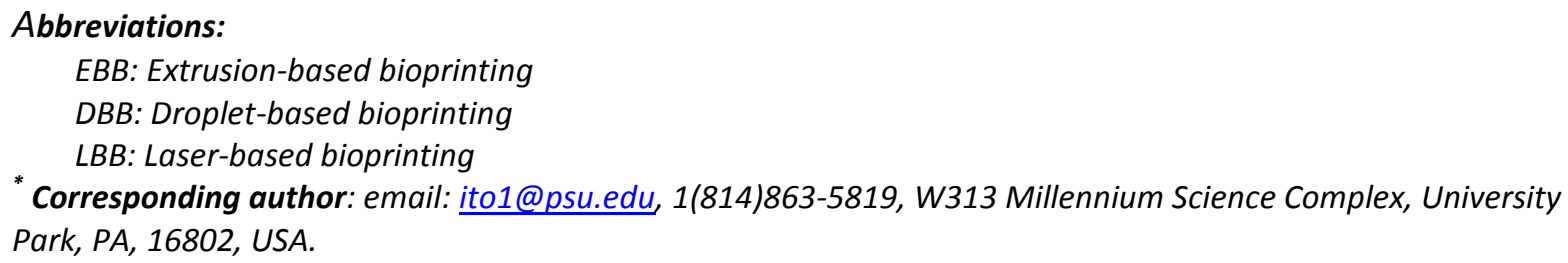


The need for hierarchical assembly of three dimensional (3D) heterocellular tissues has been escalating in medicine and biotechnology. It has spurred the development of new technologies with the ultimate goal of creating de novo functional tissues and organs (Ozbolat and $\mathrm{Yu}, 2013$ ). The principle of bioprinting can be defined as the placement of cells within biomaterials into spatially defined structures using automated 3D bioprinter technologies. This process, first named "cytoscribing," was inspired by classic two dimensional (2D) paper printers, as the droplets of colored ink are similar in size to biologics (Klebe, 1988). In the last two decades, various bioprinting processes have emerged along with various process-compatible bioink materials. The process of bioprinting requires a delivery medium for cells which can be deposited into designed shapes acquired from computer-aided design (CAD) models. The CAD models can be generated using 3D medical images obtained through magnetic resonance imaging (MRI), computed tomography (CT) scanning, and other techniques (Kucukgul et al., 2014; J.-S. Lee et al., 2014; Pati et al., 2013). Soft biomaterials loaded with living cells are called bioink, and are the "raw material" of bioprinting processes.

The development of bioink materials allows scientists to manipulate biological and biochemical environments as well as living cells to create complex biological constructs. The milestones of success are measured by sustained viability of cells during short- and long-term culture, cell spreading and proliferation, cell-cell and cell-extracellular matrix (ECM) interactions, and functionality of the bioprinted constructs. Although, a wide array of biomaterials have been developed for tissue engineering and regenerative medicine (Furth et al., 2007), the vast majority are not compatible with existing bioprinting technologies. Some important features of an ideal bioink material are bioprintability, high mechanical integrity and stability, insolubility in cell culture medium, biodegradability at a rate appropriate to the regenerating tissue, non-toxicity and nonimmunogenicity, and the ability to promote cell adhesion. In addition, bioink materials should be easily manufactured and processed, affordable, and commercially available. Bioprinted constructs are expected to keep their designed shape and structural strength and integrity, maintain 3D 
architecture for a defined period of time in vitro, and easily engraft with the host and degrade over time in vivo.

This paper reviews bioink materials used in 3D bioprinting processes including scaffoldbased (i.e. hydrogels, microcarriers and decellularized matrix components), and scaffold-free (i.e., cell aggregates) bioink materials. Limitations and strengths of each bioink material are elucidated and their characteristics are evaluated based on several criteria including their compatible bioprinting modalities, bioprintability, cell viability and proliferation, biomimicry, resolution, affordability, scalability, practicality, mechanical and structural integrity, bioprinting and postbioprinting maturation times, tissue fusion and formation post-implantation, degradability, commercial availability, immunogenicity, and applications. Finally, the paper provides the reader with limitations and presents future perspectives of bioprintable biomaterials.

\section{Bioink Materials}

Two major types of bioink materials have been used in bioprinting of 3D tissue and organ constructs (Ozbolat, 2015a). The first and most common one is scaffold-based bioink where cells are loaded in hydrogels or similar exogenous materials and bioprinted into 3D constructs. Cell-laden hydrogels allow cell proliferation and growth, and facilitate formation of tissue. In the second type of bioink, cells are bioprinted without the use of an exogenous biomaterial, in a scaffold-free process mimicking embryonic development. Cells are first formed into neo-tissues that are engineered for bioprinting processes; resulting neo-tissues are then deposited in specific patterns where they fuse and mature for fabrication of larger-scale functional tissues.

\subsection{Scaffold-based Bioink Materials}

\subsubsection{Hydrogels}

A class of crosslinked polymeric substances capable of absorbing and retaining large quantities of water is generally referred to a hydrogel. Hydrogels in tissue engineering are classified into two groups: naturally-derived hydrogels such as gelatin, fibrin, collagen, chitosan, and alginate and synthetically-derived hydrogels such as Pluronic ${ }^{\circledR}$ or polyethylene glycol (PEG). Naturally-derived 
hydrogels can be further categorized based on where they have been derived from. Hydrogels such as collagen, fibrin, and gelatin are generally derived from vertebrates and so they possess inherent signaling molecules for cell adhesion whereas hydrogels like alginate and agarose are derived from other living organisms such as algae or sea weeds which lack these signaling molecules (Gasperini et al., 2014; Lee and Mooney, 2012). Hydrogels are used in biofabrication and tissue engineering for a wide array of applications such as drug delivery (Yang et al., 2011), contact lenses (White et al., 2011) and wound dressings (Kamoun et al., 2015). Some are able to mimic the native tissue environment as they possess several essential features of the native ECM components (Tibbitt and Anseth, 2009). These ECM-like properties allow cell encapsulation in a highly hydrated, mechanically strong 3D environment; however, both natural and synthetic hydrogels have some limitations. Natural hydrogels generally have weak mechanical properties while synthetic counterparts lack major components such as bioactive molecules for cell adhesion or migration (Zhu and Marchant, 2011). Biocompatibility of hydrogels is influenced by their inherent hydration levels. Hydrogels can absorb up to 1,000 times their original weight in aqueous medium without dissolving (Ahmed, 2013), making them ideal for cell encapsulation. Because they are highly permeable to oxygen, nutrients and other water-soluble compounds, hydrogels are attractive materials for fabrication of tissue constructs (Thomas et al., 2009; Zhu and Marchant, 2011). In contrast to polymeric scaffolds used in tissue engineering where cells are generally seeded on the surface of scaffolds, hydrogels provide a congenial environment for embedded cells, which enables them to migrate in any direction in 3D and communicate with each other through a porous flexible network (Benedikt et al., 2000; Drury and Mooney, 2003; Rajan et al., 2006; Yamamoto et al., 2010). Distinct features of natural and synthetic hydrogels cannot be clearly stated; however, most natural hydrogels are cell friendly.

\subsubsection{Bioprintability of Hydrogels}

Over the past few decades, numerous hydrogels have been prepared by altering the chemical backbone of polymers for tissue engineering applications. However, not all hydrogels can 
be considered "bioprintable." Bioprintability of hydrogels are governed by their rheological properties and the target bioprinting modality. According to their bioprinting mechanisms, bioprinting processes can be classified under three major modalities: extrusion-based bioprinting (EBB), droplet-based bioprinting (DBB), and laser-based bioprinting (LBB) (Dababneh and Ozbolat, 2014; Gudupati et al., 2016; Ozbolat and Hospodiuk, 2016). Each bioprinting modality has different bioink requirements according to the bioprinting mechanism employed (see Fig. 1).

Extrusion-based bioprinting employs pneumatic-, mechanical- or solenoid-driven microextrusion along with a computer-controlled writing process. Hydrogels used in EBB broadly fall under the category of non-Newtonian fluids, where viscosity is strongly dependent upon shear rate (Jungst et al., 2016). Hydrogels with shear thinning and thixotropic behavior are well suited for EBB processes. In shear thinning hydrogels, shear forces align the random polymer chains in a favorable direction making them extrudable. Thixotropy, a time-dependent shear thinning behavior, enables the bioink to assume a stable form at rest in the barrel, exhibit low viscosity inside the nozzle tip during extrusion and regain its stability post-bioprinting. The supported viscosity for EBB ranges from $30 \mathrm{mPa} / \mathrm{s}$ to $60 \times 10^{7} \mathrm{mPa} / \mathrm{s}$ (Mandrycky et al., 2016). The hydrogel concentration changes the viscosity level, i.e. $25 \%$ Pluronic ${ }^{\circledR} \mathrm{F}-127$ has $30 \mathrm{mPa} / \mathrm{s}$ while $40 \%$ concentration has $>600 \times 10^{6} \mathrm{mPa} / \mathrm{s}$ (Chang et al., 2011). A reported paper stated that there is no significant difference in bioink viscosity when cell density is under $2 \times 10^{6} / \mathrm{mL}$ (Ouyang et al., 2016). In addition, the bioink should possess low adhesion and surface tension properties to eliminate its attachment on the surface of the nozzle tip, and easily overcome the surface tension-driven droplet formation enabling successful filament extrusion. In addition, the bioink should have rapid gelation characteristics so that it can retain its shape without spreading. Moreover, appropriate substrates (with high surface roughness and low wettability) should be in place so that the bioink can stick to the substrate and retain its shape. Recent examples for the use of EBB include perfusable chip models allowing dynamic perfusion up to 45 days (Kolesky et al., 2016), microfluidic channel-based on collagen and gelatin (Lee et al., 2016), directly bioprinted vascular constructs (Jia et al., 2016) and micro-fibrous scaffolds with 
encapsulated endothelial cells and seeded cardiomyocytes mimicking myocardium (Zhang et al., 2016).

Droplet-based bioprinting utilizes various energy sources such as electric, sound and heat to generate droplets of bioink in a high-throughput manner. According to their droplet generation mechanisms, DBB processes can be classified under four groups: inkjet (thermal, piezoelectric or electrostatic) bioprinting, electro-hydrodynamic jetting, acoustic droplet election and micro-valve bioprinting. In general, the bioink used in DBB should have low viscosity and a non-fibrous nature so that it can easily flow through the tubing system and nozzle without clogging problems. In addition, the bioink needs to possess a rheopectic behavior, which is a time-dependent dilatant behavior resulting in increased viscosity as shear is applied triggering droplet formation due to an increase in viscosity following ejection. The viscosity level in DBB process is supported between 3.5 and 12 $\mathrm{mPa}$ /s, which depends on the bioink concentration (Mandrycky et al., 2016). The bioink should also have appropriate surface tension. It should have sufficient wettability to travel through the cartridge correctly but not leak out, flooding of the print head and wetting the exterior of the nozzle tip. In addition, the droplets should solidify immediately after landing. Droplet-substrate interactions are also important as appropriate substrate surface properties are needed to prevent spreading, splashing or rebounding of droplets.

Laser-based bioprinting utilizes laser energy for fabrication of tissue constructs or highprecision patterning of biologics and can be classified under two groups: processes based on cell transfer (i.e., laser-guided direct writing (LGDW) (Odde and Renn, 1999), matrix-assisted pulsed laser evaporation-direct write (MAPLE-DW) (Riggs et al., 2011) or laser-induced forward transfer (LIFT) (Michael et al., 2013)) and processes involving photopolymerization (i.e., stereolithography (SLA) (Arcaute et al., 2010), dynamic optical projection stereolithography (DOPsL) (Zhang et al., 2012) or two-photon polymerization (2PP) (Ovsianikov et al., 2014)). In the former approach, the bioink is transferred from a cartridge to a substrate by laser-induced jet formation; however, in the latter approach, the laser beam selectively solidifies a photocurable bioink material (in a vat) through 
polymerization. The bioink used for cell transfer processes should possess sufficient adhesion and low surface tension characteristics so that it can uniformly spread on the intermediate layer and adhere to it without dripping. The viscosity for LBB in general ranges from 1 to $300 \mathrm{mPa} / \mathrm{s}$ (Mandrycky et al., 2016). The bioink should easily transfer thermal energy into kinetic energy and exhibit high viscoelasticity so that well-defined jets can be formed with rest of the bioink maintained in the cartridge. The bioink needs to have a rapid gelation capability so jets can solidify without spreading. In the literature, the greatest crosslinking speed was reported as 10 seconds to solidify an $8 \mathrm{~mm}$ diameter hydrogel with 90\% cell viability (Wang et al., 2016). Moreover, jet-substrate interactions are also important (similar to DBB); therefore, an appropriate substrate should be selected to prevent spreading and splashing of the jets. For bioink in processes involving photopolymerization, photopolymerizable hydrogels should be used. The bioink should be further reinforced with non-toxic water-soluble photo-initiators and light absorbers to initiate photopolymerization and enable fabrication of tissue constructs with uniform layer thickness. Recently reported work based on gold nano-rods suspended in collagen enabled laser beam absorption, which locally denatured collagen avoiding the need for photo-initiators (Hribar et al., 2015). Stability and high-mechanical strength as well as the ability to retain cells uniformly distributed in the pre-cursor solution are other important requirements of such bioink selection.

In addition, the bioink should possess an appropriate gelation mechanism driven by chemical, physical or enzymatic crosslinking as outlined below.

\subsubsection{Crosslinking Mechanisms of Hydrogels}

\subsection{Physical Crosslinking}

In the field of tissue engineering, there has been a growing interest in polymers which can be effectively crosslinked without the use of any exogenous agents, thus minimizing the risk of chemical contamination or chemically-induced toxicity (Hennink and van Nostrum, 2012). Apart from obvious advantages, such polymeric hydrogels foster a more congenial environment for embedded cells, proteins and other biologics. Ionic, hydrophobic and hydrogen bonding 
interactions, stereo-complexation, self-assembly of amphiphilic peptides or polymers into micellar structures are some of the well-established mechanisms which are known to drive physical crosslinking of hydrogels (Jungst et al., 2016).

Ionic crosslinking involves the association of polymer chains by non-covalent interactions. A crosslinked hydrogel network is formed when molecules containing opposite charges are blended, e.g. polyelectrolyte solution and multivalent ions (Gulrez et al., 2011). The ions of opposite charges electrostatically attract each other giving rise to a crosslinked polymeric network. The network can also be disrupted by using specific chelators to remove the multivalent ions from the polymeric network in order to reverse the gelation process.

In some hydrogels, hydrophobic interactions or hydrogen bonding interactions play a significant role in crosslinking. These interactions often tend to be temperature dependent and alter the rheology of the hydrogel network with changing temperature. Some hydrogels exhibit a random coil conformation at high temperatures; upon lowering the temperature, the polymer chains adapt a more ordered conformation forming junction points and consequently aggregating as physical gels (Jeong et al., 2002). Others undergo the reverse process. In reverse gelation, polymeric strands mostly contain both hydrophobic and hydrophilic regions (Pradines et al., 2015). At low temperatures, water (solvent) molecules dissolve the hydrophilic parts of the molecule leading to complete dissolution of monomer chains. There is a strong binding affinity between water molecules and monomeric chains, leading to highly ordered water molecules along the monomeric chains. The forces of interaction here are primarily hydrogen bonding forces, where the binding is an enthalpydriven process; however, when the temperature increases, entropy overcomes enthalpy as water molecules become randomly oriented and hydrophobic interactions between the monomeric chains become predominant. Thus, the chains dehydrate as the water molecules break free. With the increase in temperature, the polymeric interactions become more dominant as compared to the hydrogen bonding forces. 
The association of disordered molecules into an ordered state by virtue of its nature or by electrostatic or covalent interactions is referred to as "self-assembly," which is a primary mechanism of gelation observed in amphiphilic peptide molecules (Hauser et al., 2015). Synthetic peptides with a cationic polar head group and anionic groups along its backbone undergo rapid self-assembly from a random coil configuration to form ordered $\alpha$ helices and $\beta$ sheets. With increased concentration, $\beta$ sheets undergo further self-assembly to form nano-fibrous networks that bear close resemblance to the native ECM. Some of the most commonly employed physically crosslinked hydrogels in bioprinting are agarose, alginate, chitosan, collagen, gelatin, Matrigel ${ }^{\mathrm{TM}}$ and Pluronic $^{\circledR}$, which are further discussed in Section 2.1.1.3 in details.

\subsection{Chemical Crosslinking}

Chemically-crosslinked hydrogels, characterized by covalent bonding between polymer chains, often provide better mechanical stability compared to physically-crosslinked ones. Chemical crosslinking can involve exogenous crosslinking agents or formation of reactive species by photoirradiation; however, the use of a crosslinker can induce undesirable reactions with the hydrogel surface or result in cytotoxicity (Hennink and van Nostrum, 2012). Some of the widely studied mechanisms for chemical crosslinking of polymers include condensation reactions, crosslinking by Schiff base formation (a compound formed by the nucleophilic addition of an amine and a carbonyl group) (Dragan, 2014), or photo-crosslinking (Z. Wang et al., 2015).

Schiff base is a compound formed by the nucleophilic addition of an amine to a carbonyl functional group. Amine containing amino acids, natural polysaccharides or other synthetic polymers can be easily crosslinked under mild reaction conditions in the presence of crosslinkers containing aldehyde functionalities such as glutaraldehyde or other polyaldehydes (Hennink and van Nostrum, 2012). Other complimentary functional groups that can also react with aldehydes to form crosslinked hydrogels include alcohol and hydrazides (Hennink and van Nostrum, 2012). The degree of crosslinking depends on the concentration of the crosslinker used. A high degree of crosslinking results in a hydrogel with strong mechanical properties; however, this reduces the degradation time 
of the hydrogel. Release of drugs, growth factors or other biologics immobilized in a bioprinted hydrogel matrix might take longer to diffuse into the surrounding tissue region due to stronger encapsulation between the chemically-crosslinked polymer chains. Some frequently used crosslinking agents (i.e., glutaraldehyde) are used to induce chemical crosslinking reactions between complimentary functional groups. While glutaraldehyde might induce cytotoxicity (Takigawa and Endo, 2006), genipin is a benign naturally-derived crosslinker, which has been used to crosslink gelatin (Bigi et al., 2002), collagen (Yan et al., 2010), chitosan (Chen et al., 2004; Moura et al., 2011), and fibrin (Gamboa-Martnez et al. 2015). The amine groups of the amino acids present in fibrin undergo a nucleophilic, ring closure type of reaction to form crosslinked hydrogels with genipin (Gamboa-Martnez et al. 2015).

Photopolymerization is one of the widely used crosslinking mechanisms, where low molecular weight monomers or oligomers undergo a process called curing to form a crosslinked polymeric network, when exposed to radiation (Decker, 2002). The crosslinking process is initiated in the presence of a photo-initiator which forms excited molecular species on irradiation with light and onsets the polymerization process. Often pure hydrogels do not crosslink independently unless an external initiator is added or the molecule is chemically modified with functional groups capable of undergoing free radical polymerization. The physical properties of the hydrogel can be efficiently controlled by proper modulation of the rate and degree of crosslinking by photopolymerization. Some commonly used photo-initiators in bioprinting include Irgacure (2-hydroxy-1-[4-(2hydroxyethoxy) phenyl]-2-methyl-1-propanone) (Aubin et al., 2010), Eosin y (Z. Wang et al., 2015), VA-086 (2, 2'-azobis [2-methyl-N-(2-hydroxyethyl) propionamide]) (Billiet et al., 2014), and Biokey (lithium phenyl-2,4,6-trimethylbenzoylphosphinate) (Fairbanks et al., 2009). While some photoinitiators produce free radicals via unimolecular bond cleavage, others undergo bimolecular reactions by producing excited species which undergo collision with another initiator molecule to generate free radicals. Irgacure is the most widely used photo-initiator in the bioprinting community but it is only non-toxic below a certain threshold quantity. Even at concentration of $0.5 \%(\mathrm{w} / \mathrm{v})$, this 
initiator has proven to be extremely detrimental to cells unless the excess photo-initiator is leached out of fabricated constructs (Arcaute et al., 2006). A few important requirements for photo-initiators are their water solubility, type of radiation and exposure time required to generate free radicals. Although Irgacure is water soluble, it requires the use of ultraviolet (UV) light which is detrimental to cells with prolonged exposure. Long term exposure to UV can damage the DNA, can induce undesired crosslinking or affect cell functionality. In contrast, the use of photo-initiators such as Eosin $Y$ and Biokey is advantageous as crosslinking can occur in visible light within a short span of time (Fairbanks et al., 2009). Using a low concentration $(<0.1 \%)$ photo-initiator, as recommended by some studies (Fedorovich et al., 2009), can minimize toxicity but diminishes mechanical properties. Low mechanical properties often give rise to increased swelling and enhanced depth of curing, which deteriorates the bioprinted construct quality. Methacrylated gelatin (GeIMA) and PEG are two of commonly used polymers capable of undergoing photopolymerization.

\subsection{Enzymatic Crosslinking}

The most popular enzymatically-crosslinked hydrogel in tissue engineering is fibrin (Benedikt et al., 2000; Scheraga, 2004). It is composed of fibrinogen and thrombin, the major precursors involved in blood clotting. Thrombin is a serine protease that converts fibrinogen, a complex glycoprotein, into fibrin. Cytocompatibility and cell adhesive properties make fibrin a widely used bioink in bioprinting (Ehsan et al., 2014; Y.-B. Lee et al., 2010; Yu et al., 2012). It is possible to manipulate the integrity of other hydrogels, like gelatin, by using transglutaminase, a bacterial enzyme (Gómez-Guillén et al., 2011). Transglutaminase catalyzes the formation of isopeptide bonds by a transamidation-mediated reaction between the gamma-carbonyl group of a glutamine residue and the epsilon-amino group of a lysine residue (Sakai et al., 2009). Thrombin, as well as transglutaminase, are $\mathrm{Ca}^{2+}$ dependent enzymes.

\subsubsection{Hydrogels used in bioprinting}

Bioprintability of hydrogels is a key attribute to the success of 3D bioprinting; each hydrogel brings different properties and requirements to the bioprinting process. Hydrogels used in 
bioprinting technology are herein described in detail with respect to their chemical content, crosslinking behavior, biocompatibility, and bioprintability under EBB, DBB and LBB.

\subsection{Natural hydrogels}

Agarose is a naturally-derived polysaccharide molecule which undergoes gradual gelation at low temperatures and liquefies at the temperatures ranging from 20 to $70^{\circ} \mathrm{C}$, depending on the hydroxyethylation (Serwer et al., 1983; Tako and Nakamura, 1988). It has been suggested that the gelation mechanism goes through three stages, namely initiation, nucleation and pseudoequilibrium (Tako and Nakamura, 1988). In solid state, agarose is brittle, but maintains its shape for a long period of time at a broad range of temperatures. Agarose is not as cell-friendly as alginate and Pluronic ${ }^{\circledast}$, as cell proliferation rate and the biosynthesis of cell components is limited (Fedorovich et al., 2008). Low cell adhesion and spreading suggest that agarose is a poor material for cell culture; however, it serves well as a mold material for 3D culture of cell aggregates (Livoti and Morgan, 2010). Its biological properties can, however, be improved by blending with other hydrogels such as collagen (Duarte Campos et al., 2014). Agarose has been used in EBB providing superior stability and construct thickness when compared to collagen/agarose blends. Cell viability was maintained; however, cells retained a round as opposed to a spread morphology (Duarte Campos et al., 2014). In addition, agarose has been printed for construction of support structures to facilitate aggregation of bioprinted cell aggregates (Ozbolat, 2015a) (see Fig. 2A). Agarose has a thermally-reversible feature and can be used as a sacrificial material in a bulky scaffold of a thermally stable hydrogel. It can be liquefied and drained, leaving a hollow, perfusable structure (W. Lee et al., 2010). Agarose has been used in DBB, particularly in micro-valve bioprinting of mammalian cells yielding high cell viability (Xu et al., 2005). For micro-valve bioprinting, a temperature-controller is required to keep agarose in liquid state. In general, its viscous nature does not allow inkjet bioprinting as it can easily clog the nozzle. Agarose is a promising candidate for LBB due to its viscoelastic nature and rapid gelation mechanism. It has been deposited using LIFT technology, successfully maintaining high cell viability (Koch et al., 2010). 
Alginate is a popular hydrogel used in bioprinting processes due its biocompatibility, various choices of crosslinking and bioprinting methods, low price, and ease of use in the creation of 3D structures (Ozbolat and Hospodiuk, 2016). It is a polysaccharide made of alternating B-Dmannuronate (M) and its C-5 epimer $\alpha$-L-guluronate ( $G$ ) units (Jungst et al., 2016). The $G$ subunits are responsible for forming the gel phase of alginate. As the number of $G$ subunits increase, the degree of gelation increases. Alginate undergoes ionic crosslinking in calcium chloride $\left(\mathrm{CaCl}_{2}\right)$ or calcium sulfate $\left(\mathrm{CaSO}_{4}\right)$ solutions. The divalent calcium ions form a bridge, due to the attraction of negatively charged carboxylic acid groups between two neighboring alginate chains (Lai et al., 2016). Alginate has been widely used for cell encapsulation, including neural stem cells (Purcell et al., 2009), skeletal myoblasts (Hill et al., 2006), and articular chondrocytes (Ab-Rahim et al., 2013; Alsberg et al., 2002). Moreover, alginate provides favorable conditions for adipogenic differentiation and does not alter cell morphology (Galateanu et al., 2012). In addition to cell encapsulation, alginate has been successfully used as a 3D matrix for in-vitro culture of organoids and embryos, i.e. pancreatic islets (Tomei et al., 2014). However, despite the intrinsic properties of alginate that make it a favorable material for tissue engineering applications, chemical modifications are often required to promote desirable cellular functions, provide a greater range of mechanical properties, and facilitate controlled release of encapsulated factors. It was shown that, due to the highly hydrophilic nature of alginate, proteins are minimally adsorbed thus hampering cell attachment (Rowley et al., 1999). This can be overcome by modifying the alginate surface with peptides, such as RGD, to provide molecule binding sites for cell adhesion (Yong and Mooney, 2012). Extrusion-based bioprinting of alginate has been one of the most popular techniques in the bioprinting community (Seunghyun Ahn et al., 2012; SeungHyun Ahn et al., 2012; Markstedt et al., 2015; Ozbolat and Koc, 2010; Yu et al., 2013). Alginate has several advantages for use in EBB, including ease of crosslinking and a wide range of concentrations with superior mechanical properties. Alginate can be extruded in one of two forms, precursor and pre-crosslinked, depending on the application. Alginate in $2-4 \%$ $(w / v)$ is extrudable, structurally-stable and biologically acceptable and, after contacting the 
crosslinker, solidifies rapidly and maintains its 3D shape (see Fig. 2B) (Dolati et al., 2014; Ozbolat et al., 2014; Y Zhang et al., 2013; Zhang et al., 2015). The concentration of alginate determines the viscosity of the solution, porosity and crosslinking time. It is possible to form pre-crosslinked alginate by mixing with low concentrations of the crosslinker, which increases its printability (Cohen et al., 2010b). Depending on the purpose, the bioprinted constructs can be strengthen by further addition of the crosslinker. Droplet-based bioprinting of alginate is feasible as long as its concentration allows for droplet formation (in general $<2 \%$ in inkjet bioprinting (Gudupati et al., 2016)). Exploiting the crosslinking mechanism of alginate with $\mathrm{CaCl}_{2}$, heterogeneous tissue constructs comprised of amniotic fluid-derived stem cells (AFSCs), detrusor smooth muscle cell (dSMCs), and biliary epithelial cells (BECs) were fabricated (Xu et al., 2013). Mechanical properties of bioprinted constructs can also be improved by combining alginate with other functional materials. For example, bifurcated vascular tissue constructs were fabricated within fluorocarbon employing a blend of $3 \%(\mathrm{w} / \mathrm{v})$ low melting agarose and 3\% (w/v) low viscosity alginate (Blaeser et al., 2013). The buoyant forces of the fluorocarbon solution supported soft tissue constructs. Similarly, zigzag cellular constructs were fabricated by printing 3T3 fibroblast-loaded alginate solution into a $\mathrm{CaCl}_{2}$ crosslinker pool, where the crosslinker provided buoyancy support (Xu et al., 2012). Using an opposite configuration, another work also demonstrated bioprinting of alginate; heart-like tissue constructs were fabricated by bioprinting the crosslinker $\left(\mathrm{CaCl}_{2}\right)$ solution into an alginate pool using a modified HP inkjet printer (Xu et al., 2009). Laser-based bioprinting with alginate of different concentrations has been widely described using MAPLE-DW, where an alginate suspension containing cells was placed on the ribbon then pulsed with a laser (Gudapati et al., 2014; Guillotin et al., 2010; Yan et al., 2013). Successful bioprinting depended upon alginate concentration and viscosity, surface tension, the bioink layer thickness coated on the intermediate layer, gelation times, wettability, and laser fluence (Gudapati et al., 2014).

Chitosan, a linear polysaccharide molecule obtained from deacetylation of chitin, has a wide range of applications in tissue engineering such as cartilage regeneration, devices for hemostatic and 
antibacterial activity, formation of sponge scaffolds, and fabrication of wound dressings (Croisier and Jérôme, 2013). The best concentration for optimal biological response is $1.5 \%(\mathrm{w} / \mathrm{w})$ with a degree of acetylation between 30 and 40\% (Montembault et al., 2006). Due to its unstable mechanical properties and limited bioprintability (see Fig. 2C), chitosan is an appropriate material for cell encapsulation, but not for the formation of large scale scaffolds (Geng et al., 2005). Chitosan has been used in EBB for bioprinting of perfusable vessel-like microfluidic channels, where chitosan was crosslinked by an ionic crosslinker, sodium hydroxide ( $\mathrm{NaOH}$ ) (Yahui Zhang et al., 2013). The polymer and the crosslinker solution were printed simultaneously using a coaxial nozzle unit with the crosslinker solutions in the inner core diffusing out towards the polymer resulting in hollow tubular constructs. Bioprinting of chitosan using DBB and EBB has not yet been attempted.

Collagen type $\mathbf{I}$ is a triple helical biocompatible protein obtained from natural sources which has been extensively used in bioprinting (Ferreira et al., 2012). It is one of the major components of connective tissues and occupies about $25 \%$ of the entire protein mass in most mammals. Collagen is a highly conserved protein cross-species causing minimal immunological reactions. Collagen matrix facilitates not only cell adhesion but also enhances cell attachment and growth due to abundant integrin-binding domains. Although collagen type I has been used in bioprinting, it has limitations as it remains in a liquid state at low temperatures and forms a fibrous structure with increased temperature or neutral $\mathrm{pH}$. Complete gelation can take up to half an hour at $37^{\circ} \mathrm{C}$. This slow gelation rate makes bioprinting of 3D constructs difficult, since deposited collagen remains liquid for more than 10 minutes. Also, cells deposited in collagen are not homogeneously distributed, as gravity pulls down the cells before gelation takes place. Low mechanical properties and instability along with the abovementioned issues necessitate the use of supportive hydrogels for collagen. Extrusion-based bioprinting has utilized collagen alone as a bioink (Smith et al., 2004); however, mixing it with Pluronic ${ }^{\circledR}$ has generated promising results (Homenick et al., 2011). The cell number increased significantly after 24 hours post-bioprinting demonstrating that collagen is suitable for cell growth. Fully crosslinked, bioprinted constructs can even be perfused (V. Lee et al., 2014). Droplet- 
based bioprinting also takes advantage of collagen as a bioink material; however, collagen needs to be deposited before the onset of crosslinking (Deitch et al., 2008). In one study, Boland's group used collagen as a bioink constituent to investigate cell adhesion and proliferation on collagen-coated cell repellant substrates (Roth et al., 2004). Additionally, the same group fabricated a bilayer skin graft that generated neo-skins on mice that are near-identical to native skin with micro-vessels (Yanez et al., 2015). As collagen possesses a fibrous micro-architecture, its use in inkjet bioprinting is highly limited, therefore micro-valve bioprinting has been preferred. For example, fibrin-collagen bioink incorporating one of two cell types, AFSCs or mesenchymal stem cells (MSCs), was bioprinted using a valve-based bioprinter into wound sites as a treatment for skin burns (Skardal et al., 2012). Similarly, LBB has been successfully used to coat thin layers of collagen on laser-absorbing material; due to collagen's sticky nature it can be easily transferred with a laser pulse (see Fig. 2D) (Michael et al., 2013).

Fibrin is a hydrogel formed by the enzymatic reaction between thrombin and fibrinogen, the key proteins involved in blood clotting. It supports extensive cell growth and proliferation (Cui and Boland, 2009), plays a significant role in wound healing and has been used in fabrication of skin grafts (Skardal et al., 2012; Yanez et al., 2015). Rheology of gelled fibrin has been extensively studied because of its nonlinear elasticity (Janmey et al., 2009). The fibrin network is comprised of filaments forming as soft complex that allows a high degree of deformation without breakage (Janmey et al., 2009). Human umbilical vein endothelial cells (HUVECs) exhibit angiogenic behavior when cocultured with fibroblasts in fibrin. This is an essential factor in the vascularization of large tissue constructs and provides an effective in-vitro model for analysis of the fundamentals of the angiogenic process (Nakatsu et al., 2003). The disadvantage of using fibrin for in-vivo applications is the possibility of a severe immune reaction or transmission of infectious diseases when heterologous proteins are used. In order to increase the efficacy and safety of fibrin hydrogels, bacteria and viruses must be inactivated or fibrinogen and thrombin produced as recombinant proteins by mammalian cell lines. In addition, the degradation of fibrin is rapid, which is not 
conductive to long-term culture. Due to the non-shear-thinning nature of fibrinogen and thrombin, fibrin is rarely extruded. However, despite these drawbacks, a few studies have utilized fibrin (Gruene et al., 2011). Weak mechanical properties do not allow manipulation on fibrin after gelation rendering EBB of pre-crosslinked fibrin a challenge. However, bioprinting of the two components of fibrin is an ideal option for DBB (see Fig. 2E). Bioprinting of thrombin is feasible using inkjet (piezoor thermal-inkjet) bioprinting, but fibrinogen leads to clogging issues with unstable droplet formation due to its fibrous nature. In general, fibrinogen at low concentrations ( $<2 \mathrm{mg} / \mathrm{mL}$ ) is usable but such a concentration range limits the mechanical properties of bioprinted constructs. Therefore, micro-valve bioprinting is more convenient for DBB of fibrinogen (Gudupati et al., 2016). For example, thermal-inkjet bioprinting was employed for bioprinting human microvascular endothelial cells (HMVECs), but cell were loaded in culture media and precisely bioprinted on crosslinked fibrin (Cui and Boland, 2009). Cells aligned in fibrin and formed into an extensive capillary network after 21 days of culture. Fibrinogen and thrombin can be bioprinted from separate cartridges and combined on a platform to form a hydrogel; alternating layers of neural cells and fibrin gel were bioprinted generating viable neural constructs with a potential in neural engineering applications (Xu et al., 2006). Because of its prolonged crosslinking time and dependence on thrombin concentration, fibrin is generally difficult to print into a designed shape. Fibrin is not a suitable bioink material for LBB due to its delicate structure; however, it can be mixed with other LBB compatible hydrogels such as hyaluronic acid (HA) (Gruene et al., 2011).

Gelatin, a denatured form of collagen protein, is used in food and pharmaceutical industries (Gómez-Guillén et al., 2011; Liang et al., 2004). It is extracted from bones, skin, and connective tissues of animals (Gómez-Guillén et al., 2002). At low temperatures, gelatin strands self-associate to form helical structures leading to a gel-like form, which reverts back to a random coil conformation as temperature increases (Chiou et al., 2008). Gelatin retains the Arg-Gly-Asp (RGD) sequence from its precursor, is less immunogenic, and promotes cell adhesion, differentiation, migration, and proliferation (Sakai et al., 2009). Gelatin in gel form can be obtained by thermally-induced 
crosslinking and it can easily liquefy at $37^{\circ} \mathrm{C}$. The weight of unmodified gelatin gel decreases by $50 \%$ after around 10 hours of incubation and the gel completely dissolves within 24 hours (Sakai et al., 2009). To avoid dissolution, a variety of chemical crosslinking methods have been examined; however, such methods are problematic in in-situ and in-vivo applications where constructs contain living cells as crosslinking agents are cytotoxic (Liang et al., 2004). Popular enzymatic crosslinkers, such as transglutaminase, have been successfully used (Jin and Dijkstra, 2010). Other crosslinkers include horseradish peroxidase (HRP) and hydrogen peroxide $\left(\mathrm{H}_{2} \mathrm{O}_{2}\right)$ (Sakai et al., 2009). Gelatin can be successfully gelled in vivo and remained intact for one week without inducing necrosis in surrounding tissues (Sakai et al., 2009). Gelatin encapsulated cells demonstrate long term viability, but limited cell elongation (Benton et al., 2009; Nichol et al., 2010). Gelatin is rarely bioprinted in its native form due to its poor mechanical properties. To employ gelatin for bioprinting, it has been chemically crosslinked by the addition of agents such as glutaraldehyde (Hellio and Djabourov, 2006). The free amine groups along the gelatin polymer backbone undergo a nucleophilic addition reaction followed by dehydration with the two aldehyde groups of glutaraldehyde that form an imine functional group commonly referred to as a Schiff base (Hennink and van Nostrum, 2012). Often the degree of gelation depends on the $\mathrm{pH}$ of the medium. Molecules which are capable of accepting or losing protons with an increase or decrease in $\mathrm{pH}$ are sensitive to a change in the local $\mathrm{pH}$ environment. Using EBB, hepatocyte-laden gelatin was bioprinted into spatially-defined 3D structures. Hepatocytes remained viable and conducted their biological functions for more than two months (Wang et al., 2006). Gelatin is, however, not a popular hydrogel for DBB. Some studies have been performed by blending fibrin with gelatin for liver tissue biofabrication (Wei Xu et al., 2007). Boland et al. presented DBB of gelatin/alginate blend; however, $\mathrm{CaCl}_{2}$ solution was selectively printed onto the blended solution (see Fig. 2G) (Boland et al., 2007). Gelatin has been successfully used in LBB due to its viscoelastic properties, stability and ability to hold cells in precise positions without damaging cells (see Fig. 2F) (Raof et al., 2011; Schiele et al., 2011). Additionally, its 
thermosensitive properties allow for cell transfer and ease of removal post-printing to reveal an application-specific growth surface.

Hyaluronic acid, a linear non-sulfated glycosaminoglycan, is ubiquitous in almost all connective tissues and a major ECM component of cartilage (Zhang et al., 2009). It behaves similar to collagen type I and has properties that can be beneficial in the treatment of osteoarthritis (Migliore and Granata, 2008). It is comprised of repeating disaccharide units of D-glucuronic acid and $\mathrm{N}$-acetyl-D-glucosamine moieties linked by alternating $\beta-1,4$ and $\beta-1,3$ glycosidic linkages (Zhong et al., 1994). The three major functional groups, which govern the chemical activity of HA, are the glucuronic carboxylic acid group, the secondary hydroxyl group and the $\mathrm{N}$-acetyl group. Hyaluronic acid is widely used in tissue engineering due to its excellent biocompatibility and ability to form flexible hydrogels (Luo et al., 2000). Chemical modification of HA is an illustrative example of a bioink molecule polymerized by photo-crosslinking. To use HA as a bioink, chemical modifications of these groups are often carried out to enhance its rheological properties (Burdick and Prestwich, 2011); however, HA has slow gelation rate and poor mechanical properties. Hyaluronic acid is favored due to its role in early embryonic development, cell friendly nature, and controllable mechanics, architecture and degradation. Human embryonic stem cells encapsulated in HA, as opposed to 2D culture cells, maintained their phenotype, normal karyotype, and full differentiation capability (Gerecht et al., 2007). Additionally, the high molecular weight of HA adds an essential structural and organizational element into the ECM of native tissues (Kreger and Voytik-Harbin, 2009; Toole, 2004). It is instrumental in cell migration (Baier et al., 2007; Turley et al., 2002), nerve regeneration (Faroni et al., 2015; Ikeda et al., 2003; Seidlits et al., 2010), neuronal (Baier et al., 2007; Banerjee and Toole, 1991; Margolis et al., 1975; Mészár et al., 2008; Rauch et al., 2005) and glial development (Back et al., 2005; Liu et al., 2004), and wound healing (Aya and Stern, 2014). Hyaluronic acid has only minor cross-species variation and excellent biocompatibility (Dana et al., 2004; Leach et al., 2003). Pescosolido et al. developed a semi-interpenetrating network (semi-IPN) bioink by combining HA with a photopolymerizable dextran derivative (Pescosolido et al., 2011) (see 
Fig. 2H). In that study, a hydroxyethyl-methacrylate (HEMA) derivative of dextran was prepared by activating the HEMA group with $\mathrm{N}, \mathrm{N}^{\prime}$-carbonyldiimidazole and coupled it to dextran, forming dexHEMA. Hyaluronic acid/dextran-HEMA solutions were exposed to UV radiations in the presence of a photo-initiator inducing polymerization of the dextran chains. Hyaluronic acid moieties became entangled in the chemically crosslinked dextran network. Hyaluronic acid has been used in EBB but is generally blended with other hydrogels to enhance its bioprintability and solidification ability. For example, Skardal et al. used hyaluronic hydrogels crosslinked with tetrahedral polyethylene glycol (PEG) derivatives for bioprinting vessel-like constructs (Skardal et al., 2010c). To form extrudable ECM hydrogels, the symmetrical tetra-PEG molecules were acrylated to form tetraacrylates (TetraPAcs) then co-crosslinked with thiolated gelatin and HA derivatives. In another study conducted by the same group (Skardal et al., 2010b), methacrylated derivatives of gelatin (GE-MA) and hyaluronic acid (HE-MA) were synthesized separately and photo-crosslinked by a two-step process, before and after extrusion, to form more compact firm structures. Dynamic crosslinking of thiol modified-HA by gold nanoparticles was also studied in order to develop a hydrogel capable of reforming itself during and after bioprinting (Skardal et al., 2010a). Use of HA in DBB has not been demonstrated so far due to its viscous nature and slow gelation rate; however, it has been employed in LBB when combined with other hydrogels such as fibrin (Gruene et al., 2011) to facilitate faster crosslinking. The bioink consisting of human adipose-derived stem cells (ASCs) or endothelial colonyforming cells (ECFCS) combined with hyaluronic acid and fibrinogen was coated on the donor slide and bioprinted using LIFT. The collector slide was blade-coated with HA-fibrinogen as well and subsequently crosslinked by thrombin. Alternating layers of HA-fibrinogen combined with both cell types were bioprinted to study the interaction between the two cell types.

Matrigel $^{\mathrm{TM}}$, a commercial product, is a gelatinous ECM protein mixture secreted by Engelbreth-Holm-Swarm mouse sarcoma cells (Kleinman and Martin, 2005). It promotes cellular outgrowth from tissue fragments, vascularization and differentiation of various cell types (Gaetani et al., 2012; Kleinman and Martin, 2005). One of the major advantages of culturing cells on Matrigel ${ }^{\mathrm{TM}}$ 
is that it promotes complex cellular behavior which is difficult to observe on other surfaces. For example, endothelial cells create capillary sprouts in Matrigel ${ }^{\mathrm{TM}}$ (Kleinman and Martin, 2005). Molecules promoting endothelial cell network formation (Paul et al., 2013) are potential candidates for use in tissue regeneration therapies while the molecules that inhibit such formation can be used for anti-cancer therapies. Matrige $\mathrm{I}^{\mathrm{TM}}$ has been vital in the development of tumor xenograft models in rodents for discovery of novel cancer treatments (Benton et al., 2011). Matrigel ${ }^{\mathrm{TM}}$ is an expensive material; however, it has the ability to create mechanically strong, 3D bioprinted constructs with higher cell survival rates than other popular hydrogels such as agarose and alginate (Melchels et al., 2012). Thermal gelation properties of Matrige $\mathrm{I}^{\mathrm{TM}}$ and collagen type I are similar; however, gelation of Matrige ${ }^{\mathrm{TM}}$ is thermally reversible. Crosslinking occurs between $24-37^{\circ} \mathrm{C}$ and gelation takes about half an hour, beginning at temperatures above $4^{\circ} \mathrm{C}$. In EBB, Matrige $\mathrm{I}^{\mathrm{TM}}$ needs to be bioprinted before becoming fully crosslinked; thus, a cooling chamber is essential. To accelerate the crosslinking process after deposition and maintain the printed shape, a heated plate should be employed. In EBB, Matrigel ${ }^{\mathrm{TM}}$ has been used in a radioprotection study on liver cell lines (Snyder et al., 2011) (see Fig. 2I) and osteo- and endothelial-progenitor cell printing (Fedorovich et al., 2011). For DBB, Matrigel ${ }^{\mathrm{TM}}$ has not been used as a bioink material but employed as a substrate to place and pattern cells (Horváth et al., 2015). Its thermal crosslinking property and optimal viscosity make it an attractive bioink for LBB. Matrigel ${ }^{\mathrm{TM}}$ has been used for developing cellular constructs with precisely placed cells using MAPLE-DW cell transfer. A study conducted by Schiele et al. involved encapsulation of many cell types, such as dermal fibroblasts, neural stem, myoblasts, breast cancer cells and bovine pulmonary artery endothelial in Matrige ${ }^{\mathrm{TM}}$ (Schiele et al., 2009). The donor slide was coated with Matrigel ${ }^{\mathrm{TM}}$ containing cells while the receiver was coated only with Matrigel ${ }^{\mathrm{TM}}$. In a similar study, 3D cellular constructs were fabricated using multiple layers of human osteosarcoma cells bioprinted onto Matrigel ${ }^{\mathrm{TM}}$ substrates, using LIFT technique (Barron et al., 2004).

\subsection{Synthetic hydrogels}


While natural polymers offer a favorable environment similar to native ECM for tissue engineering applications, synthetic polymers can be adapted according to the requirements of bioprinting processes. Synthetic polymers can be chemically modified with not only crosslinkable functional groups, but also with domains capable of enhancing the structural and mechanical properties of bioprinted constructs. This enables one to carefully engineer the design of the polymer backbone with either cell adhesive domains containing the RGD sequence or with domains responsive to external electric or magnetic stimulus.

Methacrylated gelatin, the denatured form of collagen consisting of methacrylate groups conjugated to its amine side groups, has been used for tissue engineering due to its favorable biological and adjustable mechanical characteristics (Benton et al., 2009; Nichol et al., 2010). Despite low cell proliferation rates, GelMA has relatively high mechanical strength, low swelling ratio, and is amenable to blending with other hydrogels to increase cell survival. In 5\% micro-patterned GelMA, cells elongated, migrated, and formed interconnected networks with surrounding cells (Nichol et al., 2010). At higher concentrations, $10 \%$ or $15 \%$, cells do not migrate; however, individual cells showed limited elongation and some multicellular networks formed. Methacrylated gelatin is frequently used in EBB studies such as bioprinting of chondrocytes (Schuurman et al., 2013), liver cells (Bertassoni et al., 2014; Billiet et al., 2014; Schuurman et al., 2013; Visser et al., 2013) and mesenchymal stem cells (MSCs) (Du et al., 2015). It has low viscosity at room temperature and is easy to extrude, and its crosslinking rate can be manipulated by the length of exposure to UV light. Methacrylated gelatin forms a biomimetic (Nichol et al., 2010) as well as an enzymatically degradable (Hutson et al., 2011) hydrogel that is mechanically strong when photo-crosslinked in the presence of a photo-initiator. For example, Demirci's group bioprinted bone morphogenetic protein2 (BMP-2) and transforming growth factor (TGF- $\beta 1$ ) using DBB on a GelMA substrate to mimic a native fibrocartilage microenvironment. This substrate differentiated bioprinted human MSCs toward osteogenic and chondrogenic lineages in a spatial manner (Kuo and Demirci, 2014). Methacrylated gelatin has also been combined with other synthetic polymers such as polyethylene 
glycol diacrylate (PEGDA) and photo-crosslinked by eosinY based photo-initiator (Z. Wang et al., 2015). Crosslinking ability with visible light, long-term biocompatibility, bioprintability, and enhanced rheology are some of the advantageous features of this bioink formulation. Scaffolds with a porous architecture based on GelMA have also been bioprinted using LBB, where HUVECs spread over scaffold within four days (Gauvin et al., 2012) (see Fig. 2J). Recently, Ovsianikov's group demonstrated the first bioprinting of cells using 2PP (Ovsianikov et al., 2014). MG63 cells were encapsulated in GelMA hydrogel loaded with water-soluble photo-initiators. Ying-Yang structures were then bioprinted with solid and hollow parts, where cells exposed to the laser were damaged; however, they were able to proliferate and filled all the available space in three weeks of in-vitro culture.

Pluronic $^{\circledast}$ F-127 is a trade name for synthetic polymer poloxamer-based polymeric compound. It exhibits a polymeric architecture consisting of two hydrophilic blocks between a hydrophobic block making it an effective surfactant (Mesa et al., 2005). There are 11 types of Pluronic $^{\circledast}$ polymers which differ by molar mass, percentage of composites, functionality, and temperature of crosslinking which can vary from 10 to $40^{\circ} \mathrm{C}$ (S. Wang et al., 2015). Pluronic ${ }^{\oplus}$ undergoes reverse gelation as it starts to crosslink with increasing temperature. Pluronic ${ }^{\circledR}$ copolymer structures erode quickly and cannot hold structural integrity for longer than a few hours; however, Pluronic ${ }^{\circledR}$, in combination with other hydrogels such as polyethylene glycol (PEG), is useful for drug delivery and controlled release applications (Gong et al., 2009). Increase of mechanical strength was shown also by addition of methacrylated hyaluronic acid and then bioprinted into fluorescent tube (see Fig. 2K) (Müller et al., 2015). The study performed by Vashi et al. showed that bone marrowderived mesenchymal stem cells were able to interact with each other in a 3D Pluronic ${ }^{\circledR}$ environment and adipogenic induction started after four days of culture (Vashi et al., 2008). Pluronic ${ }^{\circledR}$, without any additives, can maintain the viability of cells for up to five days with a dramatic decrease thereafter. However, when supplemented with $60 \mathrm{nM}$ hydrocortisone, cell viability was preserved even in higher concentrations of Pluronic ${ }^{\circledR}$ (Khattak et al., 2005). Pluronic ${ }^{\circledR}$ can be cured 
by UV light for bioink applications; however, the radiation type and duration can impact cell viability (Johnson, 2011) and the concentration of the photo-initiator can affect the metabolic activity of cells. Chemical crosslinking can make the gel more resistant to thermal degradation (Masutani et al., 2014). Pluronic ${ }^{\circledast}$ can be crosslinked enzymatically whereby two ends of PEO side chains can be formed into self-assembled micelles (Lee et al., 2011). Pluronic ${ }^{\circledR}$ does not lose its thermallyreversible properties, but its mechanical strength increases with enzymatic crosslinking. In EBB, acceptable bioprintability of Pluronic ${ }^{\circledast}$ is obtained above $20^{\circ} \mathrm{C}$ as it becomes more viscous and exhibits shear-thinning behavior. Therefore, Pluronic ${ }^{\circledast}$, depending on its concentration, requires a heating system around the needle in order to transition from liquid to gel state; a heated plate to maintain the temperature of the construct after deposition should also be considered. Nonetheless, it is more advantageous to maintain Pluronic ${ }^{\circledR}$ in a semiliquid state in order to preserve cell viability in homogeneous suspension. In the case of prolonged bioprinting times, a cooling system might be needed in order to maintain a lower temperature in the bioink reservoir. The reversible properties of Pluronic ${ }^{\circledR}$ can be useful in fabrication of complex constructs. Pluronic ${ }^{\circledR}$ in solid form (at room temperature or higher) can be surrounded by a second type of hydrogel then placed at $4^{\circ} \mathrm{C}$ to liquefy the Pluronic ${ }^{\circledast}$. This procedure creates perfusable channels within bulky cell-laden constructs (Wu et al., 2011). The thermosensitive nature of Pluronic ${ }^{\circledR}$ and its high viscosity is problematic for DBB and so has not been used. Laser-based bioprinting has not been attempted as Pluronic ${ }^{\circledR}$ is not viscoelastic, maintains a solid coating on the quartz support and cannot transfer thermal energy to kinetic energy which is essential for jet formation.

Poly(ethylene glycol) has been widely used in medical and non-pharmaceutical products (Alexander et al., 2013; Lin and Anseth, 2009; Pasut et al., 2008; S. Wang et al., 2015). It is a linear polyether hydrophilic compound which can be conjugated with proteins (Alconcel et al., 2011; Zhang et al., 1998), enzymes (Pasut et al., 2008), liposomes (Ishida et al., 2005), and other biomolecules. It has been employed as a drug delivery agent (Alconcel et al., 2011; Lin and Anseth, 2009; Veronese and Pasut, 2005), and used in biosensing or signaling (Sharma et al., 2004), and pharmaceutical 
applications (Alconcel et al., 2011). PEG is generally considered as a hydrophilic polymer resistant to protein adsorption; however, recent studies revealed that incubation of PEG functionalized nanocarriers in human plasma caused adsorption of Clusterin, an apolipoprotein, which further assisted in the "stealth effect" of PEG-based materials and minimized cellular uptake of these PEG nanacarriers (Schöttler et al., 2016). Hence, some cells, particularly chondrocytes and osteoblasts, encapsulated in PEG survive well even without addition of biological constituents (Benoit et al., 2006). Other cell types may require additional cell adhesion components, such as RGD peptides or fibronectin coating. Fibronectin pre-coating improves cell adhesion, spreading, and the organization of the actin cytoskeleton (Vladkova et al., 1999). PEGylation inhibits protein adsorption making PEG a very useful synthetic polymer for bioprinting of tissue constructs for regenerative medicine. Poly(ethylene glycol) is water soluble and its mechanical properties can be manipulated through variation of its chemistry (Gao G1, Yonezawa T, Hubbell K, Dai G, 2015). Altering the composition of PEG-based hydrogels in tandem with photo-crosslinkage in the presence of a photo-initiator allows alterations to the structural, functional, and mechanical properties of fabricated tissues. One of the major limitations of PEG is its poor mechanical strength; therefore, addition of diacrylate (DA) of methacrylate (MA) is highly beneficial. However, additives such as DA and MA require photocrosslinking by exposure to UV light for a specific length of time to obtain the desired mechanical properties. Excessive exposure to UV light can dramatically reduce cell viability. For example, rat aortic smooth muscle cells have been successfully photo-encapsulated in PEG with 20 seconds of UV exposure (Mann et al., 2001). Poly(ethylene glycol) was also used in creation of micro-gels that were assembled in seconds using acoustic waves (Xu et al., 2011). Poly(ethylene glycol) diacrylate (PEGDA) and poly(ethylene glycol) methacrylate (PEG-MA) hydrogels are used in all types of bioprinting modalities: EBB (Bertassoni et al., 2014; Hockaday et al., 2012; Skardal et al., 2010c; Wüst et al., 2014), DBB (Cui et al., 2012a), and LBB (Hribar et al., 2014). Photopolymerization of PEG-based hydrogels with tunable mechanical properties has been widely demonstrated using EBB. Hockaday et al. performed 3D printing of anatomically-correct aortic valve scaffolds using PEG-DA hydrogels 
(see Fig. 2L) (Hockaday et al., 2012). Scaffolds were then seeded with porcine aortic valve interstitial cells, where cells demonstrated adhesion with minimum spreading or proliferation in 21 days. Earlier work, however, demonstrated that the immobilization of cell adhesion sites and growth factors during EBB promoted cell spreading and proliferation (Fedorovich et al., 2007; Zhang et al., 1998). Due to greater mechanical stiffness compared to naturally-derived polymers, such as alginate, fibrin, agarose and collagen type I, PEG has been extensively used in DBB. Using thermal inkjet bioprinting, Cui et al. bioprinted human articular chondrocytes in PEGDMA into osteochondral plugs in a layer-by-layer fashion with UV exposure following each layer, producing a 3D scaffold with uniform allocation of cells and neo-cartilage formation (Cui et al., 2012a, 2012b). In a similar study, acrylated-PEG was bioprinted with acrylated-RGD peptide, followed by photopolymerization of the bioprinted layer (Gao G1, Yonezawa T, Hubbell K, Dai G, 2015). Bone marrow-derived human MSCs were suspended in PEGDMA in conjunction with hydroxyapatite (HA) nanoparticles and bioactive glass (BG) and bioprinted using a thermal inkjet bioprinter (Gao et al., 2014), which conferred spatial control of the distribution of cells and bioactive ceramic materials in the fabricated bone tissue constructs. Poly(ethylene glycol)-based hydrogels have been widely used in LBB, including SLA and DOPsL. Bioprinting using SLA was first demonstrated with a commercial SLA 3D printer (SLA-250, 3D Systems), where Chinese hamster ovary cells were encapsulated in PEGDMA with over $90 \%$ cell viability (Dhariwala et al., 2004). In a similar approach, the same 3D printer equipped with He-Cd laser was used for encapsulation of 3T3 fibroblasts in PEGDMA to fabricate well-defined cylindrical scaffolds with multiple channels (Arcaute et al., 2006). In addition to SLA applications, DOPsL enabled fabrication of vascularized tissue construct using PEGDA hydrogels to study the migration behavior of HeLa cells (Huang et al., 2014). It was demonstrated that HeLa cells migrated significantly when the vasculature diameter was decreased.

Table 1 provides sample bioprinting and bioink formulation parameters along with bioprinters used in EBB, DBB and LBB of all the hydrogels presented in this paper.

\subsubsection{Decellularized Matrix Components}


Cells secrete specific molecules to create extracellular matrix (ECM), a localized environment which fosters cell attachment, proliferation, signaling, and tissue development. In an attempt to recapitulate this natural tissue environment, a bioink material based on decellularized extracellular matrix ( $\mathrm{dECM}$ ) has been developed. Preparation of $\mathrm{dECM}$ bioink requires removal of cellular material using chemical, physical and enzymatic processes without damage or loss of ECM (Ott et al., 2008). To determine if the matrix is fully decellularized, samples are evaluated by DNA quantification assays. Successful decellularization methods remove about $98 \%$ of the cellular content (Pati et al., 2014). The dECM is then further solubilized to a desired concentration, which results in a gel-like substance suitable for bioprinting (see Fig. 3A1). Other advantages of dECM are based on the nature-simulating bio-composition such as mechanical properties and appropriate microenvironment for cells for their proliferation and differentiation activities, and porous micro-structure retaining bioactive agents in the scaffold (Chan and Leong, 2008). Decellularized extracellular matrix is an excellent allogenic or xenogeneic biomaterial that has been used in tissue engineering yielding a number commercial products such as Alloderm ${ }^{\circledR}$, SurgiSIS ${ }^{\circledR}$ and Synergraft $^{\circledast}$ (Gilbert et al., 2006). A recent study showed that bioprinted constructs of $\mathrm{dECM}$ and stem cells did not induce cytotoxicity or inflammation after in-vivo implantation (Pati et al., 2015). Pati et al. printed a decellularized adipose tissue matrix loaded with human stem cells in tandem with melt-extrusion of PCL (see Fig. $3 A 2)$. As the printed $d E C M$ could not retain its shape post-bioprinting, the printed PCL provided the structural frame necessary to maintain the stability of dECM (see Fig. 3A3). Decellularized extracellular matrix bioink supported high cell viability over two weeks in culture and promoted the expression of adipogenic genes without additional supplementation.

\subsubsection{Microcarriers}

Microcarriers are supportive structures for cell growth and expansion; they are made of synthetic (i.e., dextran, plastic, glass) or natural (cellulose, gelatin, and collagen) materials with specific engineered porosities (Malda and Frondoza, 2006). Typically, they have been used as reinforcement blocks in bioprinting (Turner and Flynn, 2012). The shape of microcarriers, 
interconnected pores in a spherical architecture, allows cells to attach and grow on the surface (see Fig. 3B1). They provide an expansive monolayer environment, vastly improving the cell culturing process (Goh et al., 2013). Nutrient and gas transfer between the media and attached cells is more efficient than in 2D culture. Large numbers of cell-laden microcarriers can be suspended in cell media and cultured in environmentally controlled bioreactors. The surface of $1 \mathrm{~g}$ of microcarriers is equivalent to the surface of fifteen $75 \mathrm{~cm}^{2}$ culture flasks (Malda and Frondoza, 2006). Moreover, they improve the compressive modulus of constructs, support differentiation of stem cells to desired lineages, and preserve phenotypic stability at high cell concentrations (Levato et al., 2014). Using EBB, microcarriers can be loaded and bioprinted in hydrogels, where a representative bioprinting process is illustrated in Fig. 3B2. The ability to use high cell concentrations without compromising viability makes this a promising approach. Bioprinting MSCs pre-seeded on polylactic acid (PLA) microcarriers, Levato et al. showed that cells merely suspended in hydrogels exhibited less interaction, aggregation and osteogenic differentiation than cell-loaded microcarriers in hydrogels (Levato et al., 2014) (see Fig. 3B3).

\subsection{Scaffold-free Bioink Materials}

Evolution of organ development is based on cellular self-assembly mechanisms (Rivron et al., 2009). The cellular environment of a tissue construct needs to resemble its native counterpart for cells to maintain their phenotype, establish appropriate cell-cell interactions and express tissue specific proteins. Three-dimensional cell aggregate configurations provide a more hospitable environment for tissue self-assembly to occur than monolayer cell cultures. Tissue morphogenesis is dependent upon the formation of multicellular aggregates bound by cadherin molecules (Albelda and Buck, 1990; Heilshorn et al., 2005). Cadherin facilitates strong intercellular adhesion enabling signal transduction and an increase in integrin expression and binding to RGD motifs in the deposited ECM components (Behrens, 1999).

\subsubsection{Tissue Spheroids}


Tissue spheroids constitute a scaffold-free bioink type, where cells are organized spherically into $200-400 \mu \mathrm{m}$ diameter cell aggregates that can serve as building blocks and tissue models for tissue engineering and pharmaceutics, respectively. Several techniques have been demonstrated for fabrication of tissue spheroids. One of the most popular methods is culturing cells in microwells with rounded-ends on a cell-adhesion inert mold made of hydrogels such as agarose (Dean et al., 2007; Livoti and Morgan, 2010; Mehesz et al., 2011), methacrylated hyaluronic acid (MeHA) (Wheeldon et al., 2010) and alginate (Yamada et al., 2011). In this approach, thousands to millions of cells are seeded into an array of microwells and cultured for 24-48 hours to facilitate cell aggregation (see Fig. 3C1). Cells fall to the bottom of the microwells and settle in close contact with each other, driving the cells to spontaneously adhere to one another to minimize free energy and develop into a neo-tissue (Athanasiou et al., 2013). Over time, as tissue spheroids are formed, their size diminishes due to radial contraction; this is attributed to intracellular cytoskeletal reorganization from cadherinmediated cell-cell binding (Akkouch et al., 2015). Other approaches are also used in tissue spheroid fabrication. One is the hanging drop method (Del Duca et al., 2004), which relies on self-assembly driven by gravity. A cell suspension in a small volume $(15-30 \mu \mathrm{l})$ is pipetted onto the lid surface of a tissue culture plate. After inverting the lid, the droplets remain attached; however, gravity concentrates the cells at the bottom of droplet facilitating aggregation of cells. Microfluidic-assisted technology is another approach enabling cell aggregation inside cell traps (Jin et al., 2011; Torisawa et al., 2009; Zhang et al., 2014). Usually constructed by polydimethylsiloxane (PDMS) stamping, Ushape traps are created on an angled perfusion channel. During perfusion, cells are entrapped within U-shape and begin aggregation on contact. The device can be set in the vertical position to increase the effect of gravity. The major advantage of this method is the improved oxygen and media flow around the aggregates, which prevents necrosis. The major disadvantage is the difficulty of extraction of intact aggregates from PDMS. Another recent method is acoustic wave-assisted cell assembly (Guo et al., 2015) where cells are deposited onto a membrane, which vibrates in a specific frequency to form defined shapes. 
Bioprinting of tissue spheroids has been performed using EBB only (Mironov et al., 2009); as shown in Fig. 3C2, tissue spheroids within the gel medium can be loaded into a dispensing tip using slight mechanical pressure and extruded one by one to generate a precise spatial conformation. The speed of this process is driven by a mechanical ram which extrudes the bioink through a pipette unit. Along with spheroids, an agarose support structure (mold) is also printed to support fusion and maturation of the deposited spheroids. Over time, as shown in Fig. 3 C3, spheroids fuse to each other creating larger scale tissues that can be easily removed from the mold (Norotte et al., 2009). Instead of using a mold support, a recent work demonstrated the bioprinting of spheroids by picking them from a reservoir and placing and skewering them on a needle array (Itoh et al., 2015).

\subsubsection{Cell Pellet}

The cell pellet technique is based on centrifugal or gravitational forces that concentrate cells at the bottom of conical tube (Khalil et al., 2001). The pellet can then be transferred to a micropipette or other mold where intercellular interactions are further established to improve cohesion (see Fig. 3D1). The cell pellet technique is a practical method to create aggregates without the need for sophisticated systems; however, medium and oxygen circulation is limited and cell viability decreases markedly after 24 hours. One notable exception is chondrocytes, where a low oxygen level is desirable for enhanced production of ECM, including collagen type II and chondrogenic proteins (Schrobback et al., 2012). Cell pellet-based bioink has been used in EBB where the pellet was extruded into a confined space generated by 3D printing of a supporting agarose mold as demonstrated in Fig. 3D2 (Owens et al., 2013). The agarose support mold facilitated aggregation of cells resulting in tubular hetero-cellular nerve grafts (Owens et al., 2013) and aortic constructs (see Fig. 3D3) (Kucukgul et al., 2014).

\subsubsection{Tissue Strands}

Tissue strands can be defined as cylindrical neo-tissues that are engineered for bioprinting of scale-up tissues (Akkouch et al., 2015; Yu et al., 2016). The process for tissue strand formation has 
been recently established (Yin Yu and Ozbolat, 2014). Cells at very high density are injected and packed into hollow alginate tubes. Semipermeable alginate tubes allow the exchange of medium with nutrition and oxygen; the cells grow in given shape as they do not attach to the alginate luminal surface. When cells aggregate into a neo-tissue (see Fig. 3E1), the tube is dissolved using a decrosslinker solution. The formed tissue strand is then placed into a custom-made bioprinter head and extruded mechanically (see Fig. 3E2). Tissue strands must be optimally matured to ensure appropriate bioprinting conditions. Immature strands that are not fully aggregated may not form the desired shape and can disintegrate during bioprinting. Tissue strands that are overmature may not be malleable enough for deposition. A low level of oxygen in the core of strand may be a drawback for some tissue constructs, however this method is especially suitable for cartilage formation, as chondrocytes preferentially proliferate in hypoxic conditions (see Fig. 3E3) (Schrobback et al., 2012).

\section{Comparative Evaluation of Bioink Materials}

In this section, currently available bioink materials are compared and evaluated based on several performance metrics including their (i) compatibility with different bioprinting modalities, (ii) bioprintability, (iii) biomimicry, (iv) resolution, (v) affordability, (vi) scalability, (vii) practicality, (viii) mechanical and structural integrity, (ix) bioprinting and post-bioprinting maturation times, (x) degradability, (xi) commercial availability, (xii) immunogenicity and (xiii) applications and has been summarized in Table 2.

\subsection{Compatibility with Bioprinting Modalities}

Although there is a wide variety of bioink materials, including hydrogels, dECM, microcarriers, and cell aggregates, not all of the currently available bioprinting modalities are compatible with every bioink material. Extrusion-based bioprinting has the greatest flexibility among existing bioprinting modalities, due to the extrusion mechanism as well as the larger nozzle diameters. Extrusion-based bioprinting can facilitate bioprinting of hydrogels, cell aggregates (in spheroid, strand and cell pellet form), dECM components and microcarriers in bulk hydrogels. Other bioprinting modalities including DBB and LBB support bioprinting of hydrogels only. Since the nozzle 
orifice diameter in DBB is very small $(<120 \mu \mathrm{m})$ (Ozbolat and Hospodiuk, 2016)), bioprinting of cell aggregates and microcarriers is challenging as the nozzle tip can easily clog and does not support formation of droplets as previously discussed (Gudupati et al., 2016). Although not yet attempted, DBB of $\mathrm{dECM}$ is technically feasible assuming the $\mathrm{dECM}$ viscosity is low and does not generate a fibrous gel. In LBB, bioprinting of cell aggregates, $\mathrm{dECM}$ and microcarriers have not been attempted; however, due to the large mass of microcarriers and cell aggregates, bioprinting with LBB will represent a technical challenge.

\subsection{Bioprintability}

The bioprintability of hydrogels is superior to that of other bioink types. As long as the crosslinking mechanism is incorporated into the layer-by-layer fabrication scheme, bioprinting of hydrogels is relatively straightforward as other bioink types require additional processes and customized systems for the extrusion setup. For example, cell aggregates need to be loaded in a custom-made extrusion-head. Tissue spheroids need to be loaded into a pipette unit and delivered in a medium (Tan et al., 2014). The act of loading cell aggregates into the pipette unit can be problematic as tissue spheroids can start to aggregate; this can result in nozzle clogging. In addition, it is difficult to achieve the necessary close contact between spheroids post-bioprinting, resulting in poor tissue formation. Extrusion of cell pellets, on the other hand, is relatively simple; however, an additional support structure (such as agarose mold) should be printed in tandem to promote aggregation of cells. Tissue strands, on the other hand, can be bioprinted in solid form without the need for a molding structure or a delivery medium. However, it is crucial that the strands are engineered to be both malleable and mechanically strong to facilitate proper bioprinting (Yu et al., 2016). Bioprinting dECM requires $3 D$ printing of a frame to structurally support the dECM until full gelation is complete. Recent work demonstrated 3D printing of dECM with PCL (Pati et al., 2014), but degradation of the PCL structure is problematic when the printed construct is implanted in vivo. Bioprinting microcarriers is relatively straightforward, but loading them at high densities can cause nozzle clogging issues. 


\subsection{Cell viability and proliferation}

Cell viability in hydrogels depends on the hydrogel type, its concentration, and the postencapsulation time. A few reports compare cell viability among several hydrogels. One compared the effects of Matrigel, Pluronic ${ }^{\circledR}$ F-127 (25\%), alginate (2\%), and agarose (1\%) on cell viability over time (Fedorovich et al., 2008). After five hours of incubation, no significant differences in cell viability were detected; however, one day later, the cell viability in Pluronic ${ }^{\circledR}$ dropped to $20 \%$. After seven days, cells in Matrigel and alginate maintained about $90 \%$ viability, while viability in agarose decreased to $70 \%$, and no viable cells were detected in Pluronic ${ }^{\circledR}$. The same report showed no significant difference between printed and manually deposited scaffolds in terms of cell viability and proliferation. For further comparison, the reader is referred to (Malda et al., 2013). Another factor that is influential in cell viability is the bioprinting modality, where cell viability after DBB and EBB processes is greater than $85 \%$ and $98 \%$, respectively (Chang et al., 2011). Hydrogel concentration also affects cell survival, i.e. a blend of $5 \%$ gelatin and $1 \%$ alginate maintained almost $100 \%$ viability; however, in a blend of $10 \%$ gelatin and $1 \%$ alginate, the viability drops to $70 \%$ after six hours postbioprinting (Ouyang et al., 2016). A $2 \%$ alginate concentration maintains about $90 \%$ viability, whereas a $6 \%$ results in only $35 \%$ viability (Yu et al., 2013). Cell aggregate-based bioink materials can maintain high cell viability if the aggregate size is small; however, cell viability in the core decreases dramatically when the aggregate size exceeds 400-500 $\mu \mathrm{m}$ in diameter (Ozbolat and Hospodiuk, 2016). Bioprinted dECM maintains one of the highest viability rates among hydrogels; over $95 \%$ viability has been reported in multiple articles (Jang et al., 2016; Pati et al., 2014, 2013).

\subsection{Biomimicry}

Cell encapsulation in hydrogels allows patterning of cells; however, subsequent ECM formation, digestion and degradation of the hydrogel matrix, interactions and proliferation of encapsulated cells are all issues that require careful attention. There are intrinsic limitations associated with cell-encapsulation in hydrogels such as restricted cell interactions, proliferation and colonization of immobilized cells within the hydrogel matrix, and the inability of cells to spread, 
stretch and migrate to successfully generate the new tissue, particularly at high hydrogel concentrations (Ozbolat, 2015a). Cell aggregate-based bioink materials, however, exhibit better biomimetic characteristics facilitating both homo- and hetero-cellular interactions due high cell densities and lack of exogenous matrix immobilization. These tissue constructs closely resemble the native tissue and preserve cell phenotype and functionality for extended periods of times. Microcarriers in hydrogels also allow better interaction between cells due to inherent high cell density. Decellularized matrix components provide a highly biomimetic environment for cell proliferation and differentiation as they are comprised of matrix proteins essential for cellular activities.

\subsection{Resolution}

Resolution of bioprinting processes depends on the bioprinting modality as well as the bioink. When bioprinting cells in hydrogels using LBB, $5.6 \pm 2.5 \mu \mathrm{m}$ resolution can be achieved (Ozbolat and $\mathrm{Yu}, 2013$ ). In DBB and EBB, the range can increase to approximately 50 and $100 \mu \mathrm{m}$, respectively (Ozbolat and Yu, 2013). Incorporating cell aggregates and microcarriers into EBB can further deteriorate the resolution. Particularly, cell aggregates in spheroid and strand forms have a diameter ranging from 250 to $450 \mu \mathrm{m}$ (Mehta et al., 2012; Yu et al., 2016). Although bioprinting of a cell pellet can result in higher resolution compared to bioprinting of tissue spheroids and strands, a reduction in nozzle diameter can have detrimental effect on the cell pellet as cells are directly exposed to the shear stress rather than cushioned within a hydrogel matrix. Although original design structure can be closely fabricated using these bioink materials, most do not retain shape and will spread, shrink or swell depending on the bioink and culture conditions.

\subsection{Affordability}

Most bioprintable hydrogels are affordable although some naturally-derived hydrogels such as Matrigel ${ }^{\mathrm{T} M}$, fibrin and collagen can be expensive. Microcarriers are also quite affordable as they are made of synthetic polymers (Malda and Frondoza, 2006). Cell aggregates, on the other hand, are expensive to produce and can require highly sophisticated approaches to their construction, as 
discussed previously. Hundreds of millions of cells are needed to prepare them in sufficient quantity, depending on the cell size and the rate of ECM deposition. Expansion of cells in these numbers is labor-intensive, costly, and time-consuming. Decellularized extracellular matrix-based bioink can also be expensive as a large amount of native tissue is needed to produce a small volume of bioink.

\subsection{Scalability}

In general, bioprintable hydrogels are scalable; the majority can be obtained in abundant quantities compared to cell aggregates and dECM. Although tissue spheroids are not easy to scale up, cell pellets or tissue strands provides relatively better scalability (Yu et al., 2016). Decellularized extracellular matrix, on the other hand, currently lacks scalability as the original tissue yields a very small amount of dECM. Therefore, dECM can be considered scalable for bioprinting when reinforced with an affordable hydrogel. Microcarriers are smaller in size; however, they are scalable and can be loaded in hydrogels in higher densities as long as they do not clog the nozzle unit during bioprinting.

\subsection{Practicality}

Hydrogel-based bioink materials can be considered the most practical bioink type for bioprinting living tissues; the process can be as simple as loading cells into a hydrogel precursor solution. Different hydrogel types possess varying levels of ease in bioprinting, depending on their crosslinking mechanisms. Other bioink types can be challenging in terms of preparation and processing as well as bioprinting. For example, preparation of cell aggregates is labor intensive and time consuming. The addition of hydrogels to the process may be necessary for delivery in an extrusion process, support aggregation of cells, or fusion of cell aggregates making the entire process quite complicated. For dECM preparation, well-established protocols are needed to generate the bioink with appropriate biological and biochemical characteristics. Moreover, the bioink needs to be loaded in a compatible hydrogel solution adding complexity to the process. Microcarriers, on the other hand, require the fabrication of porous biodegradable delivery particles for initial seeding of the cells. Upon satisfactory attachment and spreading of cells, microcarriers are then loaded in a hydrogel solution for the bioprinting mission. With the exception of hydrogels 
(excluding blend hydrogels requiring multiple crosslinking mechanisms), all other bioink types are a multi-step approach and therefore, are not considered practical.

\subsection{Mechanical and Structural Integrity}

Hydrogels and $\mathrm{dECM}$ components provide superior structural support for cells in 3D until they are able secrete their own ECM. Mechanical and structural properties of hydrogels depend on their type and concentration; a lower concentration is more supportive of cell proliferation and growth, but demonstrates inferior mechanical properties. Microcarriers, on the other hand, provide a mechanically strong 3D scaffold as an environment for cells. Cell aggregates have no structural and mechanical support at the beginning of neo-tissue formation; later, cells support each other through cadherin-mediated cell-cell adhesion followed by ECM deposition (Takeichi, 1988), which lends further integrity to the 3D structure. Depending on the cell type used, mechanical properties alter over time. Parenchymal cells of metabolically highly active organs such as liver, pancreas and heart do not secrete many ECM components and the resulting cell aggregates are very weak in their mechanical and structural integrity. Therefore, supporting stromal cells should be co-cultured to provide enough strength for bioprinting purposes. Although mechanical properties are important, they can affect the diffusion and permeability of the bioink adversely. In general, permeability of cell aggregates is lower than that of hydrogels and the diffusion of media and oxygen is limited. Cell aggregates over $400 \mu \mathrm{m}$ can experience hypoxia at their core, curtailing cell survival (Mehta et al., 2012).

\subsection{Bioprinting and post-bioprinting incubation time}

The bioprinting time depends on the size and porosity of the construct as well as the resolution of the bioink. Generally, the bioprinting time of hydrogels and microcarriers loaded in hydrogels is shorter (i.e., few minutes). Bioprinting of dECM takes longer than hydrogels as bioprinting and solidification of the structural PCL support adds extra time. Bioprinting of cell aggregates such as tissue spheroids may take a significant amount of time using a pick-and-place type of robotic dispenser (i.e., minutes to an hour depending on the construct size and complexity) 
(Itoh et al., 2015). In addition, printing the supporting mold structure also contributes to prolonged fabrication times. Although the bioprinting step takes longer using cell aggregates, post-printing maturation and tissue formation time is significantly shorter than that of hydrogels and microcarrierloaded hydrogels. Complete tissue fusion and maturation can be obtained successfully in a week, whereas this process is much longer with hydrogels (Yin Yu and Ozbolat, 2014).

\subsection{Tissue fusion and formation post-implantation}

Bioprinted scaffolds that are subsequently implanted need to integrate with the vasculature of the host tissue and surrounding ECM. A host immune-response or improper development of the implanted tissue can result in rejection. The implanted structure must provide sufficient mechanical support over the regeneration time yet degrade at a suitable rate. This balance of mechanical strength and degradation rate is especially important in hard tissue formation. The requirements for full regeneration of any tissue type can be met by careful design of the bioink formulation. Besides acting as a mechanical support for cells, bioink materials can mimic the natural ECM environment to enhance cell recruitment, proliferation, differentiation, and fusion of the tissue construct with host tissue. Moreover, the bioprinted tissue needs to be of an appropriate size for the recipient. In order for the implant to align correctly with the host tissue, bioink deposition at sufficient resolution is critical. Bioprinted hydrogels constructs in smaller sizes without a macro-vasculature network can engraft with the host; however, endothelial cells should be encapsulated during the bioprinting process or endothelial progenitor cells should be recruited from the host so that perfusable microvasculature can be formed in constructs over time and anastomose with the vasculature from the host. The key for successful vascular formation and anastomosis is delivery of sufficient nutrient and oxygen to the developing tissue construct. Most recently, a technology combining 3D scanning and the bioprinting of hydrogel into a defined form has been demonstrated (Kang et al., 2016). PCL polymer, cell-laden blend of gelatin, fibrinogen, and glycerol, and Pluronic ${ }^{\oplus}$ F-127 as a sacrificial material were sequentially printed on a temporary porous scaffold creating a native-tissue relevant shape with a prolonged degradation time. For the cell aggregate-based bioink materials, a few 
recent implantation work demonstrated the fusion of bioprinted tissues with the host. Researchers from Japan recently showed that multicellular tissue spheroids were bioprinted into 3D vascular grafts, maturated in a bioreactor and implanted into the abdominal aortae of rats (Itoh et al., 2015). The study showed that the vascular graft fused to the host and re-endothelialized upon implantation. Owens et al. reported the self-assembly of tissue spheroids into cylindrical nerve grafts that were subsequently implanted in the sciatic nerves of rats, which enabled the recovery of both motor and sensory function (Owens et al., 2013). Decellularized ECM bioink derived from adipose tissue has been 3D bioprinted and subcutaneously implanted into mice (Pati et al., 2015). It was observed that bioprinted scaffolds supported adipose tissue remodeling. Post-implantation cytotoxicity and chronic inflammation was not detected. Implantation of bioprinted constructs using microcarriers, on the other hand, has not been demonstrated yet.

\subsection{Degradability}

Degradability of bioink materials depends on the selected hydrogels or their blend, concentrations, temperature, conditions (in vitro or in vivo) and presence of external additives. Hydrogels that are highly sensitive to external conditions are thermosensitive hydrogels, which are easy to dissolve, and thereby lose their shape if environmental conditions are not constant. Also, degradation can be varied by hydrolytic or enzymatic labile components within a hydrogel (Nicodemus and Bryant, 2008). Additionally, the presence of cells within hydrogels limits the choice of chemical formulations while still maintaining mechanical strength. Because of their hard polymer composition, microcarriers degrade slower than hydrogels and may release substance that are toxic to cells. In summary, the degradation rate of $3 \mathrm{D}$ constructs must be designed according to the application.

\subsection{Commercial availability}

Both natural and synthetic hydrogels and microcarriers made of polymers, including PLA, glass, alginate, dextran, and acrylamide in different forms, are commercially available (Jakob et al., 2016; Malda et al., 2003; Malda and Frondoza, 2006). As tissue engineering and biofabrication 
technologies have advanced by leaps and bounds over the past decade, 3D culturing of cells has gained the attention of commercial enterprises and a wide array of spheroid models (such as tumor or other tissue models for drug screening) are now available (Alhasan et al., 2016). Despite substantial progress, there is still a great need for representative spheroid models for several tissue types in the research community. Tissue strands and dECM based bioink materials are relatively new and are not currently available commercially.

\subsection{Immunogenicity}

The introduction of any biological or non-biological material has the potential to induce an immune response when implanted into a host. In a recent study, hydrogels obtained from other species such as collagen type I obtained from rat tail generated a low-level of immune response as demonstrated by an in-vitro lymphocyte proliferation assay (Murphy et al., 2013). Therefore, the bioink, such as hydrogels and dECM components, obtained from other species can induce an immune response. However, cell aggregates fabricated from autologous cells are not expected to elicit immunogenic issues.

\subsection{Applications}

Bioprinted tissue and organ constructs have been used in various fields including tissue engineering and regenerative medicine, drug screening, cancer research, and high-throughput assays (Ozbolat et al., 2016); however, not all bioink types have been utilized in these application areas yet. Hydrogels have been extensively used in bioprinting for tissue engineering and regenerative medicine as well as drug testing, cancer research and high-throughput assays. Recently, cell aggregate-based bioink materials have been used in fabrication of tissue models for drug screening (Peng et al., 2016). Although the present bioink types detailed in this paper have been used in tissue engineering and regenerative medicine research extensively, a clinical trial has yet to be performed.

\section{Limitations}


Despite the recent progress in development of new bioink materials for 3D bioprinting, there are still several challenges in this emerging field. Further advancements are essential in bioink technology including synthesis and processing of new materials for bioprinting. The main objectives are to minimize cell loss and maximize cell-cell interactions, vascularize large scale tissue constructs, improve mechanical properties, and gain a comprehensive understanding of additional compounds for supporting 3D bioprinted constructs. Although a large number of hydrogels offer great potential for tissue engineering, a limited number has been adopted in bioprinting due to their lack of bioprintability.

Hydrogels are the most favorable material type for cell support; however, there are several weaknesses related to bioprinting. First, hydrogels do not contain specific ECM proteins for particular cell types. Therefore, they are unable to provide a native environment. Second, hydrogels encapsulate and confine cells, limiting their interactions. Also, it is difficult to achieve the same high cell density as in native tissues. The concentration of hydrogels also plays an important role as increased concentration improves mechanical properties, but limits biological activities. Also, more rigid hydrogels require higher pressure levels for extrusion or generation of droplets. A higher concentration of hydrogel lowers the mobility of cells resulting in limited cell proliferation and deposition of ECM proteins. The cellular microenvironment provided in hydrogels may differ significantly from native tissues. Hydrogels degrade much slower in vitro, due to the lack of enzymes, immune response, and blood flow. However, hydrogels must be designed to degrade in vivo in a synchronized manner with respect to the new tissue formation. Another important shortcoming is the toxicity of degradation products that can be harmful to cells or the newly formed tissue. Instability is another important limitation, which may occur at various stages of the bioprinting process. Most hydrogels are extremely soft and can easily spread and lose their structural integrity during the bioprinting process.

Microcarrier technology is an efficient method for cell expansion in a small volume; however, this technology requires bioreactors to provide constant movement of microcarriers and 
appropriate environmental parameters for cell growth. One of the limitations is the need for a more complex detachment system to harvest cells, depending on the scaffold material. Another limitation is the possibility of nozzle clogging due to inherent adhesive properties of microcarriers, gravitational effects or high density in hydrogels. In addition, the bioprinting process requires a balance between the media dilution necessary for deposition on the bioprinting stage and close contact between microcarriers in the bioprinted construct. Moreover, degradation products of microcarriers can be toxic to cells if hard polymeric ones are used. Despite its limitations, microcarrier technology has been utilized in other application areas (Malda and Frondoza, 2006), and may be an important and powerful tool for tissue engineering in the near future.

The cell pellet is a dense mass of cells in a suspension with a minimal amount of culture media. Cells quickly form aggregates in the shape that they are cast, i.e. tissue strands or spheroids. It is the most practical scaffold-free bioprinting approach, but the major hurdle is the limited size of constructs to ensure the availability of oxygen in the center of constructs. Also, the need for a temporary molding structure limits the size of tissues to very thin tubular shapes (i.e., blood vessels (Norotte et al., 2009) and nerve conduits (Owens et al., 2013)). The construct properties ultimately depend on the cell type, the number of cells, and the final construct dimensions.

Despite the variety of tissue spheroid fabrication techniques, there are still limitations with the use of tissue spheroids within the bioprinting domain. Tissue spheroids may experience necrosis in their core, but this can be overcome by vascularization or fabricating luminized spheroids (Fleming et al., 2010). However, if the culture relies on endothelial cells to create vascularization, the angiogenic process can take more than 48 hours. This method is especially important for scale-up fabrication of tissues, where the primary issue is vascularization within the construct (Ozbolat, 2015b). Several difficulties can be encountered during the bioprinting of tissue spheroids. First of all, loading tissue spheroids into a nozzle (i.e. glass pipette) is highly challenging. Spheroids are not a uniform size and can be easily deformed or broken, depending on the cell type and maturity of spheroid. The nozzle must be designed to be large enough to hold the spheroids inside and allow 
extrusion without clogging. Also, the medium surrounding the tissue spheroids should also have appropriate properties. A characteristic feature of cell aggregates is rapid fusion, which is a desirable attribute post-bioprinting, but not during the bioprinting process. On the other hand, if spheroids are too sparse in hydrogels, they will not contact one another upon bioprinting.

Tissue strands are an alternative approach to spheroids, differing in shape and preparation methods. The major drawback is the lack of full automation of the process as loading of tissue strands is performed manually. Also, bioprinting parameters need to be optimized for each tissue specific strand. Another disadvantage is the requirement for high numbers of cells, depending on the desired length of the strand; additionally, tissue strands shrink substantially during maturation due to contraction. For constructs that require larger diameters for construction of scalable tissues, vascularization of the construct needs to be incorporated.

A native organ source is essential for the acquisition of dECM. Even after procuring the organ, it is a fairly tedious procedure requiring careful techniques for decellularizing the organ while causing minimal damage to the ECM, multiple washing steps to ensure removal of all externally added chemical or enzymatic reagents, and proper disinfection of the acquired decellularized organ (Pati et al., 2014). Even if a successful extraction is executed, the risk of an immunoreaction by the recipient remains. Moreover, the volume of final product is extremely limited compared to the size of the original organ. Decellularized matrix also loses its mechanical and structural integrity as well as some biochemical properties when homogenized. In addition, toxic residues from the decellularization process can remain (Crapo et al., 2011). The high cost of the bioink, the need for rigorous protocols, and low yields of product are limitations of dECM-based bioink materials (Ozbolat and Hospodiuk, 2016). The major weakness of dECM relative to the bioprinting process is its weak mechanical properties; therefore, 3D printing of a support frame is essential. The cost of dECM depends upon the quantity of ECM in the tissue. If the ECM content is low, the cost of harvesting $\mathrm{dECM}$ is high. With some tissue types, the preparation process may result in loss of a large portion of ECM. Other procedures such as chemical treatment can contribute to dECM 
contamination and toxicity. Finally, cells seeded in AECM will rapid degrade the bioink due to the production of cellular matrix metalloproteinases (MMPs). Thus, further research is needed to optimize the use of $d E C M$ in bioprinting.

While each bioink type has its own advantages over others, hybrid tissue constructs can be envisioned as the combination of two or more complementary bioink types (Armstrong et al., 2016). In hybrid constructs, two types of bioink types can be integrated; in bioprinting a pancreas-on-a-chip model, engineered islets (in tissue spheroid form) can be loaded in hydrogels to create an in-vitro vascularized pancreatic tissue model (Peng et al., 2016).

\section{Future Directions}

Despite the great progress in biomaterial development for tissue engineering and regenerative medicine, relatively few research endeavors have been devoted to the development of biomaterials for bioprinting processes; the majority of biomaterials researchers do not consider refinement of their biomaterials for use in the domain of bioprinting. Therefore, further effort should be devoted to engineering new bioprintable materials. A new field of study in the design and development of novel bioink materials is likely to emerge in the near future. In order to develop such bioink materials, compatible bioprinting processes should be first identified as each bioprinting modality possesses different requirements for the bioink materials.

New bioink development for EBB is crucial as the majority of researchers in the bioprinting domain use EBB due to its practicality and the ability to fabricate larger scale tissue constructs. Bioink materials used in EBB should possess various properties, but the most important characteristics are shear thinning, rapid crosslinking and solidification capabilities. Hydrogels lacking rapid solidification capabilities tend to spread upon extrusion and cannot retain the originallybioprinted shape. There are currently only a few hydrogel types exhibiting such properties such as Pluronic ${ }^{\circledR}$ and sodium alginate, but these bioink materials do not support cell growth and successful tissue regeneration. Therefore, new bioink materials possessing all these characteristics will be most valuable. In addition, new bioprinting approaches can also be developed to overcome the intrinsic 
limitations of soft hydrogels. For example, in the recently demonstrated bioplotting approach, hydrogels (such as alginate, fibrin and collagen) were extruded and bioprinted in a hydrogel bath loaded with gelation micro-particles (Hinton et al., 2015). The addition of gelation micro-particles at $22^{\circ} \mathrm{C}$ (when the bath is in solid state) kept the bioprinted gel in place and maintained the shape. In this case, the hydrogel bath acted as a mold support for the bioplotted solution. At the same temperature, when the nozzle moved, the bath near the nozzle acted like a liquid allowing the bioink solution to be extruded and plotted into the hydrogel bath. This behavior of the bath is explained by the Bingham plastic behavior of such materials. Upon increasing the temperature of the hydrogel bath, the bath reverted to a liquid phase and the bioplotted construct could be easily removed.

In DBB, bioink materials are utilized in two different aspects including (i) bioink materials that are ejected for droplet formation and (ii) substrate materials for droplet deposition. For bioink materials used in DBB, novel hydrogels should be developed that have lower viscosity, but possess sufficient mechanical and structural properties as well as appropriate gelation properties to allow rapid solidification of droplets. In addition, such bioink materials should not have a fibrous microarchitecture (i.e., collagen and fibrinogen) that can easily clog the nozzle or tubing line within the cartridge head. Bioprinting of larger scale tissue constructs using DBB is limited to a few bioink materials including alginate-agarose blend hydrogels; however, these bioink materials do not favor growth of cells. For substrate biomaterials, where cells are directly patterned on a hydrogel film (substrate), only thin constructs could be obtained and research studies have been limited to 2D patterns. These substrate materials should spread on the printing table uniformly and be easily peeled off by practical means such as thermal alteration of the surface chemistry (i.e., from hydrophobic to hydrophilic), a technique used in cell sheet technology (Yamato and Okano, 2004). For this purpose, a hybrid bioprinting platform can be developed, where the substrate can be applied at a finite thickness followed by bioprinting and patterning of the cell suspension.

For bioink materials used in LBB, two separate considerations are given as the requirements for processes based on cell transfer differ from those involving photopolymerization. For bioink 
development utilized in cell transfer technologies, new bioink materials should be developed with specific properties such as the ability to spread and create a uniform film on the ribbon, viscoelasticity that facilitates jetting with minimum satellite formation and controlled droplet deposition, quick gelation capabilities to provide sufficient mechanical integrity and hold the entire bioprinted construct in place in 3D. In addition, appropriate substrate biomaterial should be in place, similar to the substrates used in DBB, to provide appropriate landing of the bioink without splashing or spreading. In addition, the bioink should be designed and engineered to easily peel off from the printing stage. For hydrogels used in processes based on photopolymerization, new bioink developments are essential as current photocurable materials are of insufficient strength to generate structurally integrated hard tissue constructs. In processes involving photopolymerization, the photocurable bioink determines the speed of curing and resolution of the process; the bioink should possess certain mechanical, biological and chemical properties to serve for different tissue fabrication purposes. In this regard, the right combination of photocurable materials, curing agent, solvent, bioreagent and light absorber should be selected in order to design the optimal process. Along with photocurable hydrogels, photo-initiators have been used to start the solidification process as well as improve the mechanical stability of the tissue constructs. However, they are not easily applied to bioprinting as photo-initiators are toxic. Low concentration photo-initiators have been used (Fedorovich et al., 2009; Lu and Chen, 2012), but generally result in poor mechanical properties, excessive swelling and an increased depth of curing. This affects the solidification of other layers and deteriorates the quality of bioprinting. Thus, development of new photocurable materials and water-soluble photo-initiators are essential to the bioprinting field.

In addition to the bioprintability property, biological properties of hydrogels play a crucial role in successful regeneration of tissues. As synthetically designed hydrogels lack natural proteins with cell adhesion ligands, inclusion of these proteins or RGD peptides can improve cell adhesion. One of the major drawbacks of currently available hydrogel materials is that they do not facilitate differentiation of cells into multiple lineages. As the majority of native tissues and organs have 
heterocellular niches, where multiple cell types interact in a highly complex microenvironment, only a limited effort has been given to the development of smart bioink materials that can facilitate differentiation of stems cell into different lineages. For example, one of the important problems in regenerative medicine is the development of osteochondral models with smooth transitions between the cellular architecture and the corresponding ECM. Although the use of growth factors or recombinant DNA has been utilized in bioink materials, shortcomings still exist such as limited sustainability and transfection efficiency, respectively. Therefore, bioink materials reinforced with nanomaterials that can induce differentiation of cells with a seamless transition in a chondral bone model would be ideal. In addition, mechanical, chemical and physical stimuli can be further applied to enhance the differentiation capacity of such bioink materials (Carrow and Gaharwar, 2015).

Scaffold-free approaches should be further investigated in order to develop physiologicallyrelevant tissue constructs. The majority of available scaffold-free bioink materials and the compatible bioprinting processes utilize a mold support for cell aggregation, tissue fusion and maturation. This mold support needs to be printed in tandem with the cellular construct limiting the size of the tissues. A recent work demonstrated bioprinting of scaffold-free tissue strands without the use of a mold support; this was attempted for cartilage tissue due to its avascular nature (Yu et al., 2016). Future attempts should include vascularization within scaffold-free aggregates in multiple scales including neovascularization within cell aggregates, capillaries sprouting from the aggregates, and anastomosing capillaries formed within the tissue construct. Alternatively, aggregates can be designed and fabricated in such a way that a porous interconnected network can be integrated within their geometric domain. With integrated pores, cell aggregates should be able to keep their mechanical and structural integrity, while media transport will be enabled throughout the internal architecture. As integration of such porous architecture might be difficult to apply to tissue spheroids due to their small size, tissue strands will be an ideal structure to incorporate such architecture. In addition to efforts in developing scaffold-free bioink materials, compatible bioprinting processes are also required in order to successfully bioprint cell aggregate-based bioink 
materials. Mechanical properties of cell aggregates need to be further investigated. The mechanical properties of cell aggregates increase with culture time resulting in more collagen and elastin deposition; however, further maturation limits their fusion capabilities and self-assembly characteristics post-bioprinting. Therefore, cells in aggregates should be engineered to over express collagen and elastin in order to increase the cohesiveness in a shorter period of time using maturogens such as TGF $\beta-1$, serotonin and periostin to support collagen accumulation, fibrogenic activity and collagen fibrilogenesis, respectively (Hajdu et al., 2010). Improvement in cohesion of cell aggregates also eliminate other challenges during bioprinting, such as loading and bioprinting of solid aggregates into custom-made cartridge heads.

Programmable biomaterials based on natural proteins can be one of the future trends in generating superior constructs by altering genetic sequences of biomaterials. With recent advances in CRISPR technology (Doudna and Charpentier, 2014), genetic engineering has become a powerful tool in medicine and such technology can be adopted into design and development of protein or DNA-based biomaterials. Such materials can be programmed to exhibit appropriate properties on demand, such as the ability to facilitate cell attachment, as well as provide a highly porous network for their encapsulation and growth. Having programmable mechanical properties such as the elasticity and tensile/compression strength based on the target tissue type will be extremely valuable. Such biomaterials have been recently used in fabrication of thermoplastics (Jung et al., 2016); however, they can be further refined to generate hydrogel-like environment.

The vast majority of efforts have been devoted to engineering cells; however, engineering ECM produced by cells will have great benefits such as improving mechanical properties of ECM and controlling its micro-architecture (i.e., orientation, thickness and porosity of protein fibers and composition). For example, successful tissue regeneration for articular cartilage or muscle requires mechanically improved tissue constructs rather than simply implanting freshly bioprinted tissue constructs into lesion sites. For such tissues, the utilized bioink materials can be "trained" to recapitulate the native organization prior to the bioprinting process and the bioprinting process can 
be used as an assembly platform. As mentioned previously, articular cartilage has a stratified nature with collagen type II fibers orienting horizontally at the superficial layer, where their orientation transition to random organization in the middle zone and attain a vertical orientation with thicker fibers in the deeper zones. The cell concentration varies throughout the structure as well. New bioink materials can be developed in such a way that the ECM of native tissue can be recapitulated within these bioink materials prior to bioprinting. For example, the density, thickness and mechanical properties of collagen type II proteins can be enhanced by training the bioink material under cyclic compression and biochemical stimulation. Recent attempts in bioprinting tissue strands demonstrate the ability to control the orientation of collagen fibers along the longitudinal axis of the strands (Yu et al., 2016).

\section{Summary}

This paper reviews the bioink materials used in 3D bioprinting technology, including hydrogels, microcarriers, dECM and cell aggregates, and presents a detailed comparative evaluation of these bioink materials under various performance metrics. Future efforts in the evolution of bioink materials need to bring about solutions that will strengthen mechanical properties to stabilize bioprinted constructs, provide biological compounds to allow better cellular interactions, facilitate an appropriate environment to generate physiologically-relevant, functional tissues that are vascularized and can be engrafted with the host tissue after implantation. The abovementioned issues are some of the major reasons that researchers are still far from bioprinting functional organs of the clinically-relevant size. However, with newly engineered bioink materials and compatible bioprinting processes on the horizon, 3D bioprinting will be a key technology for the future of tissue engineering, regenerative therapies and pharmaceutics.

\section{Acknowledgements}

This work has been supported by National Science Foundation CMMI Awards 1349716 and 1462232, and Osteology Foundation Grant \# 15-042. The authors are grateful to the support from the Engineering Science and Mechanics Department at the Penn State University. The authors 
confirm that there are no known conflicts of interest associated with this publication and there has been no significant financial support for this work that could have influenced its outcome.

\section{References}

Ab-Rahim, S., Selvaratnam, L., Raghavendran, H.R.B., Kamarul, T., 2013. Chondrocyte-alginate constructs with or without TGF-B1 produces superior extracellular matrix expression than monolayer cultures. Mol. Cell. Biochem. 376, 11-20.

Ahmed, E.M., 2013. Hydrogel: Preparation, characterization, and applications. J. Adv. Res. 6, 105121.

Ahn, S., Lee, H., Bonassar, L.J., Kim, G., 2012. Cells (MC3T3-E1)-laden alginate scaffolds fabricated by a modified solid-freeform fabrication process supplemented with an aerosol spraying. Biomacromolecules 13, 2997-3003.

Ahn, S., Lee, H., Puetzer, J., Bonassar, L.J., Kim, G., 2012. Fabrication of cell-laden three-dimensional alginate-scaffolds with an aerosol cross-linking process. J. Mater. Chem. 22, 18735-18740.

Akkouch, A., Yu, Y., Ozbolat, I.T., 2015. Microfabrication of scaffold-free tissue strands for threedimensional tissue engineering. Biofabrication 7, 31002.

Albelda, S., Buck, C., 1990. Integrins and other cell adhesion molecules. FASEB J.

Alconcel, S.N.S., Baas, A.S., Maynard, H.D., 2011. FDA-approved poly(ethylene glycol)-protein conjugate drugs. Polym. Chem. 2, 1442-1448.

Alexander, A., Ajazuddin, Khan, J., Saraf, S., Saraf, S., 2013. Poly(ethylene glycol)-poly(lactic-coglycolic acid) based thermosensitive injectable hydrogels for biomedical applications. J. Control. Release 172, 715-29.

Alhasan, L., Qi, A., Al-Abboodi, A., Rezk, A., Chan, P.P.Y., Iliescu, C., Yeo, L.Y., 2016. Rapid Enhancement of Cellular Spheroid Assembly by Acoustically Driven Microcentrifugation. ACS Biomater. Sci. Eng. 2, 1013-1022. 
Alsberg, E., Anderson, K.W., Albeiruti, A., Rowley, J.A., Mooney, D.J., 2002. Engineering growing tissues. Proc. Natl. Acad. Sci. U. S. A. 99, 12025-30.

Arcaute, K., Mann, B., Wicker, R., 2010. Stereolithography of spatially controlled multi-material bioactive poly(ethylene glycol) scaffolds. Acta Biomater. 6, 1047-1054.

Arcaute, K., Mann, B.K., Wicker, R.B., 2006. Stereolithography of three-dimensional bioactive poly(ethylene glycol) constructs with encapsulated cells. Ann. Biomed. Eng. 34, 1429-1441.

Armstrong, J.P.K., Burke, M., Carter, B.M., Davis, S.A., Perriman, A.W., 2016. 3D Bioprinting Using a Templated Porous Bioink 1724-1730.

Athanasiou, K.A., Eswaramoorthy, R., Hadidi, P., Hu, J.C., 2013. Self-Organization and the SelfAssembling Process in Tissue Engineering. Annu. Rev. Biomed. Eng. 15, 115-136.

Aubin, H., Nichol, J.W., Hutson, C.B., Bae, H., Sieminski, A.L., Cropek, D.M., Akhyari, P., Khademhosseini, A., 2010. Directed 3D cell alignment and elongation in microengineered hydrogels. Biomaterials 31, 6941-6951.

Aya, K.L., Stern, R., 2014. Hyaluronan in wound healing: Rediscovering a major player. Wound Repair Regen. 22, 579-593.

Back, S. a, Tuohy, T.M.F., Chen, H., Wallingford, N., Craig, A., Struve, J., Luo, N.L., Banine, F., Liu, Y., Chang, A., Trapp, B.D., Bebo, B.F., Rao, M.S., Sherman, L.S., 2005. Hyaluronan accumulates in demyelinated lesions and inhibits oligodendrocyte progenitor maturation. Nat. Med. 11, 966972.

Baier, C., Baader, S.L., Jankowski, J., Gieselmann, V., Schilling, K., Rauch, U., Kappler, J., 2007. Hyaluronan is organized into fiber-like structures along migratory pathways in the developing mouse cerebellum. Matrix Biol. 26, 348-358.

Banerjee, S., Toole, B.P., 1991. Monoclonal Antibody to Chick Embryo Hyaluronan-Binding Protein : Changes in Distribution of Binding Protein during Early Brain Development. Dev. Biol. 197, 186- 
197.

Barron, J.A., Spargo, B.J., Ringeisen, B.R., 2004. Biological laser printing of three dimensional cellular structures. Appl. Phys. A 79, 1027-1030.

Behrens, J., 1999. Cadherins and catenins: Role in signal transduction and tumor progression. Cancer Metastasis Rev. 18, 15-30. 6

Benedikt, P., Jockenhoevel, S., Hoerstrup, S.P., Ye, Q., Zu, G., Sakyama, S., Hubbell, J.A., Turina, M., 2000. Fibrin gel as a three dimensional matrix in cardiovascular tissue engineering 17, 587-591.

Benoit, D.S.W., Durney, A.R., Anseth, K.S., 2006. Manipulations in hydrogel degradation behavior enhance osteoblast function and mineralized tissue formation. Tissue Eng. 12, 1663-73.

Benton, G., Kleinman, H.K., George, J., Arnaoutova, I., 2011. Multiple uses of basement membranelike matrix (BME/Matrigel) in vitro and in vivo with cancer cells. Int. J. Cancer 128, 1751-1757.

Benton, J.A., DeForest, C.A., Vivekanandan, V., Anseth, K.S., 2009. Photocrosslinking of gelatin macromers to synthesize porous hydrogels that promote valvular interstitial cell function. Tissue Eng. Part A 15, 3221-30.

Bertassoni, L.E., Cardoso, J.C., Manoharan, V., Cristino, A.L., Bhise, N.S., Araujo, W., Zorlutuna, P., Vrana, N.E., Ghaemmaghami, A.M., Dokmeci, M.R., Khademhosseini, A., 2014. Direct-write bioprinting of cell-laden methacrylated gelatin hydrogels. Biofabrication 6, 24105.

Bigi, A., Cojazzi, G., Panzavolta, S., Roveri, N., Rubini, K., 2002. Stabilization of gelatin films by crosslinking with genipin. Biomaterials 23, 4827-4832.

Billiet, T., Gevaert, E., De Schryver, T., Cornelissen, M., Dubruel, P., 2014. The 3D printing of gelatin methacrylamide cell-laden tissue-engineered constructs with high cell viability. Biomaterials 35, $49-62$.

Blaeser, A., Duarte Campos, D.F., Weber, M., Neuss, S., Theek, B., Fischer, H., Jahnen-Dechent, W., 
2013. Biofabrication Under Fluorocarbon: A Novel Freeform Fabrication Technique to Generate High Aspect Ratio Tissue-Engineered Constructs. Biores. Open Access 2, 374-384.

Boland, T., Tao, X., Damon, B.J., Manley, B., Kesari, P., Jalota, S., Bhaduri, S., 2007. Drop-on-demand printing of cells and materials for designer tissue constructs. Mater. Sci. Eng. C 27, 372-376.

Burdick, J.A., Prestwich, G.D., 2011. Hyaluronic Acid Hydrogels for Biomedical Applications. Adv. Mater. 23, H41-H56.

Carrow, J.K., Gaharwar, A.K., 2015. Bioinspired Polymeric Nanocomposites for Regenerative Medicine. Macromol. Chem. Phys. 248-264.

Chan, B.P., Leong, K.W., 2008. Scaffolding in tissue engineering: General approaches and tissuespecific considerations. Eur. Spine J. 17.

Chang, C.C., Boland, E.D., Williams, S.K., Hoying, J.B., 2011. Direct-write bioprinting threedimensional biohybrid systems for future regenerative therapies. J. Biomed. Mater. Res. B. Appl. Biomater. 98, 160-70.

Chen, S.-C., Wu, Y.-C., Mi, F.-L., Lin, Y.-H., Yu, L.-C., Sung, H.-W., 2004. A novel pH-sensitive hydrogel composed of N,O-carboxymethyl chitosan and alginate cross-linked by genipin for protein drug delivery. J. Control. Release 96, 285-300.

Chiou, B. Sen, Avena-Bustillos, R.J., Bechtel, P.J., Jafri, H., Narayan, R., Imam, S.H., Glenn, G.M., Orts, W.J., 2008. Cold water fish gelatin films: Effects of cross-linking on thermal, mechanical, barrier, and biodegradation properties. Eur. Polym. J. 44, 3748-3753.

Christensen, K., Xu, C., Chai, W., Zhang, Z., Fu, J., Huang, Y., 2015. Freeform inkjet printing of cellular structures with bifurcations. Biotechnol. Bioeng. 112, 1047-1055.

Cohen, D.L., Lipton, J.I., Bonassar, L.J., Lipson, H., 2010a. Additive manufacturing for in situ repair of osteochondral defects. Biofabrication 2, 35004. 4 
Cohen, D.L., Lo, W., Tsavaris, A., Peng, D., Lipson, H., Bonassar, L.J., 2010b. Increased Mixing Improves Hydrogel Homogeneity and Quality of Three-Dimensional Printed Constructs. Tissue Eng. Part C Methods 17, 239-248.

Crapo, P.M., Gilbert, T.W., Badylak, D.V.M., 2011. An overview of tissue and whole organ decellularization processes. Biomaterials 32, 3233-3243.

Croisier, F., Jérôme, C., 2013. Chitosan-based biomaterials for tissue engineering. Eur. Polym. J. 49, 780-792.

Cui, X., Boland, T., 2009. Human microvasculature fabrication using thermal inkjet printing technology. Biomaterials 30, 6221-7.

Cui, X., Breitenkamp, K., Finn, M.G., Lotz, M., D'Lima, D.D., 2012a. Direct Human Cartilage Repair Using Three-Dimensional Bioprinting Technology. Tissue Eng. Part A 18, 1304-1312.

Cui, X., Breitenkamp, K., Lotz, M., D'Lima, D., 2012b. Synergistic action of fibroblast growth factor-2 and transforming growth factor-beta1 enhances bioprinted human neocartilage formation. Biotechnol. Bioeng. 109, 2357-2368

Dababneh, A.B., Ozbolat, I.T., 2014. Bioprinting Technology: A Current State-of-the-Art Review. J. Manuf. Sci. Eng. 136, 61016.

Dana, N., Parker, V., Meredith, M., Mark, G., Lori, S., 2004. Photocrosslinkable Hyaluronan as a Scaffold for Articular Cartilage Repair 32, 391-397.

Dean, D.M., Napolitano, A.P., Youssef, J., Morgan, J.R., 2007. Rods, tori, and honeycombs: the directed self-assembly of microtissues with prescribed microscale geometries. FASEB J. 21, 4005-4012.

Decker, C., 2002. Light-induced crosslinking polymerization. Polym. Int. 51, 1141-1150.

Deitch, S., Kunkle, C., Cui, X., Boland, T., Dean, D., 2008. Collagen Matrix Alignment Using Inkjet 
Printer Technology. MRS Proc. 1094.

Del Duca, D., Werbowetski, T., Del Maestro, R.F., 2004. Spheroid preparation from hanging drops: Characterization of a model of brain tumor invasion. J. Neurooncol. 67, 295-303.

Dhariwala, B., Hunt, E., Boland, T., 2004. Rapid prototyping of tissue-engineering constructs, using photopolymerizable hydrogels and stereolithography. Tissue Eng. 10, 1316-1322.

Dolati, F., Yu, Y., Zhang, Y., Jesus, A., Sander, E.A., Ozbolat, I.T., 2014. In vitro evaluation of carbonnanotube-reinforced bioprintable vascular conduits. Nanotechnology 25, 145101.

Doudna, J.A., Charpentier, E., 2014. The new frontier of genome engineering with CRISPR-Cas9. Science (80-. ). 346, 1258096.

Dragan, E.S., 2014. Design and applications of interpenetrating polymer network hydrogels. A review. Chem. Eng. J. 243, 572-590.

Drury, J.L., Mooney, D.J., 2003. Hydrogels for tissue engineering: Scaffold design variables and applications. Biomaterials 24, 4337-4351.

Du, M., Chen, B., Meng, Q., Liu, S., Zheng, X., Zhang, C., Wang, H., Li, H., Wang, N., Dai, J., 2015. $3 D$ bioprinting of BMSC-laden methacrylamide gelatin scaffolds with CBD-BMP2-collagen microfibers. Biofabrication 7, 44104.

Duan, B., Hockaday, L., Kang, K.H., Butcher, J.T., 2013. 3D Bioprinting of heterogeneous aortic valve conduits with alginate/gelatin hydrogels. J. Biomed. Mater. Res. - Part A 101A, 1255-1264.

Duarte Campos, D.F., Blaeser, A., Korsten, A., Neuss, S., Jäkel, J., Vogt, M., Fischer, H., 2014. The Stiffness and Structure of Three-Dimensional Printed Hydrogels Direct the Differentiation of Mesenchymal Stromal Cells Toward Adipogenic and Osteogenic Lineages. Tissue Eng. Part A 117.

Ehsan, S.M., Welch-Reardon, K.M., Waterman, M.L., Hughes, C.C.W., George, S.C., 2014. A three- 
dimensional in vitro model of tumor cell intravasation. Integr. Biol. Quant. Biosci. from nano to macro 6, 603-10.

Fairbanks, B.D., Schwartz, M.P., Bowman, C.N., Anseth, K.S., 2009. Photoinitiated polymerization of PEG-diacrylate with lithium phenyl-2,4,6-trimethylbenzoylphosphinate: polymerization rate and cytocompatibility. Biomaterials 30, 6702-6707.

Faroni, A., Mobasseri, S.A., Kingham, P.J., Reid, A.J., 2015. Peripheral nerve regeneration: Experimental strategies and future perspectives. Adv. Drug Deliv. Rev. 82, 160-167.

Fedorovich, N.E., Alblas, J., de Wijn, J.R., Hennink, W.E., Verbout, A.J., Dhert, W.J., 2007. Hydrogels as extracellular matrices for skeletal tissue engineering: state-of-the-art and novel application in organ printing. Tissue Eng. 13, 1905-25.

Fedorovich, N.E., De Wijn, J.R., Verbout, A.J., Alblas, J., Dhert, W.J., 2008. Three-dimensional fiber deposition of cell-laden, viable, patterned constructs for bone tissue printing. Tissue Eng. Part A $14,127-133$.

Fedorovich, N.E., Oudshoorn, M.H., van Geemen, D., Hennink, W.E., Alblas, J., Dhert, W.J.A., 2009. The effect of photopolymerization on stem cells embedded in hydrogels. Biomaterials 30, 344353.

Fedorovich, N.E., Wijnberg, H.M., Dhert, W.J., Alblas, J., 2011. Distinct tissue formation by heterogeneous printing of osteo- and endothelial progenitor cells. Tissue Eng. Part A 17, 21132121.

Ferreira, A.M., Gentile, P., Chiono, V., Ciardelli, G., 2012. Collagen for bone tissue regeneration. Acta Biomater. 8, 3191-200.

Fleming, P.A., Argraves, W.S., Gentile, C., Neagu, A., Forgacs, G., Drake, C.J., 2010. Fusion of uniluminal vascular spheroids: A model for assembly of blood vessels. Dev. Dyn. 239, 398-406.

Furth, M.E., Atala, A., Van Dyke, M.E., 2007. Smart biomaterials design for tissue engineering and 
regenerative medicine. Biomaterials 28, 5068-5073.

Gaetani, R., Doevendans, P., Metz, C.H.G., Alblas, J., Messina, E., Giacomello, A., Sluijter, J.P.G., 2012. Cardiac tissue engineering using tissue printing technology and human cardiac progenitor cells. Biomaterials 33, 1782-1790.

Galateanu, B., Dimonie, D., Vasile, E., Nae, S., Cimpean, A., Costache, M., 2012. Layer-shaped alginate hydrogels enhance the biological performance of human adipose-derived stem cells. BMC Biotechnol. 12, 35.

Gamboa-Martinez, T.C., Luque-Guillen, V., Gonzalez-Garcia, C., Gomez Ribelles, J.L., Gallego-Ferrer, G., 2015. Crosslinked fibrin gels for tissue engineering: Two approaches to improve their properties. J. Biomed. Mater. Res. - Part A 103, 614-621.

Gao, G., Schilling, A.F., Yonezawa, T., Wang, J., Dai, G., Cui, X., 2014. Bioactive nanoparticles stimulate bone tissue formation in bioprinted three-dimensional scaffold and human mesenchymal stem cells. Biotechnol. J. 9, 1304-1311.

Gao G1, Yonezawa T, Hubbell K, Dai G, C.X., 2015. Inkjet-bioprinted acrylated peptides and PEG hydrogel with human mesenchymal stem cells promote robust bone and cartilage formation with minimal printhead clogging. Biotechnol J 1-28.

Gasperini, L., Mano, J.F., Reis, R.L., 2014. Natural polymers for the microencapsulation of cells. J. $R$. Soc. Interface 11, 20140817.

Gauvin, R., Chen, Y.C., Lee, J.W., Soman, P., Zorlutuna, P., Nichol, J.W., Bae, H., Chen, S., Khademhosseini, A., 2012. Microfabrication of complex porous tissue engineering scaffolds using 3D projection stereolithography. Biomaterials 33, 3824-3834.

Geng, L., Feng, W., Hutmacher, D.W., Wong, Y.S., Loh, H.T., Fuh, J.Y.H., 2005. Direct writing of chitosan scaffolds using a robotic system. Rapid Prototyp. J. 11, 90-97.

Gerecht, S., Burdick, J., Ferreira, L.S., Townsend, S., Langer, R., Vunjak-Novakovic, G., 2007. 
Hyaluronic acid hydrogel for controlled self-renewal and differentiation of human embryonic stem cells. Proc. Natl. Acad. Sci. U. S. A. 104, 11298-303.

Gilbert, T.W., Sellaro, T.L., Badylak, S.F., 2006. Decellularization of tissues and organs. Biomaterials 27, 3675-3683.

Goh, T.K.-P., Zhang, Z.-Y., Chen, A.K.-L., Reuveny, S., Choolani, M., Chan, J.K.Y., Oh, S.K.-W., 2013. Microcarrier culture for efficient expansion and osteogenic differentiation of human fetal mesenchymal stem cells. Biores. Open Access 2, 84-97.

Gómez-Guillén, M.C., Giménez, B., López-Caballero, M.E., Montero, M.P., 2011. Functional and bioactive properties of collagen and gelatin from alternative sources: A review. Food Hydrocoll. $25,1813-1827$.

Gómez-Guillén, M.C., Turnay, J., Fernández-Díaz, M.D., Ulmo, N., Lizarbe, M.A., Montero, P., 2002. Structural and physical properties of gelatin extracted from different marine species: A comparative study. Food Hydrocoll. 16, 25-34.

Gong, C.Y., Shi, S., Dong, P.W., Zheng, X.L., Fu, S.Z., Guo, G., Yang, J.L., Wei, Y.Q., Qian, Z.Y., 2009. In vitro drug release behavior from a novel thermosensitive composite hydrogel based on Pluronic f127 and poly(ethylene glycol)-poly(epsilon-caprolactone)-poly(ethylene glycol) copolymer. BMC Biotechnol. 9, 8.

Gruene, M., Pflaum, M., Hess, C., Diamantouros, S., Schlie, S., Deiwick, A., Koch, L., Wilhelmi, M., Jockenhoevel, S., Haverich, A., Chichkov, B., 2011. Laser Printing of Three-Dimensional Multicellular Arrays for Studies of Cell-Cell and Cell-Environment Interactions. Tissue Eng. Part C Methods 17, 973-982.

Gudapati, H., Yan, J., Huang, Y., Chrisey, D.B., 2014. Alginate gelation-induced cell death during laser-assisted cell printing. Biofabrication 6, 35022.

Gudupati, H., Dey, M., Ozbolat, I., 2016. A Comprehensive Review on Droplet-based Bioprinting: Past, 
Present and Future. Biomaterials 102, 20-42.

Guillotin, B., Souquet, A., Catros, S., Duocastella, M., Pippenger, B., Bellance, S., Bareille, R., Rémy, M., Bordenave, L., Amédée, J., Guillemot, F., 2010. Laser assisted bioprinting of engineered tissue with high cell density and microscale organization. Biomaterials 31, 7250-6.

Gulrez, S.K.., Al-Assaf, S., Phillips, G.O., 2011. Hydrogels: Methods of Preparation, Characterisation and Applications in Molecular and Environmental Bioengineering.

Guo, F., Li, P., French, J.B., Mao, Z., Zhao, H., Li, S., Nama, N., Fick, J.R., Benkovic, S.J., Huang, T.J., 2015. Controlling cell-cell interactions using surface acoustic waves. Proc. Natl. Acad. Sci. U. S. A. $112,43-8$.

Hauser, C.A.E., Loo, Y., Lakshmanan, A., Ni, M., Toh, L.L., Wang, S., 2015. Peptide Bioink: SelfAssembling Nanofibrous Scaffolds for 3D Organotypic Cultures. Nano Lett. 15, 6919-6925. Heilshorn, S.C., Liu, J.C., Tirrell, D.A., 2005. Cell-binding domain context affects cell behavior on engineered proteins. Biomacromolecules 6, 318-323.

Hellio, D., Djabourov, M., 2006. Physically and chemically crosslinked gelatin gels. Macromol. Symp. $241,23-27$.

Hennink, W.E., van Nostrum, C.F., 2012. Novel crosslinking methods to design hydrogels. Adv. Drug Deliv. Rev. 64, 223-236.

Hill, E., Boontheekul, T., Mooney, D.J., 2006. Designing scaffolds to enhance transplanted myoblast survival and migration. Tissue Eng. 12, 1295-1304.

Hinton, T.J., Jallerat, Q., Palchesko, R.N., Park, J.H., Grodzicki, M.S., Shue, H., Ramadan, M.H., Hudson, A.R., Feinberg, A.W., 2015. Three-dimensional printing of complex biological structures by freeform reversible embedding of suspended hydrogels. Sci. Adv. 1, 1-10.

Hockaday, L., Kang, K.H., Colangelo, N.W., Cheung, P.Y.C., Duan, B., Malone, E., Wu, J., Girardi, L.N., 
Bonassar, L.J., Lipson, H., Chu, C.C., Butcher, J.T., 2012. Rapid 3D printing of anatomically accurate and mechanically heterogeneous aortic valve hydrogel scaffolds. Biofabrication 4, 35005.

Homenick, C.M., de Silveira, G., Sheardown, H., Adronov, A., 2011. Pluronics as crosslinking agents for collagen: novel amphiphilic hydrogels. Polym. Int. 60, 458-465.

Hopp, B., Smausz, T., Kresz, N., Barna, N., Bor, Z., Kolozsvári, L., Chrisey, D.B., Szabó, A., Nógrádi, A., 2005. Survival and Proliferative Ability of Various Living Cell Types after Laser-Induced Forward Transfer. Tissue Eng. 11, 1817-1823.

Horváth, L., Umehara, Y., Jud, C., Blank, F., Petri-Fink, A., Rothen-Rutishauser, B., 2015. Engineering an in vitro air-blood barrier by 3D bioprinting. Sci. Rep. 5, 7974.

Hribar, K.C., Meggs, K., Liu, J., Zhu, W., Qu, X., Chen, S., 2015. Three-dimensional direct cell patterning in collagen hydrogels with near-infrared femtosecond laser. Sci. Rep. 5, 17203.

Hribar, K.C., Soman, P., Warner, J., Chung, P., Chen, S., 2014. Light-assisted direct-write of 3D functional biomaterials. Lab Chip 14, 268-75.

Huang, T.Q., Qu, X., Liu, J., Chen, S., 2014. 3D printing of biomimetic microstructures for cancer cell migration. Biomed. Microdevices 16, 127-132.

Hutson, C.B., Nichol, J.W., Aubin, H., Bae, H., Yamanlar, S., Al-Haque, S., Koshy, S.T., Khademhosseini, A., 2011. Synthesis and Characterization of Tunable Poly(Ethylene Glycol): Gelatin Methacrylate Composite Hydrogels. Tissue Eng. Part A 17, 1713-1723.

Ikeda, K., Yamauchi, D., Osamura, N., Hagiwara, N., Tomita, K., 2003. Hyaluronic acid prevents peripheral nerve adhesion. Br. J. Plast. Surg. 56, 342-347.

Ishida, T., Harada, M., Xin, Y.W., Ichihara, M., Irimura, K., Kiwada, H., 2005. Accelerated blood clearance of PEGylated liposomes following preceding liposome injection: Effects of lipid dose and PEG surface-density and chain length of the first-dose liposomes. J. Control. Release 105, 
305-317.

Itoh, M., Nakayama, K., Noguchi, R., Kamohara, K., Furukawa, K., Uchihashi, K., Toda, S., Oyama, J.I., Node, K., Morita, S., 2015. Scaffold-free tubular tissues created by a bio-3D printer undergo remodeling and endothelialization when implanted in rat aortae. PLoS One 10, 1-16.

Jakob, P.H., Kehrer, J., Flood, P., Wiegel, C., Haselmann, U., Meissner, M., Stelzer, E.H.K., Reynaud, E.G., 2016. A 3-D cell culture system to study epithelia functions using microcarriers. Cytotechnology 68, 1813-25.

Jang, J., Kim, T.G., Kim, B.S., Kim, S.W., Kwon, S.M., Cho, D.W., 2016. Tailoring mechanical properties of decellularized extracellular matrix bioink by vitamin B2-induced photo-crosslinking. Acta Biomater. 33, 88-95.

Janmey, P., Winer, J.P., Weisel, J.W., 2009. Fibrin gels and their clinical and bioengineering applications. J. R. Soc. Interface 6, 1-10.

Jeong, B., Kim, S.W., Bae, Y.H., 2002. Thermosensitive sol-gel reversible hydrogels. Adv. Drug Deliv. Rev. 54, 37-51.

Jia, W., Gungor-Ozkerim, P.S., Zhang, Y.S., Yue, K., Zhu, K., Liu, W., Pi, Q., Byambaa, B., Dokmeci, M.R., Shin, S.R., Khademhosseini, A., 2016. Direct 3D bioprinting of perfusable vascular constructs using a blend bioink. Biomaterials 106, 58-68.

Jin, H.J., Kim, T., Cho, Y.H., Gu, J.M., Kim, J., Oh, Y.S., 2011. A multicellular spheroid formation and extraction chip using removable cell trapping barriers. Trans. Korean Soc. Mech. Eng. A 35, $131-134$.

Jin, R., Dijkstra, P.J., 2010. Hydrogels for Tissue Engineering Applications. Biomed. Appl. Hydrogels Handb. 101, 203-225.

Johnson, M.B., 2011. The Effect of Ultraviolet Light on Cell Viability, DNA Damage and Repair in Hutchinson-Gilford Progeria Syndrome and BJ Fibroblasts 1-34. 
Jung, H., Pena-Francesch, A., Saadat, A., Sebastian, A., Kim, D.H., Hamilton, R.F., Albert, I., Allen, B.D., Demirel, M.C., 2016. Molecular tandem repeat strategy for elucidating mechanical properties of high-strength proteins. Proc. Natl. Acad. Sci. 113, 201521645.

Jungst, T., Smolan, W., Schacht, K., Scheibel, T., Groll, J., 2016. Strategies and Molecular Design Criteria for 3D Printable Hydrogels. Chem. Rev. 116, 1496-1539.

Kamoun, E.A., Kenawy, E.-R.S., Tamer, T.M., El-Meligy, M.A., Mohy Eldin, M.S., 2015. Poly (vinyl alcohol)-alginate physically crosslinked hydrogel membranes for wound dressing applications: Characterization and bio-evaluation. Arab. J. Chem. 8, 38-47.

Kang, H., Lee, S.J., Ko, I.K., Kengla, C., Yoo, J.J., Atala, A., 2016. A 3D bioprinting system to produce human-scale tissue constructs with structural integrity. Nat. Biotechnol. 34, 312-319.

Khalil, M., Shariat-Panahi, A., Tootle, R., Ryder, T., McCloskey, P., Roberts, E., Hodgson, H., Selden, C., 2001. Human hepatocyte cell lines proliferating as cohesive spheroid colonies in alginate markedly upregulate both synthetic and detoxificatory liver function. J. Hepatol. 34, 68-77.

Khattak, S.F., Bhatia, S.R., Roberts, S.C., 2005. Pluronic F127 as a cell encapsulation material: utilization of membrane-stabilizing agents. Tissue Eng. 11, 974-83.

Klebe, R.J., 1988. Cytoscribing: A method for micropositioning cells and the construction of two- and three-dimensional synthetic tissues. Exp. Cell Res. 179, 362-373.

Kleinman, H.K., Martin, G.R., 2005. Matrigel: Basement membrane matrix with biological activity. Semin. Cancer Biol. 15, 378-386.

Koch, L., Kuhn, S., Sorg, H., Gruene, M., Schlie, S., Gaebel, R., Polchow, B., Reimers, K., Stoelting, S., Ma, N., Vogt, P.M., Steinhoff, G., Chichkov, B., 2010. Laser printing of skin cells and human stem cells. Tissue Eng. Part C. Methods 16, 847-854.

Kolesky, D.B., Homan, K.A., Skylar-Scott, M.A., Lewis, J.A., 2016. Three-dimensional bioprinting of thick vascularized tissues. Proc. Natl. Acad. Sci. U. S. A. 113, 3179-84. 
Kreger, S.T., Voytik-Harbin, S.L., 2009. Hyaluronan concentration within a 3D collagen matrix modulates matrix viscoelasticity, but not fibroblast response. Matrix Biol. 28, 336-346.

Kucukgul, C., Ozler, S.B., Inci, I., Karakas, E., Irmak, S., Gozuacik, D., Taralp, A., Koc, B., 2014. $3 D$ Bioprinting of Biomimetic Aortic Vascular Constructs with Self-Supporting Cells. Biotechnol. Bioeng. 112, 811-821.

Kuo, W.P., Demirci, U., 2014. Engineering Anisotropic Biomimetic Fibrocartilage Microenvironment by Bioprinting Mesenchymal Stem Cells in Nanoliter Gel Droplets. Mol. Pharm. 11, 2151-2159.

Lai, K.K., Renneberg, R., Mak, W.C., 2016. High efficiency single-step biomaterial-based microparticle fabrication via template-directed supramolecular coordination chemistry. Green Chem. 18, $1715-1723$.

Leach, J.B., Bivens, K.A., Patrick, C.W., Schmidt, C.E., 2003. Photocrosslinked hyaluronic acid hydrogels: Natural, biodegradable tissue engineering scaffolds. Biotechnol. Bioeng. 82, 578589.

Lee, H., Cho, D.-W., 2016. One-step fabrication of an organ-on-a-chip with spatial heterogeneity using a 3D bioprinting technology. Lab Chip 16, 2618-2625.

Lee, J.-S., Hong, J.M., Jung, J.W., Shim, J.-H., Oh, J.-H., Cho, D.-W., 2014. 3D printing of composite tissue with complex shape applied to ear regeneration. Biofabrication 6, 24103.

Lee, K.Y., Mooney, D.J., 2012. Alginate: Properties and biomedical applications. Prog. Polym. Sci. 37, $106-126$.

Lee, S.H., Lee, Y., Lee, S.W., Ji, H.Y., Lee, J.H., Lee, D.S., Park, T.G., 2011. Enzyme-mediated crosslinking of Pluronic copolymer micelles for injectable and in situ forming hydrogels. Acta Biomater. 7, 1468-1476.

Lee, V., Lanzi, A., Ngo, H., Yoo, S.-S., Vincent, P., Dai, G., 2014. Generation of Multi-scale Vascular Network System Within 3D Hydrogel Using 3D Bio-printing Technology. Cell. Mol. Bioeng. 7, 
460-472.

Lee, W., Lee, V., Polio, S., Keegan, P., Lee, J.H., Fischer, K., Park, J.K., Yoo, S.S., 2010. On-demand three-dimensional freeform fabrication of multi-layered hydrogel scaffold with fluidic channels. Biotechnol. Bioeng. 105, 1178-1186.

Lee, Y.-B., Polio, S., Lee, W., Dai, G., Menon, L., Carroll, R.S., Yoo, S.-S., 2010. Bio-printing of collagen and VEGF-releasing fibrin gel scaffolds for neural stem cell culture. Exp. Neurol. 223, 645-52.

Levato, R., Visser, J., Planell, J., Engel, E., Malda, J., Mateos-Timoneda, M., 2014. Biofabrication of tissue constructs by 3D bioprinting of cell-laden microcarriers. Biofabrication 6, 35020.

Liang, H.C., Chang, W.H., Liang, H.F., Lee, M.H., Sung, H.W., 2004. Crosslinking structures of gelatin hydrogels crosslinked with genipin or a water-soluble carbodiimide. J. Appl. Polym. Sci. 91, 4017-4026.

Lin, C.-C., Anseth, K.S., 2009. PEG hydrogels for the controlled release of biomolecules in regenerative medicine. Pharm. Res. 26, 631-43.

Liu, Y., Han, S.S.W., Wu, Y., Tuohy, T.M.F., Xue, H., Cai, J., Back, S.A., Sherman, L.S., Fischer, I., Rao, M.S., 2004. CD44 expression identifies astrocyte-restricted precursor cells. Dev. Biol. 276, 3146.

Livoti, C.M., Morgan, J.R., 2010. Self-assembly and tissue fusion of toroid-shaped minimal building units. Tissue Eng. Part A 16, 2051-61.

Lu, Y., Chen, S., 2012. Computer-Aided Tissue Engineering, in: Methods in Molecular Biology. Humana Press, Totowa, NJ, pp. 289-302.

Luo, Y., Kirker, K.R., Prestwich, G.D., 2000. Cross-linked hyaluronic acid hydrogel films: New biomaterials for drug delivery. J. Control. Release 69, 169-184.

Malda, J., Frondoza, C.G., 2006. Microcarriers in the engineering of cartilage and bone. Trends 
Biotechnol. 24, 299-304.

Malda, J., van Blitterswijk, C., Grojec, M., Martens, D.E., Tramper, J., Riesle, J., 2003. Expansion of bovine chondrocytes on microcarriers enhances redifferentiation. Tissue Eng. 9, 939-948.

Malda, J., Visser, J., Melchels, F.P., Jüngst, T., Hennink, W.E., Dhert, W.J. a, Groll, J., Hutmacher, D.W., 2013. 25th anniversary article: Engineering hydrogels for biofabrication. Adv. Mater. 25, 501128.

Mandrycky, C., Wang, Z., Kim, K., Kim, D.H., 2016. 3D bioprinting for engineering complex tissues. Biotechnol. Adv. 34, 422-434.

Mann, B.K., Gobin, A.S., Tsai, A.T., Schmedlen, R.H., West, J.L., 2001. Smooth muscle cell growth in photopolymerized hydrogels with cell adhesive and proteolytically degradable domains: Synthetic ECM analogs for tissue engineering. Biomaterials 22, 3045-3051.

Margolis, R.U., Margolis, R.K., Chang, L.B., Preti, C., 1975. Glycosaminoglycans of brain during development. Biochemistry 14, 85-88.

Markstedt, K., Mantas, A., Tournier, I., Martínez Ávila, H., Hägg, D., Gatenholm, P., 2015. $3 D$ Bioprinting Human Chondrocytes with Nanocellulose-Alginate Bioink for Cartilage Tissue Engineering Applications. Biomacromolecules 16, 1489-1496.

Masutani, E.M., Kinoshita, C.K., Tanaka, T.T., Ellison, A.K.D., Yoza, B.A., Masutani, E.M., Kinoshita, C.K., Tanaka, T.T., Ellison, A.K.D., Yoza, B.A., 2014. Increasing Thermal Stability of Gelatin by UV-Induced Cross-Linking with Glucose. Int. J. Biomater. 2014, 979636.

Mehesz, A.N., Brown, J., Hajdu, Z., Beaver, W., Silva, J.V.L. da, Visconti, R.P., Markwald, R.R., Mironov, V., 2011. Scalable robotic biofabrication of tissue spheroids. Biofabrication 3, 25002.

Mehta, G., Hsiao, A.Y., Ingram, M., Luker, G.D., Takayama, S., 2012. Opportunities and challenges for use of tumor spheroids as models to test drug delivery and efficacy. J. Control. Release 164, 192-204. 
Melchels, F.P.W., Domingos, M.N., Klein, T.J., Malda, J., Bartolo, P.J., Hutmacher, D.W., 2012. Additive manufacturing of tissues and organs. Prog. Polym. Sci. 37, 1079-1104.

Mesa, M., Sierra, L., Patarin, J., Guth, J.L., 2005. Morphology and porosity characteristics control of SBA-16 mesoporous silica. Effect of the triblock surfactant Pluronic F127 degradation during the synthesis. Solid State Sci. 7, 990-997.

Mészár, Z., Felszeghy, S., Veress, G., Matesz, K., Székely, G., Módis, L., 2008. Hyaluronan accumulates around differentiating neurons in spinal cord of chicken embryos. Brain Res. Bull. 75, 414-418.

Michael, S., Sorg, H., Peck, C.-T., Koch, L., Deiwick, A., Chichkov, B., Vogt, P.M., Reimers, K., 2013. Tissue engineered skin substitutes created by laser-assisted bioprinting form skin-like structures in the dorsal skin fold chamber in mice. PLoS One 8, e57741.

Migliore, A., Granata, M., 2008. Intra-articular use of hyaluronic acid in the treatment of osteoarthritis. Clin. Interv. Aging 3, 365-369.

Mironov, V., Visconti, R.P., Kasyanov, V., Forgacs, G., Drake, C.J., Markwald, R.R., 2009. Organ printing: tissue spheroids as building blocks. Biomaterials 30, 2164-74.

Montembault, A., Tahiri, K., Korwin-Zmijowska, C., Chevalier, X., Corvol, M.T., Domard, A., 2006. A material decoy of biological media based on chitosan physical hydrogels: application to cartilage tissue engineering. Biochimie 88, 551-564.

Moura, M.J., Faneca, H., Lima, M.P., Gil, M.H., Figueiredo, M.M., 2011. In situ forming chitosan hydrogels prepared via ionic/covalent Co-cross-linking. Biomacromolecules 12, 3275-3284.

Müller, M., Becher, J., Schnabelrauch, M., Zenobi-Wong, M., 2015. Nanostructured Pluronic hydrogels as bioinks for 3D bioprinting. Biofabrication 7, 35006.

Murphy, S. V., Skardal, A., Atala, A., 2013. Evaluation of hydrogels for bio-printing applications. J. Biomed. Mater. Res. - Part A 101 A, 272-284. 
Nakatsu, M.N., Sainson, R.C.A., Aoto, J.N., Taylor, K.L., Aitkenhead, M., P??rez-del-Pulgar, S., Carpenter, P.M., Hughes, C.C.W., 2003. Angiogenic sprouting and capillary lumen formation modeled by human umbilical vein endothelial cells (HUVEC) in fibrin gels: The role of fibroblasts and Angiopoietin-1. Microvasc. Res. 66, 102-112.

Nichol, J.W., Koshy, S.T., Bae, H., Hwang, C.M., Yamanlar, S., Khademhosseini, A., 2010. Cell-laden microengineered gelatin methacrylate hydrogels. Biomaterials 31, 5536-5544.

Nicodemus, G.D., Bryant, S.J., 2008. Cell Encapsulation in Biodegradable Hydrogels for Tissue Engineering Applications. Tissue Eng. Part B. Rev. 14, 149-165.

Norotte, C., Marga, F.S., Niklason, L.E., Forgacs, G., 2009. Scaffold-free vascular tissue engineering using bioprinting. Biomaterials 30, 5910-5917.

Odde, D.J., Renn, M.J., 1999. Laser-guided direct writing for applications in biotechnology. Trends Biotechnol 17, 385-389.

Ott, H., Matthiesen, T., Goh, S.-K., Black, L., Kren, S., Netoff, T., Taylor, D., 2008. Perfusiondecellularized matrix: using nature's platform to engineer a bioartificial heart. Nat. Med. 14, 213-221.

Ouyang, L., Yao, R., Zhao, Y., Sun, W., 2016. Effect of bioink properties on printability and cell viability for 3D bioplotting of embryonic stem cells. Biofabrication 8, 35020 .

Ovsianikov, A., Mühleder, S., Torgersen, J., Li, Z., Qin, X.-H., Van Vlierberghe, S., Dubruel, P., Holnthoner, W., Redl, H., Liska, R., Stampfl, J., 2014. Laser photofabrication of cell-containing hydrogel constructs. Langmuir 30, 3787-94.

Owens, C.M., Marga, F., Forgacs, G., Heesch, C.M., 2013. Biofabrication and testing of a fully cellular nerve graft. Biofabrication 5, 45007.

Ozbolat, I.T., 2015a. Scaffold-based or Scaffold-free Bioprinting: Competing or Complementing Approaches? J. Nanotechnol. Eng. Med. 6, 24701. 
Ozbolat, I.T., 2015b. Bioprinting scale-up tissue and organ constructs for transplantation. Trends Biotechnol. 33, 395-400.

Ozbolat, I.T., Chen, H., Yu, Y., 2014. Development of "Multi-arm Bioprinter" for hybrid biofabrication of tissue engineering constructs. Robot. Comput. Integr. Manuf. 30, 295-304.

Ozbolat, I.T., Hospodiuk, M., 2016. Current advances and future perspectives in extrusion-based bioprinting. Biomaterials 76, 321-343.

Ozbolat, I.T., Koc, B., 2010. Modeling of Spatially Controlled Biomolecules in Three-Dimensional Porous Alginate Structures. J. Med. Device. 4, 41003.

Ozbolat, I.T., Peng, W., Ozbolat, V., 2016. Application areas of 3D bioprinting. Drug Discov. Today 21, $1257-1271$.

Ozbolat, I.T., Yu, Y., 2013. Bioprinting Toward Organ Fabrication: Challenges and Future Trends. IEEE Transl. Biomed. Eng. 60, 691-699.

Pasut, G., Sergi, M., Veronese, F.M., 2008. Anti-cancer PEG-enzymes: 30 years old, but still a current approach. Adv. Drug Deliv. Rev. 60, 69-78.

Pataky, K., Braschler, T., Negro, A., Renaud, P., Lutolf, M.P., Brugger, J., 2012. Microdrop printing of hydrogel bioinks into 3D tissue-like geometries. Adv. Mater. 24, 391-396.

Pati, F., Ha, D., Jang, J., Han, H.H., Rhie, J., Cho, D.-W., 2015. Biomimetic 3D tissue printing for soft tissue regeneration. Biomaterials 62, 164-175.

Pati, F., Jang, J., Ha, D.-H., Won Kim, S., Rhie, J.-W., Shim, J.-H., Kim, D.-H., Cho, D.-W., 2014. Printing three-dimensional tissue analogues with decellularized extracellular matrix bioink. Nat. Commun. 5, 3935.

Pati, F., Shim, J.H., Lee, J.S., Cho, D.W., 2013. 3D printing of cell-laden constructs for heterogeneous tissue regeneration. Manuf. Lett. 1, 49-53. 
Paul, J.D., Coulombe, K.L.K., Toth, P.T., Zhang, Y., Marsboom, G., Bindokas, V.P., Smith, D.W., Murry, C.E., Rehman, J., 2013. SLIT3-ROBO4 activation promotes vascular network formation in human engineered tissue and angiogenesis in vivo. J. Mol. Cell. Cardiol. 64, 124-131.

Peng, W., Unutmaz, D., Ozbolat, I.T., 2016. Bioprinting towards physiologically-relevant tissue models for pharmaceutics. Trends Biotechnol. 34, 722-732.

Pescosolido, L., Schuurman, W., Malda, J., Matricardi, P., Alhaique, F., Coviello, T., Van Weeren, P.R., Dhert, W.J.A., Hennink, W.E., Vermonden, T., 2011. Hyaluronic acid and dextran-based semi-IPN hydrogels as biomaterials for bioprinting. Biomacromolecules 12, 1831-1838.

Poldervaart, M.T., Wang, H., van der Stok, J., Weinans, H., Leeuwenburgh, S.C.G., Öner, F.C., Dhert, W.J. a, Alblas, J., 2013. Sustained release of BMP-2 in bioprinted alginate for osteogenicity in mice and rats. PLoS One 8, e72610.

Pradines, B., Djabourov, M., Vauthier, C., Loiseau, P.M., Ponchel, G., Bouchemal, K., 2015. Gelation and micellization behaviors of pluronic ${ }^{\circledR}$ F127 hydrogel containing poly(isobutylcyanoacrylate) nanoparticles specifically designed for mucosal application. Colloids Surfaces B Biointerfaces $135,669-676$.

Purcell, E.K., Ph, D., Singh, A., Tech, B., Kipke, D.R., 2009. Alginate composition effects on a neural stem cell-seeded scaffold. Tissue Eng. Part C. Methods 15, 541-50.

Rajan, N., Habermehl, J., Coté, M.-F., Doillon, C.J., Mantovani, D., 2006. Preparation of ready-to-use, storable and reconstituted type I collagen from rat tail tendon for tissue engineering applications. Nat. Protoc. 1, 2753-8.

Raof, N.A., Schiele, N.R., Xie, Y., Chrisey, D.B., Corr, D.T., 2011. The maintenance of pluripotency following laser direct-write of mouse embryonic stem cells. Biomaterials 32, 1802-1808.

Rauch, U., Zhou, X.H., Roos, G., 2005. Extracellular matrix alterations in brains lacking four of its components. Biochem. Biophys. Res. Commun. 328, 608-617. 
Riggs, B.C., Dias, a. D., Schiele, N.R., Cristescu, R., Huang, Y., Corr, D.T., Chrisey, D.B., 2011. Matrixassisted pulsed laser methods for biofabrication. MRS Bull. 36, 1043-1050.

Rivron, N.C., Rouwkema, J., Truckenmüller, R., Karperien, M., De Boer, J., Van Blitterswijk, C.A., 2009. Tissue assembly and organization: Developmental mechanisms in microfabricated tissues. Biomaterials 30, 4851-4858.

Roth, E.., Xu, T., Das, M., Gregory, C., Hickman, J.., Boland, T., 2004. Inkjet printing for highthroughput cell patterning. Biomaterials 25, 3707-3715.

Rowley, J.A., Madlambayan, G., Mooney, D.J., 1999. Alginate hydrogels as synthetic extracellular matrix materials. Biomaterials 20, 45-53.

Sakai, S., Hirose, K., Taguchi, K., Ogushi, Y., Kawakami, K., 2009. An injectable, in situ enzymatically gellable, gelatin derivative for drug delivery and tissue engineering. Biomaterials 30, 33713377.

Scheraga, H. a, 2004. The thrombin-fibrinogen interaction. Biophys. Chem. 112, 117-30.

Schiele, N.R., Chrisey, D.B., Corr, D.T., 2011. Gelatin-based laser direct-write technique for the precise spatial patterning of cells. Tissue Eng. Part C. Methods 17, 289-298.

Schiele, N.R., Koppes, R.A., Corr, D.T., Ellison, K.S., Thompson, D.M., Ligon, L.A., Lippert, T.K.M., Chrisey, D.B., 2009. Laser direct writing of combinatorial libraries of idealized cellular constructs: Biomedical applications. Appl. Surf. Sci. 255, 5444-5447.

Schöttler, S., Becker, G., Winzen, S., Steinbach, T., Mohr, K., Landfester, K., Mailänder, V., Wurm, F.R., 2016. Protein adsorption is required for stealth effect of poly(ethylene glycol)-and poly(phosphoester)-coated nanocarriers. Nat. Nanotechnol. 11, 1-6.

Schrobback, K., Klein, T.J., Crawford, R., Upton, Z., Malda, J., Leavesley, D.I., 2012. Effects of oxygen and culture system on in vitro propagation and redifferentiation of osteoarthritic human articular chondrocytes. Cell Tissue Res. 347, 649-663. 
Schuurman, W., Levett, P. a., Pot, M.W., van Weeren, P.R., Dhert, W.J. a, Hutmacher, D.W., Melchels, F.P.W., Klein, T.J., Malda, J., 2013. Gelatin-methacrylamide hydrogels as potential biomaterials for fabrication of tissue-engineered cartilage constructs. Macromol. Biosci. 13, 551-561.

Seidlits, S.K., Khaing, Z.Z., Petersen, R.R., Nickels, J.D., Vanscoy, J.E., Shear, J.B., Schmidt, C.E., 2010. The effects of hyaluronic acid hydrogels with tunable mechanical properties on neural progenitor cell differentiation. Biomaterials 31, 3930-3940.

Serwer, P., Allen, J.L., Hayes, S.J., 1983. Agarose gel electrophoresis ofbacteriophages and related particles III . Dependence of gel sieving on the agarose preparation. Electrophoresis 4, 232-236.

Sharma, S., Johnson, R.W., Desai, T.A., 2004. XPS and AFM analysis of antifouling PEG interfaces for microfabricated silicon biosensors. Biosens. Bioelectron. 20, 227-239.

Skardal, A., Mack, D., Kapetanovic, E., Atala, A., Jackson, J., Yoo, J., Soker, S., 2012. Bioprinted Amniotic Fluid-Derived Stem Cells Accelerate Healing of Large Skin Wounds. Stem Cells Transl. Med. 792-802.

Skardal, A., Zhang, J., McCoard, L., Oottamasathien, S., Prestwich, G.D., 2010a. Dynamically crosslinked gold nanoparticle - hyaluronan hydrogels. Adv. Mater. 22, 4736-40.

Skardal, A., Zhang, J., McCoard, L., Xu, X., Oottamasathien, S., Prestwich, G.D., $2010 b$. Photocrosslinkable hyaluronan-gelatin hydrogels for two-step bioprinting. Tissue Eng. Part A $16,2675-85$.

Skardal, A., Zhang, J., Prestwich, G.D., 2010c. Bioprinting vessel-like constructs using hyaluronan hydrogels crosslinked with tetrahedral polyethylene glycol tetracrylates. Biomaterials 31, 61736181.

Smith, C.M., Stone, A., Stewart, R.L., Simpkins, M.W., Kachurin, A.M., Warren, W.L., Williams, S.K., 2004. Three-dimensional BioAssembly tool for generating viable tissue-engineered constructs. Tissue eng 10, 1566-1576. 
Snyder, J.E., Hamid, Q., Wang, C., Chang, R., Emami, K., Wu, H., Sun, W., 2011. Bioprinting cell-laden matrigel for radioprotection study of liver by pro-drug conversion in a dual-tissue microfluidic chip. Biofabrication 3, 34112.

Takeichi, M., 1988. The cadherins: cell-cell adhesion molecules controlling animal morphogenesis. Development 102, 639-655.

Takigawa, T., Endo, Y., 2006. Effects of glutaraldehyde exposure on human health. J. Occup. Health $48,75-87$.

Tako, M., Nakamura, S., 1988. Gelation mechanism of agarose. Carbohydr. Res. 180, 277-284.

Tan, Y., Richards, D.J., Trusk, T.C., Visconti, R.P., Yost, M.J., Kindy, M.S., Drake, C.J., Argraves, W.S., Markwald, R.R., Mei, Y., 2014. 3D printing facilitated scaffold-free tissue unit fabrication. Biofabrication 6, 24111.

Thomas, B.H., Craig Fryman, J., Liu, K., Mason, J., 2009. Hydrophilic-hydrophobic hydrogels for cartilage replacement. J. Mech. Behav. Biomed. Mater. 2, 588-595.

Tibbitt, M., Anseth, K., 2009. Hydrogels as Extracellular Matrix Mimics for 3D Cell Culture. Biotechnol Bioeng. 103, 655-663.

Tomei, A.A., Manzoli, V., Fraker, C.A., Giraldo, J., Velluto, D., Najjar, M., Pileggi, A., Molano, R.D., Ricordi, C., Stabler, C.L., Hubbell, J.A., 2014. Device design and materials optimization of conformal coating for islets of Langerhans. Proc. Natl. Acad. Sci. 111, 10514-10519.

Toole, B.P., 2004. Hyaluronan: from extracellular glue to pericellular cue. Nat. Rev. Cancer 4, 528-39.

Torisawa, Y., Mosadegh, B., Luker, G.D., Morell, M., O’Shea, K.S., Takayama, S., 2009. Microfluidic hydrodynamic cellular patterning for systematic formation of co-culture spheroids. Integr. Biol. (Camb). 1, 649-654

Turley, E.A., Noble, P.W., Bourguignon, L.Y.W., 2002. Signaling properties of hyaluronan receptors. J. 
Biol. Chem. 277, 4589-4592.

Turner, A.E.B., Flynn, L.E., 2012. Design and characterization of tissue-specific extracellular matrixderived microcarriers. Tissue Eng. Part C. Methods 18, 186-197.

Vashi, A. V, Keramidaris, E., Abberton, K.M., Morrison, W. a, Wilson, J.L., O'Connor, A.J., CooperWhite, J.J., Thompson, E.W., 2008. Adipose differentiation of bone marrow-derived mesenchymal stem cells using Pluronic F-127 hydrogel in vitro. Biomaterials 29, 573-9.

Veronese, F.M., Pasut, G., 2005. PEGylation, successful approach to drug delivery. Drug Discov. Today 10, 1451-1458.

Visser, J., Peters, B., Burger, T.J., Boomstra, J., Dhert, W.J., Melchels, F.P.W., Malda, J., 2013. Biofabrication of multi-material anatomically shaped tissue constructs. Biofabrication 5, 35007.

Vladkova, T., Krasteva, N., Kostadinova, a, Altankov, G., 1999. Preparation of PEG-coated surfaces and a study for their interaction with living cells. J. Biomater. Sci. Polym. Ed. 10, 609-620.

Wang, S., Lee, J.M., Yeong, W.Y., 2015. Smart hydrogels for 3D bioprinting. Int. J. Bioprinting 1, 3-14.

Wang, X., Yan, Y., Pan, Y., Xiong, Z., Liu, H., Cheng, J., Liu, F., Lin, F., Wu, R., Zhang, R., Lu, Q., 2006. Generation of three-dimensional hepatocyte/gelatin structures with rapid prototyping system. Tissue Eng. 12, 83-90.

Wang, Z., Abdulla, R., Parker, B., Samanipour, R., 2015. A simple and high-resolution stereolithography-based 3D bioprinting system using visible light crosslinkable bioinks. Biofabrication 7, 1-29.

Wang, Z., Jin, X., Dai, R., Holzman, J.F., Kim, K., 2016. An ultrafast hydrogel photocrosslinking method for direct laser bioprinting. RSC Adv. 6, 21099-21104.

Wei Xu, Xiaohong Wang, Yongnian Yan, Wei Zheng, Zhuo Xiong, Feng Lin, Rendong Wu, Renji Zhang, 2007. Rapid Prototyping Three-Dimensional Cell/Gelatin/Fibrinogen Constructs for Medical 
Regeneration. J. Bioact. Compat. Polym. 22, 363-377.

Wheeldon, I., Ahari, A.F., Khademhosseini, A., 2010. Microengineering hydrogels for stem cell bioengineering and tissue regeneration. JALA - J. Assoc. Lab. Autom. 15, 440-448.

White, C.J., McBride, M.K., Pate, K.M., Tieppo, A., Byrne, M.E., 2011. Extended release of high molecular weight hydroxypropyl methylcellulose from molecularly imprinted, extended wear silicone hydrogel contact lenses. Biomaterials 32, 5698-5705.

Wu, W., DeConinck, A., Lewis, J., 2011. Omnidirectional printing of 3D microvascular networks. Adv. Mater. 23, H178-83.

Wüst, S., Müller, R., Hofmann, S., 2014. 3D bioprinting of complex channels - Effects of material, orientation, geometry and cell embedding. J. Biomed. Mater. Res. A 103, 2558-70.

Xu, C., Chai, W., Huang, Y., Markwald, R.R., 2012. Scaffold-free inkjet printing of three-dimensional zigzag cellular tubes. Biotechnol. Bioeng. 109, 3152-60.

Xu, F., Finley, T.D., Turkaydin, M., Sung, Y., Gurkan, U.A., Yavuz, A.S., Guldiken, R.O., Demirci, U., 2011. The assembly of cell-encapsulating microscale hydrogels using acoustic waves. Biomaterials 32, 7847-7855.

Xu, T., Baicu, C., Aho, M., Zile, M., Boland, T., 2009. Fabrication and characterization of bioengineered cardiac pseudo tissues. Biofabrication 1, 35001.

Xu, T., Gregory, C., Molnar, P., Cui, X., Jalota, S., Bhaduri, S.B., Boland, T., 2006. Viability and electrophysiology of neural cell structures generated by the inkjet printing method. Biomaterials 27, 3580-3588.

Xu, T., Jin, J., Gregory, C., Hickman, J.J., Boland, T., 2005. Inkjet printing of viable mammalian cells. Biomaterials 26, 93-99.

Xu, T., Zhao, W., Zhu, J.-M., Albanna, M.Z., Yoo, J.J., Atala, A., 2013. Complex heterogeneous tissue 
constructs containing multiple cell types prepared by inkjet printing technology. Biomaterials 34, 130-139.

Yamada, E., Yamada, M., Iwase, M., Sugaya, S., Seki, M., 2011. Replica Molding and Bonding of Microstructured Hydrogel Plates for Tissue Engineering Applications. Sci. Technol. 1834-1836.

Yamamoto, M., James, D., Li, H., Butler, J., Rafii, S., Rabbany, S., 2010. Generation of stable cocultures of vascular cells in a honeycomb alginate scaffold. Tissue Eng. Part A 16, 299-308.

Yamato, M., Okano, T., 2004. Cell sheet engineering. Mater. Today 7, 42-47.

Yan, J., Huang, Y., Chrisey, D.B., 2013. Laser-assisted printing of alginate long tubes and annular constructs. Biofabrication 5, 15002.

Yan, L.P., Wang, Y.J., Ren, L., Wu, G., Caridade, S.G., Fan, J.B., Wang, L.Y., Ji, P.H., Oliveira, J.T.J.M., Oliveira, J.T.J.M., Mano, J.F., Reis, R.L., 2010. Genipin-cross-linked collagen/chitosan biomimetic scaffolds for articular cartilage tissue engineering applications. J. Biomed. Mater. Res. - Part A 95 A, 465-475.

Yanez, M., Rincon, J., Dones, A., De Maria, C., Gonzales, R., Boland, T., 2015. In Vivo Assessment of Printed Microvasculature in a Bilayer Skin Graft to Treat Full-Thickness Wounds. Tissue Eng. Part A 21, 224-33.

Yang, Z., Nie, S., Hsiao, W.W., Pam, W., 2011. Thermoreversible Pluronic\&amp;reg; F127-based hydrogel containing liposomes for the controlled delivery of paclitaxel: in vitro drug release, cell cytotoxicity, and uptake studies. Int. J. Nanomedicine 151.

Ye, K., Felimban, R., Traianedes, K., Moulton, S.E., Wallace, G.G., Chung, J., Quigley, A., Choong, P.F.M., Myers, D.E., 2014. Chondrogenesis of infrapatellar fat pad derived adipose stem cells in 3D printed chitosan scaffold. PLoS One 9, e99410.

Yin Yu, Ozbolat, I.T., 2014. Tissue strands as "bioink" for scale-up organ printing. Conf. Proc. Annu. Int. Conf. IEEE 2014, 1428-31. 
Yong, K., Mooney, D.J., 2012. Progress in Polymer Science Alginate : Properties and biomedical applications. Prog. Polym. Sci. 37, 106-126.

Yu, Y., Brouillette, M.J., Seol, D., Zheng, H., Buckwalter, J.A., Martin, J.A., 2012. Functional FullThickness Articular Cartilage Repair by rhSDF-1 $\alpha$ Loaded Fibrin/HA Hydrogel Network via Chondrogenic Progenitor Cells Homing. Arthritis Rheum. 1-30.

Yu, Y., Moncal, K.K., Li, J., Peng, W., Rivero, I., Martin, J.A., Ozbolat, I.T., 2016. Three-dimensional bioprinting using self-assembling scalable scaffold-free "tissue strands" as a new bioink. Sci. Rep. 6, 28714.

Yu, Y., Zhang, Y., Martin, J., Ozbolat, I.T., 2013. Evaluation of cell viability and functionality in vessellike bioprintable cell-laden tubular channels. J. Biomech. Eng. 135, 91011.

Zhang, A.P., Qu, X., Soman, P., Hribar, K.C., Lee, J.W., Chen, S., He, S., 2012. Rapid fabrication of complex 3D extracellular microenvironments by dynamic optical projection stereolithography. Adv. Mater. 24, 4266-4270.

Zhang, L., Hu, J., Athanasiou, K.A., 2009. The Role of Tissue Engineering in Articular Cartilage Repair and Regeneration. Crit Rev Biomed Eng 37, 1-57.

Zhang, L.G., Zhong, D.H., Zhang, Y., Li, C.Z., Kisaalita, W.S., Wu, Z.Z., 2014. A microwell pattern for c17.2 cell aggregate formation with concave cylindrical surface induced cell peeling. Biomaterials 35, 9423-9437.

Zhang, M., Desai, T., Ferrari, M., 1998. Proteins and cells on PEG immobilized silicon surfaces. Biomaterials 19, 953-960.

Zhang, Y., Yu, Y., Akkouch, A., Dababneh, A., Dolati, F., Ozbolat, I.T.I., 2015. In vitro study of directly bioprinted perfusable vasculature conduits. Biomater. Sci. 3, 134-143.

Zhang, Y., Yu, Y., Chen, H., Ozbolat, I.T., 2013. Characterization of Printable Cellular Micro-fluidic Channels for Tissue Engineering. Biofabrication 5, 24004. 
Zhang, Y., Yu, Y., Ozbolat, I.T., 2013. Direct Bioprinting of Vessel-Like Tubular Microfluidic Channels. J. Nanotechnol. Eng. Med. 4, 20902.

Zhang, Y.S., Arneri, A., Bersini, S., Shin, S.-R., Zhu, K., Malekabadi, Z.G., Aleman, J., Colosi, C., Busignani, F., Dell'Erba, V., 2016. Bioprinting 3D Microfibrous Scaffolds for Engineering Endothelialized Myocardium and Heart-on-a-Chip. Biomaterials 110, 45-59.

Zhong, S.P., Campoccia, D., Doherty, P.J., Williams, R.L., Benedetti, L., Williams, D.F., 1994. Biodegradation of hyaluronic acid derivatives by hyaluronidase. Biomaterials 15, 359-365.

Zhu, J., Marchant, R.E., 2011. Design properties of hydrogel tissue-engineering scaffolds. Expert Rev. Med. Devices 8, 607-626.

\section{List of Tables}

Table 1. Detailed characteristic of bioprinting parameters of hydrogels using EBB, DBB, and LBB

Table 2. Comparison of bioink types used in bioprinting processes 


\section{List of Figures}

Figure 1. Modalities of bioprinting processes and their bioink requirements

Figure 2. Bioprinted hydrogels: (A) agarose filaments bioprinted within tissue spheroids (reproduced with permission from Ref. (Norotte et al., 2009)); (B) 3D printed alginate in brain shape with anatomical features (reproduced with permission from Ref. (Hinton et al., 2015)); (C) chitosan 
scaffold after 4 weeks of culture (reproduced with permission from Ref. (Ye et al., 2014)); (D) collagen type I construct for skin tissue regeneration inserted into the wound (reproduced with permission from Ref. (Michael et al., 2013)); (E) bioprinted fibrin into 3D tubular scaffolds (reproduced with permission from Ref. (Hinton et al., 2015)); (F) gelatin bioprinted by laser directwrite technique resulted in precise deposition of cells (reproduced with permission from Ref. (Raof et al., 2011)); (G) 3D bioprinted 'half-heart' scaffold using alginate/gelatin (reproduced with permission from Ref. (Xu et al., 2009)); (H) bioprinted hyaluronic acid (reproduced with permission from Ref. (Pescosolido et al., 2011)); (I) 3D bioprinted hepatic carcinoma cell-laden Matrigel graft (reproduced with permission from Ref. (Snyder et al., 2011)); (J) a 3D confocal image of cells in a GelMA scaffold fabricated by LBB (reproduced with permission from Ref. (Gauvin et al., 2012)); (K) bioprinted Pluronic ${ }^{\circledR}$ F-127 fluorescent tube (reproduced with permission from Ref. (Müller et al., 2015)); (L) PEG hydrogel bioprinted into aortic valve construct (reproduced with permission from Ref. (Hockaday et al., 2012)).

Figure 3. Different bioink types, related compatible bioprinting processes and resulted tissue constructs: (A1) cardiac dECM in gel consistency (reproduced with permission from Ref. (Pati et al., 2014)); (A2) the same dECM during bioprinting (reproduced with permission from Ref. (Pati et al., 2014)); (A3) printed hybrid construct of $\mathrm{dECM}$ and $\mathrm{PCL}$ frame imaged by scanning electron microscopy (SME) (reproduced with permission from Ref. (Pati et al., 2014)); (B1) a fluorescence image of a cell-laden microcarrier, where cell surface and nucleus were stained in green and red, respectively (reproduced with permission from Ref. (Jakob et al., 2016)); (B2) a representative image for bioprinting of microcarriers; (B3) bioprinted microcarriers loaded in GelMA hydrogel (reproduced with permission from Ref. (Levato et al., 2014)); (C1) a tissue spheroid made of beta ( $\beta$ )-TC3 mouse insulinoma and rat heart microvascular endothelial cells; (C2) tissue spheroids in a pipette tip during extrusion (reproduced with permission from Ref. (Mironov et al., 2009)); (C3) fused tissue spheroids after bioprinting (reproduced with permission from Ref. (Mironov et al., 2009)); (D1) cell pellet in a custom syringe; (D2) cell pellet bioprinting into a printed agarose mold 
(reproduced with a permission from Ref. (Kucukgul et al., 2014)); (D3) a 3D bioprinted aortic construct (reproduced with a permission from Ref. (Kucukgul et al., 2014)); (E1) a tissue strand made of fibroblasts; (E2) a cartilage strand during extrusion (reproduced with permission from Ref. (Yu et al., 2016)); (E3) cartilage tissue strand bioprinted in parallel assembled into a single cartilage patch in three weeks (reproduced with permission from Ref. (Akkouch et al., 2015)). It is to be noted here that all the above mentioned techniques utilized EBB. 
Table 1

\begin{tabular}{|c|c|c|c|c|c|c|c|c|c|c|c|c|}
\hline & \multirow{2}{*}{$\begin{array}{l}\text { Process } \\
\text { type }\end{array}$} & \multicolumn{2}{|c|}{ Crosslinking properties } & \multirow[b]{2}{*}{ Concentration } & \multirow{2}{*}{$\begin{array}{l}\text { Bioprinting } \\
\text { parameters }\end{array}$} & \multirow{2}{*}{$\begin{array}{l}\text { Construct } \\
\text { size }\end{array}$} & \multicolumn{3}{|c|}{ Cell related attributes } & \multirow[b]{2}{*}{ Bioprintability } & \multirow[b]{2}{*}{ Bioprinter used } & \multirow[b]{2}{*}{ References } \\
\hline & & type & time & & & & Type & \begin{tabular}{|c|} 
density \\
[million $/ \mathrm{mL}]$
\end{tabular} & $\begin{array}{l}\text { viability } \\
\text { (\%) }\end{array}$ & & & \\
\hline \multirow{2}{*}{ 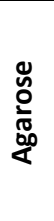 } & EBB & thermal & minutes & $0.3 \%$ & $\mathrm{n} / \mathrm{a}$ & $2.5 \mathrm{~mm}$ & MSCs & 0.1 & 98.8 & high & custom-made & $\begin{array}{c}\text { (Duarte } \\
\text { Campos et } \\
\text { al., 2014) } \\
\end{array}$ \\
\hline & DBB & thermal & $1-2 h$ & $1.5 \%$ & $\mathrm{n} / \mathrm{a}$ & $\begin{array}{c}6 \times 6.5 \\
\mathrm{~mm}\end{array}$ & $\begin{array}{c}\mathrm{CHO}: \\
\text { motoneurons }\end{array}$ & $5: 2$ & 90 & high & HP Desktop 550C & $\begin{array}{l}\text { (Xu et al., } \\
\text { 2005) }\end{array}$ \\
\hline \multirow{7}{*}{ 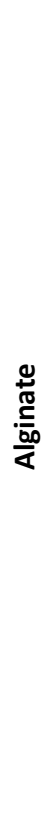 } & \multirow{4}{*}{ EBB } & ionically: $\mathrm{CaCl}_{2}$ & seconds & $2 \%$ & $\begin{array}{c}29 \mathrm{psi}, 17 \\
\mathrm{~mm} / \mathrm{s}\end{array}$ & $\begin{array}{c}430 \mu \mathrm{m} \\
\text { diameter }\end{array}$ & BMSC & 0.25 & 95 & high & Bioplotter & $\begin{array}{l}\text { (Fedorovich } \\
\text { et al., 2008) }\end{array}$ \\
\hline & & ionically: $\mathrm{CaSO}_{4}$ & 10 minutes & $2 \%$ & $\begin{array}{c}10.5 \mathrm{psi}, 10 \\
\mathrm{~mm} / \mathrm{s}\end{array}$ & $\begin{array}{c}19 \mathrm{~mm} x \\
6 \mathrm{~mm}\end{array}$ & $\mathrm{n} / \mathrm{a}$ & $\mathrm{n} / \mathrm{a}$ & $\mathrm{n} / \mathrm{a}$ & high & Fab@Home & $\begin{array}{l}\text { (Cohen et } \\
\text { al., 2010a) }\end{array}$ \\
\hline & & \multirow[b]{2}{*}{ ionically: $\mathrm{CaCl}_{2}$} & Precrosslinked & $3 \%$ & $\mathrm{n} / \mathrm{a}$ & $\begin{array}{c}20 \times 20 \times \\
3 \mathrm{~mm}\end{array}$ & gMSCs & 10 & $\mathrm{n} / \mathrm{a}$ & high & Bioscaffolder & $\begin{array}{l}\text { (Poldervaart } \\
\text { et al., 2013) } \\
\end{array}$ \\
\hline & & & $\mathrm{n} / \mathrm{a}$ & $1-2 \%$ & $\begin{array}{c}7.25-43.5 \\
\mathrm{psi}, 1-30 \\
\mathrm{~mm} / \mathrm{s}\end{array}$ & $\begin{array}{c}20 \times 20 x \\
2 \mathrm{~mm}\end{array}$ & BMSCc & 0.25 & 95 & high & Bioplotter & $\begin{array}{l}\text { (Fedorovich } \\
\text { et al., 2008) }\end{array}$ \\
\hline & DBB & ionically: $\mathrm{CaCl}_{2}$ & $\mathrm{n} / \mathrm{a}$ & $1 \%$ & \begin{tabular}{|c|}
$60 \mathrm{~Hz}$, echo \\
and dwell \\
time $45 \mu \mathrm{s}$
\end{tabular} & $\begin{array}{c}10 \times 5 \\
\mathrm{~mm}\end{array}$ & NIH 3T3 & 5 & 90.8 & high & $\begin{array}{l}\text { platform-assisted } \\
\text { 3D inkjet } \\
\text { bioprinting system }\end{array}$ & $\begin{array}{l}\text { (Christensen } \\
\text { et al., 2015) }\end{array}$ \\
\hline & \multirow[b]{2}{*}{ LBB } & \multirow[b]{2}{*}{ ionically: $\mathrm{CaCl}_{2}$} & $\mathrm{n} / \mathrm{a}$ & $0.1-1 \%$ & $\begin{array}{c}4.5-9 \mathrm{uJ} \\
160-80 \\
\mathrm{~cm} / \mathrm{s}\end{array}$ & $\begin{array}{c}3 \times 1.5 \\
\mathrm{~mm}\end{array}$ & HUVECS & $40-100$ & $\mathrm{n} / \mathrm{a}$ & high & custom-made & $\begin{array}{c}\text { (Guillotin et } \\
\text { al., 2010) }\end{array}$ \\
\hline & & & seconds & $1-8 \%$ & $\begin{array}{c}193 \mathrm{~nm}, \\
85 \% \\
\text { transmit., } \\
1.5 \mathrm{~mm} / \mathrm{s}\end{array}$ & $100 \mu \mathrm{m}$ & $\mathrm{n} / \mathrm{a}$ & $\mathrm{n} / \mathrm{a}$ & $\mathrm{n} / \mathrm{a}$ & high & MAPLE-DW & $\begin{array}{l}\text { (Yan et al., } \\
\text { 2013) }\end{array}$ \\
\hline \multirow{2}{*}{ 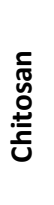 } & \multirow{2}{*}{ EBB } & \multirow{2}{*}{$\begin{array}{l}\text { pH mediated: } \\
\mathrm{CH}_{3} \mathrm{COOH}\end{array}$} & $\mathrm{n} / \mathrm{a}$ & \multirow{2}{*}{$3 \%$} & $\begin{array}{l}13 \mathrm{psi}, 15 \\
\mathrm{~cm} / \mathrm{min}\end{array}$ & $\begin{array}{c}10 \times 10 \times \\
5 \mathrm{~mm}\end{array}$ & ASCs & 0.75 & $\mathrm{n} / \mathrm{a}$ & high & Custom-made & $\begin{array}{l}\text { (Ye et al., } \\
\text { 2014) }\end{array}$ \\
\hline & & & $2 \mathrm{~h}$ & & $\begin{array}{c}29 \mathrm{psi}, 6 \\
\mathrm{~mm} / \mathrm{s}\end{array}$ & $2 \times 2 \mathrm{~cm}$ & $\begin{array}{l}\text { Porcine bone } \\
\text { marrow cells }\end{array}$ & 0.5 & $\mathrm{n} / \mathrm{a}$ & high & Custom-made & $\begin{array}{c}\text { (Geng et al., } \\
2005)\end{array}$ \\
\hline
\end{tabular}




\begin{tabular}{|c|c|c|c|c|c|c|c|c|c|c|c|c|}
\hline \multirow{5}{*}{ 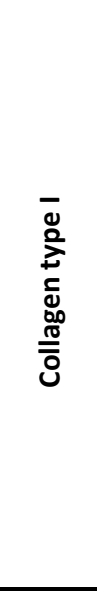 } & \multirow[b]{3}{*}{$\mathrm{EBB}$} & \multirow{2}{*}{$\mathrm{pH}$-mediated } & \multirow{2}{*}{ minutes } & \multirow{2}{*}{$0.3 \%$} & \multirow{2}{*}{\begin{tabular}{|c|}
$\begin{array}{c}1.7 \mathrm{psi}, 20 \\
\mathrm{~mm} / \mathrm{s}\end{array}$ \\
$\begin{array}{c}1.5 \mathrm{psi}, 15 \\
\mathrm{~mm} / \mathrm{s}\end{array}$ \\
\end{tabular}} & \multirow{2}{*}{$\begin{array}{l}200 \mu \mathrm{m} \\
800 \mu \mathrm{m}\end{array}$} & \multirow{2}{*}{ BAECS } & \multirow{2}{*}{$5-20$} & 33 & average & \multirow{2}{*}{ BioAssembly Tool } & \multirow{2}{*}{$\begin{array}{l}\text { (Smith et } \\
\text { al., 2004) }\end{array}$} \\
\hline & & & & & & & & & 86 & low & & \\
\hline & & $\begin{array}{l}\mathrm{pH}: \mathrm{NaHCO}_{3} \text { and } \\
\text { cooled under } 20^{\circ} \mathrm{C}\end{array}$ & $1 \mathrm{~min}$ & $0.223 \%$ & $\begin{array}{c}\text { 0-2 psi, } \\
\text { Valve } \\
\text { operating } \\
\text { time, } 600- \\
150 \mu \mathrm{s}\end{array}$ & $\begin{array}{l}1 \times 10 \mathrm{x} \\
10 \mathrm{~mm}\end{array}$ & fibroblasts & 1 & 95 & high & Custom-made & $\begin{array}{l}\text { (W. Lee et } \\
\text { al., 2010) }\end{array}$ \\
\hline & \multirow{2}{*}{ DBB } & $\begin{array}{l}\mathrm{pH}-\text { mediated and } \\
\text { thermal }\end{array}$ & $1-2 h$ & $0.1 \%$ & $n / a$ & $\begin{array}{c}6 \times 6.5 \\
\mathrm{~mm}\end{array}$ & $\begin{array}{c}\mathrm{CHO} \\
\text { motoneurons }\end{array}$ & $5 ; 2$ & 90 & high & $\begin{array}{c}\text { HP Desktop printer } \\
\text { HP 550C }\end{array}$ & $\begin{array}{l}\text { (Xu et al., } \\
\text { 2005) }\end{array}$ \\
\hline & & $\mathrm{pH}$ - mediated & $<2 \mathrm{~h}$ & $0.025-0.5 \%$ & $n / a$ & $\begin{array}{r}23 x \\
3 \mathrm{~mm}\end{array}$ & \begin{tabular}{|c|} 
rat \\
cardiomyocytes
\end{tabular} & 0.25 & $\mathrm{n} / \mathrm{a}$ & low & HP DeskJet 500 & $\begin{array}{l}\text { (Deitch et } \\
\text { al., 2008) }\end{array}$ \\
\hline \multirow{2}{*}{ 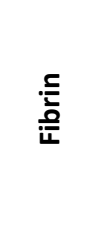 } & \multirow{2}{*}{ DBB } & \multirow{2}{*}{$\begin{array}{l}\text { Fibrinogen }[\mathrm{F}]- \\
\text { thrombin }[\mathrm{T}]\end{array}$} & seconds & $\begin{array}{c}10 \mathrm{mg} / \mathrm{mL}[\mathrm{F}] \\
20 \mathrm{U} / \mathrm{mL}[\mathrm{T}]\end{array}$ & $\begin{array}{c}250 \mathrm{k} \\
\text { drops/s }\end{array}$ & $\begin{array}{c}25 \times 5 x \\
1 \mathrm{~mm}\end{array}$ & NT2 neurons & 2 & 74.27 & low & HP Desktop 550 & $\begin{array}{c}\text { (Xu et al., } \\
2006)\end{array}$ \\
\hline & & & 6 minutes & $\begin{array}{c}60 \mathrm{mg} / \mathrm{mL}[\mathrm{F}] \\
50 \mathrm{U} / \mathrm{mL}[\mathrm{T}]\end{array}$ & $\begin{array}{c}\text { Droplets } \\
130 \mathrm{pl} ; 10- \\
\mu \mathrm{s} \text { pulse }\end{array}$ & $\begin{array}{l}8 \mathrm{~mm} \mathrm{x} \\
1.8 \mathrm{~mm}\end{array}$ & HMVEC & $1-8$ & $\mathrm{n} / \mathrm{a}$ & low & HP Deskjet 400 & $\begin{array}{l}\text { (Cui and } \\
\text { Boland, } \\
\text { 2009) }\end{array}$ \\
\hline \multirow{4}{*}{$\begin{array}{l}\stackrel{5}{ \pm} \\
\frac{\pi}{\mathbb{N}}\end{array}$} & \multirow[b]{2}{*}{ EBB } & \multirow[b]{2}{*}{ thermal } & $5 \mathrm{~min}$ & $20 \%$ & $5 \mathrm{psi}$ & $\begin{array}{c}5 \times 5 \times 3 \\
\mathrm{~mm}\end{array}$ & hepatocytes & 1 & $\begin{array}{l}90 \text { after } \\
45 \text { days }\end{array}$ & average & $\mathrm{n} / \mathrm{a}$ & $\begin{array}{l}\text { (Wang et } \\
\text { al., 2006) }\end{array}$ \\
\hline & & & $\mathrm{n} / \mathrm{a}$ & $7 \%$ & $\begin{array}{c}\text { 6-13 psi, } \\
450-750 \mu \mathrm{s} \\
\text { valve } \\
\text { operating }\end{array}$ & $\begin{array}{l}1 \times 10 \mathrm{x} \\
10 \mathrm{~mm}\end{array}$ & fibroblasts & 1 & $\mathrm{n} / \mathrm{a}$ & high & Custom-made & $\begin{array}{l}\text { (W. Lee et } \\
\text { al., 2010) }\end{array}$ \\
\hline & \multirow{2}{*}{ LBB } & \multirow{2}{*}{ thermal } & $7 \mathrm{~min}$ & $20 \%$ & $1.0 \mathrm{~J} / \mathrm{cm}^{2}$ & $\begin{array}{c}1 \times 1.5 \\
\mathrm{~mm}\end{array}$ & fibroblasts & 0.6 & 91 & high & MAPLE-DW & $\begin{array}{l}\text { (Schiele et } \\
\text { al., 2011) }\end{array}$ \\
\hline & & & $\mathrm{n} / \mathrm{a}$ & $\mathrm{n} / \mathrm{a}$ & $\begin{array}{c}10^{7} \times g, 122 \\
\mathrm{~m} / \mathrm{s}\end{array}$ & $\mathrm{n} / \mathrm{a}$ & $\begin{array}{c}\text { Schwann, } \\
\text { astroglial cells }\end{array}$ & $2-6$ & $80-85$ & average & AFA-LIFT & $\begin{array}{l}\text { (Hopp et al., } \\
\text { 2005) }\end{array}$ \\
\hline \multirow{2}{*}{ 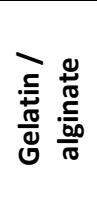 } & EBB & \multirow[b]{2}{*}{ Ionically: $\mathrm{CaCl}_{2}$} & precrosslinking & $0.06 \%$ & $5 \mathrm{~mm} / \mathrm{s}$ & $3 \times 1 \mathrm{~mm}$ & \multirow[b]{2}{*}{ NIH 3 T3 } & \multirow[b]{2}{*}{10} & 84.6 & high & Fab@Home & $\begin{array}{l}\text { (Duan et al., } \\
\text { 2013) }\end{array}$ \\
\hline & DBB & & $90 \%$ in $5 s$ & $2 w t \%$ & $\begin{array}{c}0.014-0.29 \\
\text { psi }\end{array}$ & $\begin{array}{c}250 \mu \mathrm{m} \mathrm{x} \\
300 \mu \mathrm{m} \mathrm{x} \\
3.5 \mathrm{~mm}\end{array}$ & & & $\mathrm{n} / \mathrm{a}$ & average & MicroDrop & $\begin{array}{c}\text { (Pataky et } \\
\text { al., 2012) }\end{array}$ \\
\hline
\end{tabular}




\begin{tabular}{|c|c|c|c|c|c|c|c|c|c|c|c|c|}
\hline \multirow{2}{*}{ 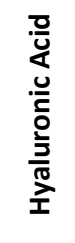 } & \multirow[t]{2}{*}{ EBB } & $\begin{array}{c}\text { Photopolymerization; } \\
\text { pH-mediated }\end{array}$ & $3 \min$ & $1.5 \%$ & $\mathrm{n} / \mathrm{a}$ & $\begin{array}{c}2 \mathrm{~mm} \\
\text { ring }\end{array}$ & $\begin{array}{c}\text { HepG2, C3A, } \\
\text { Int-407, NIH } \\
3 T 3\end{array}$ & 25 & $\mathrm{n} / \mathrm{a}$ & average & Fab@Home & $\begin{array}{l}\text { (Skardal et } \\
\text { al., 2010b) }\end{array}$ \\
\hline & & Photopolymerization & $10 \mathrm{~min}$ & $2-6 \%$ & $\mathrm{n} / \mathrm{a}$ & $\mathrm{n} / \mathrm{a}$ & $\begin{array}{l}\text { articular } \\
\text { cartilage }\end{array}$ & 5 & $\mathrm{n} / \mathrm{a}$ & average & Bioscaffolder & $\begin{array}{l}\text { (Pescosolido } \\
\text { et al., 2011) }\end{array}$ \\
\hline \multirow{4}{*}{ 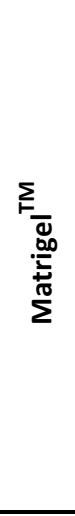 } & \multirow{2}{*}{ EBB } & \multirow{4}{*}{ thermal } & $\mathrm{n} / \mathrm{a}$ & $\begin{array}{c}\text { 1:1 ratio with } \\
\text { cells }\end{array}$ & $\begin{array}{c}0.0017 \mathrm{psi}, \\
1 \mathrm{~cm} / \mathrm{s} \\
\end{array}$ & $\begin{array}{c}0.75 \times 1 \\
\mathrm{~cm}\end{array}$ & $\begin{array}{l}\text { HepG2 and } \\
\text { M10 }\end{array}$ & 1 & $\mathrm{n} / \mathrm{a}$ & low & $\begin{array}{c}\text { Roland DXY-1100 } \\
\text { plotter }\end{array}$ & $\begin{array}{l}\text { (Snyder et } \\
\text { al., 2011) }\end{array}$ \\
\hline & & & $\mathrm{n} / \mathrm{a}$ & $\mathrm{n} / \mathrm{a}$ & $\begin{array}{c}25.4 \mathrm{psi}, 30 \\
\mathrm{~cm} / \mathrm{min}\end{array}$ & $\begin{array}{c}10 \times 20 x \\
1 \mathrm{~mm}\end{array}$ & $\begin{array}{l}\text { gEPCs and } \\
\text { MNCs }\end{array}$ & 5 & $\mathrm{n} / \mathrm{a}$ & low & Bioscaffolder & $\begin{array}{l}\text { (Fedorovich } \\
\text { et al., 2011) }\end{array}$ \\
\hline & DBB & & $30 \mathrm{~min}$ & $\mathrm{n} / \mathrm{a}$ & \begin{tabular}{|c|}
$3.6 \mathrm{psi}, 20$ \\
$\mathrm{~mm} / \mathrm{s}$ \\
$17.86 \mathrm{~Hz}$ \\
\end{tabular} & $1.12 \mathrm{~mm}$ & $\begin{array}{l}\text { alveolar EC, } \\
\text { HUVECS }\end{array}$ & 4.5 & $\mathrm{n} / \mathrm{a}$ & low & BioFactory & $\begin{array}{l}\text { (Horváth et } \\
\text { al., 2015) }\end{array}$ \\
\hline & LBB & & $\mathrm{n} / \mathrm{a}$ & $\mathrm{n} / \mathrm{a}$ & $\begin{array}{c}193 \mathrm{~nm}, \\
300 \mathrm{~Hz}\end{array}$ & $\begin{array}{l}3 \times 3 \\
\text { array }\end{array}$ & $\begin{array}{c}\text { fibroblast, } \\
\text { myoblast, } \\
\text { neural stem } \\
\text { cells, breast } \\
\text { cancer cells }\end{array}$ & $n / a$ & $\mathrm{n} / \mathrm{a}$ & average & MAPLE DW & $\begin{array}{l}\text { (Schiele et } \\
\text { al., 2009) }\end{array}$ \\
\hline \multirow{5}{*}{ 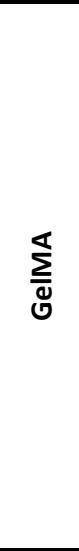 } & \multirow{2}{*}{ EBB } & \multirow{5}{*}{ photopolymerization } & minutes & $10-20 \%$ & $\begin{array}{c}14-58 \mathrm{psi} \\
30-70 \\
\mathrm{~cm} / \mathrm{min} \\
\end{array}$ & $\begin{array}{c}150-200 \\
\mu \mathrm{m}\end{array}$ & HepG2 & 1.5 & $>97$ & high & $\begin{array}{l}\text { Bioplotter } \\
\text { pneumatic }\end{array}$ & $\begin{array}{l}\text { (Billiet et al., } \\
\text { 2014) }\end{array}$ \\
\hline & & & $10-60 \mathrm{~s}$ & $5-15 \%$ & $2 \mathrm{~mm} / \mathrm{s}$ & $750 \mu \mathrm{m}$ & HepG2, NIH3T3 & $1-6$ & $>75$ & high & $\begin{array}{l}\text { NovoGen MMX } \\
\text { Bioprinter }\end{array}$ & $\begin{array}{l}\text { (Bertassoni } \\
\text { et al., 2014) }\end{array}$ \\
\hline & \multirow[b]{2}{*}{ DBB } & & 10 minutes & $10-20 \%$ & $\begin{array}{l}300 \mathrm{dpi} \\
3.6 \mathrm{k} \mathrm{Hz}\end{array}$ & $4 \times 2 \mathrm{~mm}$ & $\begin{array}{l}\text { articular } \\
\text { cartilage }\end{array}$ & 5 & 63.2 & high & $\begin{array}{l}\text { HP Deskjet } \\
500\end{array}$ & $\begin{array}{l}\text { (Cui et al., } \\
\text { 2012a) }\end{array}$ \\
\hline & & & $30 \mathrm{~s}$ & $5 \%$ & $\begin{array}{c}6.9 \mathrm{~mW} / \\
\mathrm{cm}^{2}\end{array}$ & $8 \times 8 \mathrm{~mm}$ & $\begin{array}{l}\text { MSCs, growth } \\
\text { factors }\end{array}$ & 1 & 90 & high & Custom-made & $\begin{array}{c}\text { (Kuo and } \\
\text { Demirci, } \\
2014 \text { ) }\end{array}$ \\
\hline & LBB & & $20 \mathrm{~s}$ & $10-15 \%$ & $\begin{array}{c}50 \\
\mathrm{~mW} / \mathrm{cm}^{2}\end{array}$ & $\begin{array}{c}5 \times 5 \times 1 \\
\mathrm{~mm}\end{array}$ & HUVEC & 0.02 & $n / a$ & high & $\begin{array}{c}\text { Custom-made } \\
\text { projection stereo- } \\
\text { lithography system }\end{array}$ & $\begin{array}{l}\text { (Gauvin et } \\
\text { al., 2012) }\end{array}$ \\
\hline 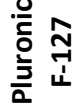 & EBB & thermal & minutes & $\begin{array}{l}30 \% ; 27 \% \\
\text { with cells }\end{array}$ & $250 \mu \mathrm{m} / \mathrm{s}$ & $\begin{array}{c}2 \times 2 \times \\
1.5 \mathrm{~mm}\end{array}$ & $\begin{array}{c}\text { Human primary } \\
\text { fibroblasts }\end{array}$ & 0.8 & 60 & high & BioAssembly Tool & $\begin{array}{l}\text { (Smith et } \\
\text { al., 2004) }\end{array}$ \\
\hline
\end{tabular}




\begin{tabular}{|c|c|c|c|c|c|c|c|c|c|c|c|c|}
\hline & & & & $25 \%$ & $\begin{array}{c}7.25-43.5 \\
\mathrm{psi}, 1-30 \\
\mathrm{~mm} / \mathrm{s}\end{array}$ & $\begin{array}{c}20 \times 20 \times \\
2 \mathrm{~mm}\end{array}$ & BMSCC & $0.25 ; 0.5$ & 85 & high & Bioplotter & $\begin{array}{l}\text { (Fedorovich } \\
\text { et al., 2008) }\end{array}$ \\
\hline & & & $\mathrm{n} / \mathrm{a}$ & $<10 \% ; 20 \%$ & $\begin{array}{c}16.5 \\
\mathrm{~mW} / \mathrm{cm}^{2} \\
3-6 \mathrm{~mm} / \mathrm{s}\end{array}$ & $\begin{array}{c}22 \times 25 \\
17 \times 20 \\
12 \times 14 \\
\mathrm{~mm}\end{array}$ & PAVICS & 0.5 & 91.3 & high & Fab@Home & $\begin{array}{l}\text { (Hockaday } \\
\text { et al., 2012) }\end{array}$ \\
\hline \multirow{2}{*}{ 岕 } & EBB & \multirow[t]{2}{*}{ Photopolymerization } & $\begin{array}{l}\text { up to } 19 \\
\text { minutes }\end{array}$ & $10 \%$ & $\begin{array}{c}300 \mathrm{dpi}, 3.6 \\
\mathrm{k} \mathrm{Hz}\end{array}$ & $4 \mathrm{~mm}$ & hMSCs & 6 & 90 & high & HP 51626A & $\begin{array}{c}\text { (Gao G1, } \\
\text { Yonezawa T, } \\
\text { Hubbell K, } \\
\text { Dai G, 2015) }\end{array}$ \\
\hline & DBB & & $10 \mathrm{~min}$ & $10-20 \%$ & $\begin{array}{c}4-8 \\
\mathrm{~mW} / \mathrm{cm}^{2}\end{array}$ & $5 \mathrm{~mm}$ & $\begin{array}{l}\text { Human } \\
\text { articular } \\
\text { cartilage }\end{array}$ & 5 & 89 & high & $\begin{array}{l}\text { HP Deskjet } \\
500\end{array}$ & $\begin{array}{l}\text { (Cui et al., } \\
\text { 2012a) }\end{array}$ \\
\hline
\end{tabular}


Table 2

\begin{tabular}{|c|c|c|c|c|c|c|c|}
\hline & & Hydrogels & Decellularized matrix & Microcarriers & Tissue spheroids & Cell pellet & Tissue strands \\
\hline \multirow{7}{*}{ 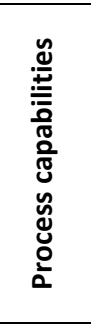 } & Resolution & High & Medium & Low & Low & Medium & Low \\
\hline & Accuracy & High & Medium & Low & Low & Medium & Low \\
\hline & Bioprinting time & Short & Medium-long & Short & Long & Medium-long & Long \\
\hline & Processing modes & EBB, DBB, LBB & EBB & EBB & EBB & EBB & EBB \\
\hline & Cell viability & High & Medium-high & High & Medium-high & Medium-high & Medium-high \\
\hline & $\begin{array}{l}\text { Control of single cell } \\
\text { printing }\end{array}$ & High & Low & Low & Low & Low & Low \\
\hline & Throughput & High & Medium-high & Medium-high & Low & Medium-high & Medium-high \\
\hline \multirow{6}{*}{ 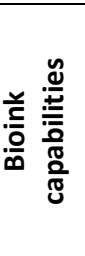 } & Bioink mode & Liquid, sol-gel, solid & Liquid & solid & solid & Liquid & solid \\
\hline & Bioprintability & High & Low-medium & High & Low & Low-medium & Low \\
\hline & Bioink viscosity & low to high & Medium to high & $\mathrm{n} / \mathrm{a}$ & $\mathrm{n} / \mathrm{a}$ & Medium to high & $\mathrm{n} / \mathrm{a}$ \\
\hline & Multicellular feasibility & yes & yes & yes & yes & yes & yes \\
\hline & Affordability & $\$-\$ \$ \$$ & $\$ \$$ & $\$ \$$ & $\$ \$ \$$ & $\$ \$$ & $\$ \$ \$$ \\
\hline & Commercial availability & yes & no & yes & yes & no & no \\
\hline \multirow{5}{*}{ 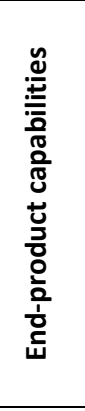 } & Cell interactions & Low & High & Medium & High & High & High \\
\hline & $\begin{array}{l}\text { Mechanical and } \\
\text { structural integrity }\end{array}$ & Low to high & Low-medium & Very high & Medium-high & Low-medium & High \\
\hline & $\begin{array}{l}\text { Tissue regeneration } \\
\text { time }\end{array}$ & Medium-long & Short-medium & Medium & Short & Short-medium & Short \\
\hline & Tissue biomimicry & Low - medium & Medium-High & Medium & High & Medium-High & High \\
\hline & Applications & $\begin{array}{l}\text { Tissue engineering, } \\
\text { transplantation, drug } \\
\text { testing, cancer } \\
\text { research }\end{array}$ & $\begin{array}{l}\text { Tissue engineering, } \\
\text { drug testing }\end{array}$ & $\begin{array}{l}\text { Tissue engineering, } \\
\text { cell proliferation, drug } \\
\text { testing }\end{array}$ & $\begin{array}{c}\text { Tissue engineering, } \\
\text { transplantation, } \\
\text { drug testing, cancer } \\
\text { research }\end{array}$ & $\begin{array}{l}\text { Tissue engineering, } \\
\text { drug testing }\end{array}$ & $\begin{array}{l}\text { Tissue engineering, } \\
\text { transplantation }\end{array}$ \\
\hline & Advantages & $\begin{array}{l}\text { Wide range of } \\
\text { capabilities, high } \\
\text { resolution, easy o } \\
\text { bioprint, wide range of } \\
\text { bioprinter types }\end{array}$ & High cell viability & $\begin{array}{l}\text { Great mechanical } \\
\text { properties, } \\
\text { economical, high cell } \\
\text { seeding capacity }\end{array}$ & $\begin{array}{l}\text { High tissue } \\
\text { biomimicry and } \\
\text { cell-cell } \\
\text { interactions }\end{array}$ & $\begin{array}{l}\text { High cell-cell } \\
\text { interactions }\end{array}$ & $\begin{array}{l}\text { High tissue } \\
\text { biomimicry, and } \\
\text { cell-cell } \\
\text { interactions, } \\
\text { scalable, }\end{array}$ \\
\hline
\end{tabular}




\begin{tabular}{|c|c|c|c|c|c|c|}
\hline Disadvantages & $\begin{array}{l}\text { Degradation-related } \\
\text { issues, limited cell-cell } \\
\text { interactions }\end{array}$ & $\begin{array}{c}\text { Expensive and labor } \\
\text { intensive, structurally } \\
\text { weak, no commercial } \\
\text { availability }\end{array}$ & $\begin{array}{l}\text { Low resolution and } \\
\text { accuracy, degradation- } \\
\text { related issues }\end{array}$ & $\begin{array}{l}\text { Low resolution and } \\
\text { accuracy, difficult to } \\
\text { bioprint }\end{array}$ & $\begin{array}{c}\text { Need a supporting } \\
\text { mold structure, low } \\
\text { printing resolution }\end{array}$ & $\begin{array}{l}\text { Difficult to bioprint, } \\
\text { low printing } \\
\text { resolution, no } \\
\text { commercial } \\
\text { availability }\end{array}$ \\
\hline
\end{tabular}




\section{Bioprinting}

Modalities

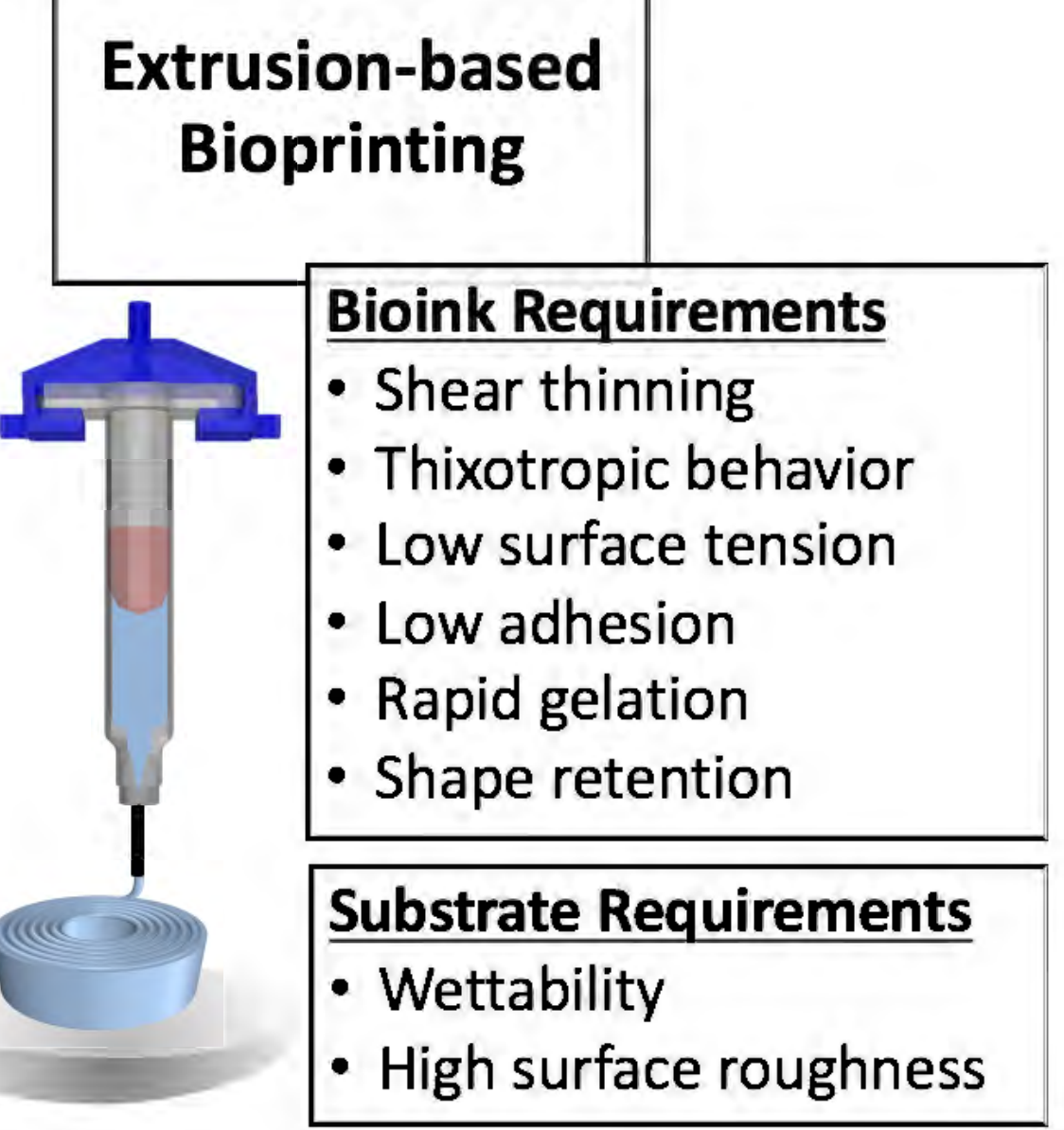

Droplet-based

Bioink Requirements

- Low viscosity

- Rheopectic behavior

- Non-fibrous nature

- Medium surface tension

- Rapid gelation

Substrate Requirements

- Wettability

- High surface roughness

- Induces viscous forces

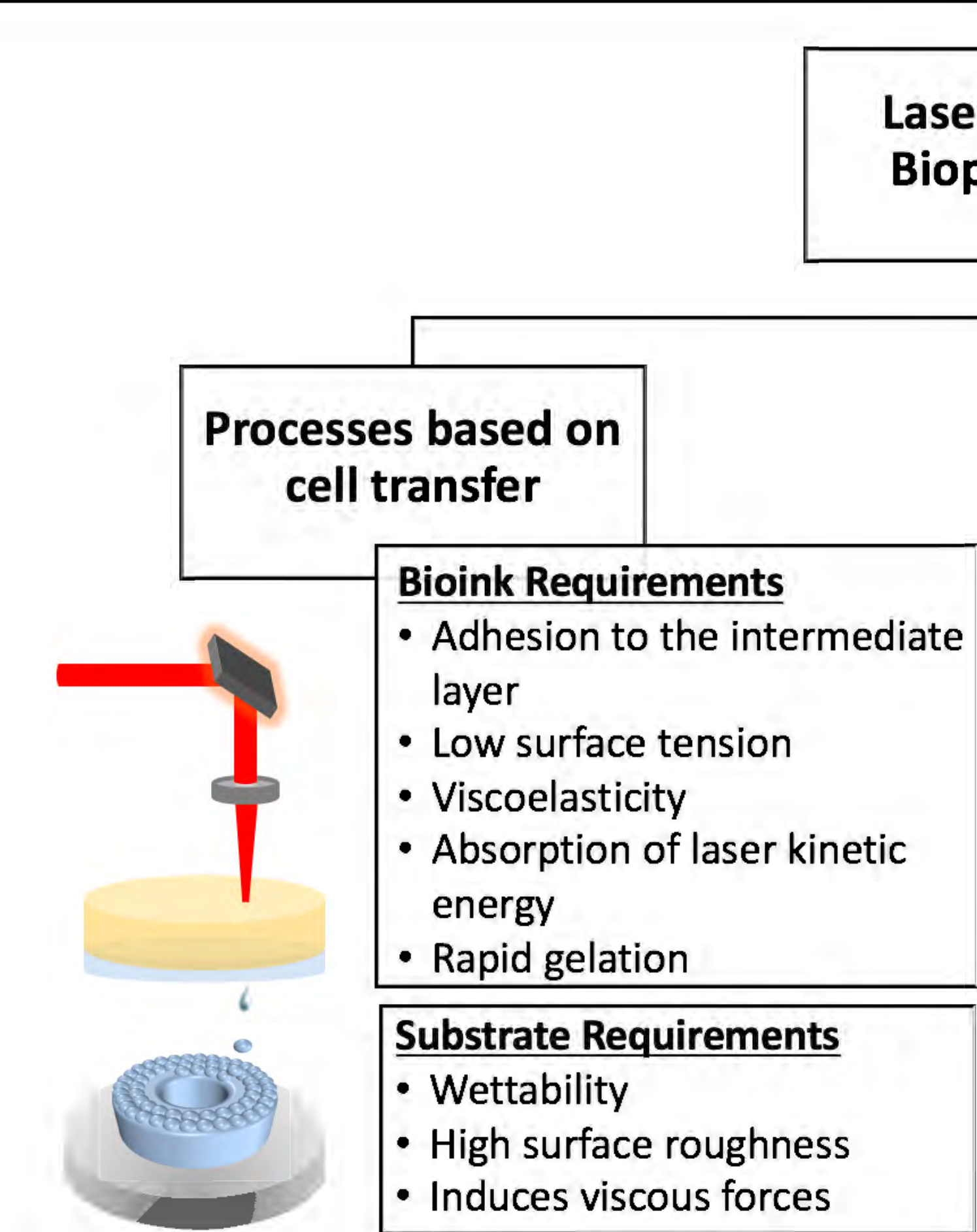

aser-based

Bioprinting

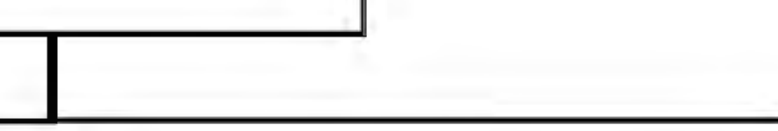

photopolymerization

Wettability

Bioink Requirements

- Undergo

photopolymerization

- Use of light absorber

- Use of photo-initiators

with low toxicity

- Stability and high-

mechanical strength

- Retention of uniform cell distribution 


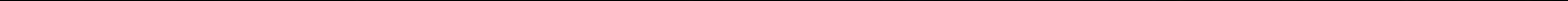




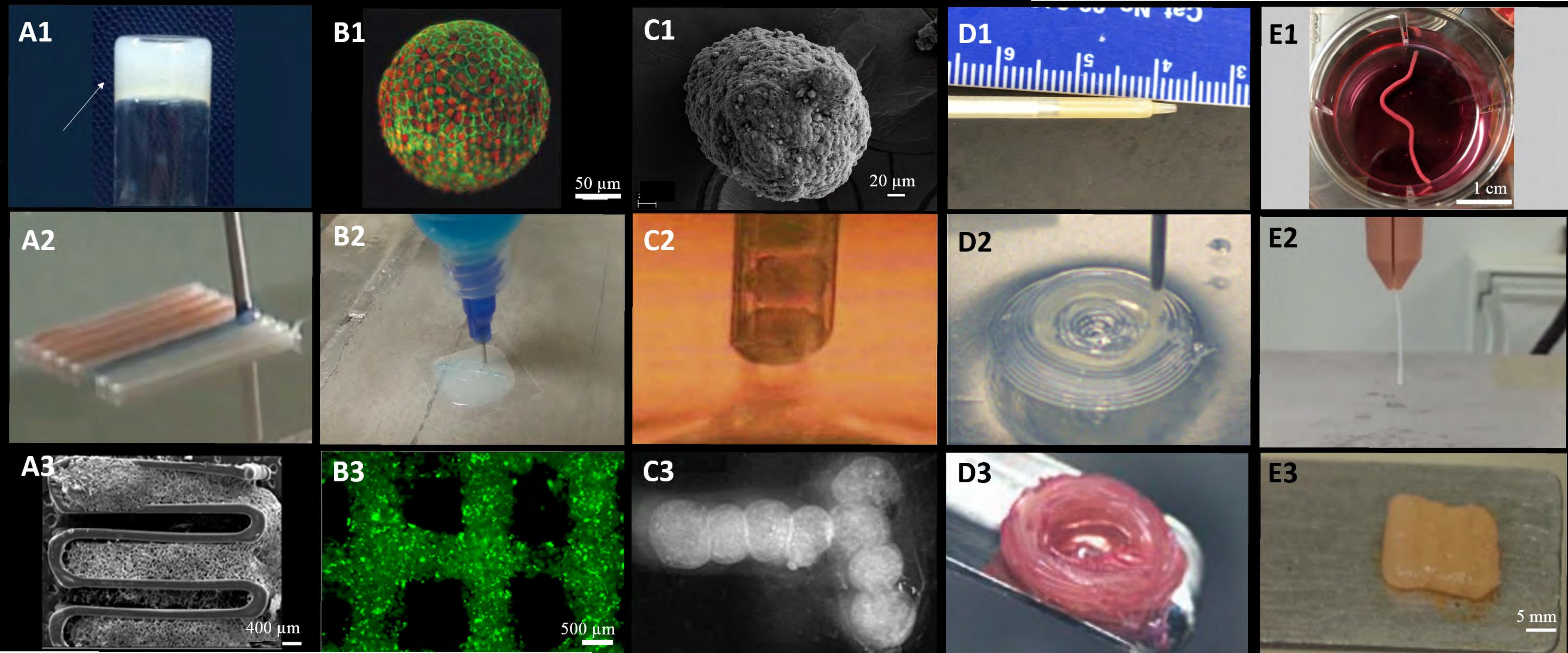

